UNIVERSIDADE DE SÃO PAULO

INSTITUTO DE ASTRONOMIA, GEOFÍSICA E CIÊNCIAS ATMOSFÉRICAS DEPARTAMENTO DE CIÊNCIAS ATMOSFÉRICAS

EDUARDO MARCOS DE JESUS

\title{
Ciclones e ciclones subtropicais sobre o sudoeste do Oceano Atlântico Sul: projeções climáticas e ventos associados
}

São Paulo

2020 



\section{Ciclones e ciclones subtropicais sobre o sudoeste do Oceano Atlântico Sul: projeções climáticas e ventos associados}

Versão corrigida. $O$ original encontra-se disponível na Unidade.

Tese apresentada ao Departamento de Ciências Atmosféricas do Instituto de Astronomia, Geofísica e Ciências Atmosféricas da Universidade de São Paulo, como requisito parcial para obtenção do título de Doutor em Ciências.

Área de concentração: Meteorologia

Orientador: Prof. Dr. Rosmeri Porfírio da Rocha

São Paulo

2020 

Aos meus pais José Raimundo (in memoriam) e Geralda Vicentina À minha companheira Andréia, minhas irmãs e irmãos com respeito e amor, acreditando que dias melhores virão 

“Que suas escolhas reflitam suas esperanças, não seus medos.”

Nelson Mandela 



\section{AGRADECIMENTOS}

Aos meus pais, José Raimundo (in memorian) e Geralda Vicentina, por toda dedicação e por mostrar a todos os filhos que o empenho se faz necessário em tempos difíceis, a vida é maior. Apesar de todas as dificuldades nunca se deram por vencidos, agradeço pelo exemplo vivo.

Às mulheres sempre presentes na minha vida, irmãs Elzi, Elisa, Elidia e minha companheira Andréia, por estarem comigo mesmo em meus momentos mais difíceis, fazendo todas as travessias sempre me apoiando e cuidando desse laço. Agradeço por estarem por perto! Aos irmãos e irmãs, por torcerem e estarem sempre de prontidão para ajudar.

À minha orientadora, Prof. Dr. Rosmeri Porfírio da Rocha, pela orientação, por sempre acreditar e pela paciência interminável comigo. Reconheço todo o apoio nesse processo, mesmo nos momentos mais turbulentos soube lidar com as situações e orientar da melhor forma. Agradeço muito por tudo.

À CAPES, ao Conselho Nacional de Desenvolvimento Científico e Tecnológico (CNPq processo 141869/2017-8) e Petrobrás (processo 2017/00671-3) pelo auxílio financeiro.

Aos Prof. Dr. Luiz Gozzo por ter contribuído muito nesse trabalho, pelo tempo dedicado na explicação de como classificou os ciclones subtropicais, permitindo que com os detalhes fornecidos o Software de classificação destes sistemas fosse desenvolvido da melhor forma e por fornecer gentilmente os dados de seu trabalho para estudo e aplicação nesta tese. E claro pelas conversas intermináveis, me ajudaram muito nessa trajetória.

À Lívia por sempre estar pronta para ajudar com os dados e resoluções de problemas com programação (cdo e shell script), neste trabalho o volume de dados foi grande e sua contribuição foi fundamental para esta tese. Obrigado também pelas conversas e por me escutar sempre!

Ao GREC por disponibilizar todos os dados necessários para realização deste trabalho.

À Prof. Dr. Michelle Reboita e a Doutora Natália Crespo por colaborarem no desenvolvimento deste trabalho.

Ao amigo André Seiji por me apresentar a linguagem Python e contribuir com algoritmo escrito em python que resolve de forma simples um problema com tabulação de dados, que com toda certeza levaria mais tempo para resolver usando o fortran para generalizar a leitura de todos dados. Obrigado pelas dicas, foram fundamentais. Ao Rafael Cesário que também contribuiu muito 
para o meu desenvolvimento com a linguagem Python. E ao Paulo Pimenta pelas dicas em diversas linguagens de programação.

Aos amigos Camila Carpenedo, Marcinha, Dejanira Braz, Rafael Cesário, Natália, Paulo Pimenta, Luan, José Flores, Isaac, Amanda, André, Cristiano Prestrelo, Alex, José Hugo, Victor e Alan pelas conversas sobre temas variados e por terem tornado esse período mais alegre.

A todos os funcionários do IAG-USP que sempre me atenderam muito bem, em especial ao pessoal da informática, sempre prestativos, resolveram os problemas das máquinas sempre muito rapidamente. 


\section{RESUMO}

de Jesus, E. M., 2020: Ciclones e ciclones subtropicais sobre o sudoeste do Oceano Atlântico Sul: projeções climáticas e ventos associados. $141 \mathrm{f}$. Tese (Doutorado) - Instituto de Astronomia, Geofísica e Ciências Atmosféricas, Universidade de São Paulo, São Paulo. Versão original.

O objetivo principal deste trabalho é entender tendências climáticas futuras de todos os ciclones e dos subtropicais, assim como nos ventos associados (em baixos e altos níveis), no sudoeste do Atlântico Sul. Foram utilizados dois conjuntos de projeções climáticas no Representative Concentration Pathways (RCP8.5) compostos de quatro regionalizações com o modelo climático regional RegCM4 (RegCM4s) aninhadas em três modelos climáticos globais (GCMs; HadGEM2-ES, MPI-ES e GFDL-ES) do CMIP5. As reanálises da ERA-Interim e CFSR forneceram o conjunto de referência para validação das simulações no período histórico (1979-2005). As análises concentram-se em dois períodos futuros (próximo: 2020-2050; distante: 2070-2099), em três principais regiões ciclogenéticas (RG1: sul-sudeste do Brasil; RG2: leste do Uruguai; RG3: sul da Argentina), e nos ciclones subtropicais. Os ciclones são rastreados utilizando vorticidade relativa ciclônica em 925 hPa, e depois em função da estrutura térmica são separados os subtropicais. Para o clima presente, RegCM4s e GCMs representam adequadamente as principais características de gênese e trajetória tanto do total de ciclones como dos subtropicais. No entanto, alguns impactos positivos da regionalização são notados. Uma importante adição de valor da regionalização é a maior habilidade dos RegCM4s em capturar as características observadas (fase e amplitude do ciclo anual, intensidade e os ventos próximo à superfície) dos ciclones iniciados em regiões afastadas das fronteiras do domínio, tais como RG1 e RG2; e também na identificação de ciclogêneses subtropicais na costa sudeste do Brasil. Além disso, a série temporal dos RegCM4s apresenta menor bias e maior correlação comparado às reanálises, melhorando a representação do total de ciclones e daqueles mais intensos no sudoeste do Atlântico Sul. Em termos de impacto, há uma maior concordância entre RegCM4s e reanálises em relação a magnitude e localização dos ventos mais fortes associados com ciclones intensos originados da RG1 e RG2 e ciclones subtropicais. Para ciclones intensos, as projeções futuras indicam intensificação dos ventos próximo à superfície e próximo da costa (sul-sudeste do Brasil e sul da Argentina) e um deslocamento para sul do jato polar de altos níveis. Há também uma tendência de diminuição no número de 
ciclogêneses em cada uma das três regiões ciclogenéticas, indicando que os ciclones intensos seriam associados com ventos mais fortes em baixos níveis próximo da costa no futuro distante. Para ciclones subtropicais, tanto os RegCM4s como GCMs também projetam tendência negativa na frequência de eventos e de intensificação dos ventos em baixos níveis associados.

Palavras chaves: projeções climáticas, ciclones, ciclones subtropicais, GCM, RCM, Atlântico Sul, ventos. 


\begin{abstract}
de Jesus, E. M., 2020: Subtropical cyclones and cyclones over the southwestern South Atlantic Ocean: climate projections and associated winds. $141 \mathrm{pp}$. Tese (Doutorado) - Instituto de Astronomia Geofísica e Ciências Atmosféricas, Universidade de São Paulo. Versão original.
\end{abstract}

The main objective of this study is to understand the climate trends of all cyclones and of the subtropical ones, as well as the associated winds (at low and upper levels), over the southwest South Atlantic Ocean. Two multi-model ensembles consisting of four RegCM4 downscaling (RegCM4s) nested in three different global circulation models (GCMs; HadGEM2-ES, MPI-ES e GFDL-ES) from CMIP5 in RCP8.5 are used. ERA-Interim and CFSR reanalyses provide the reference ensemble for the historical period (1979-2005). The analysis focus on two future periods (near-future: 2020-2050; far-future: 2070-2099), in all cyclones developing in the main cyclogenetic regions (RG1: south-southeast Brazil; RG2: eastern Uruguay; RG3: south Argentina), and on subtropical cyclones. All cyclones are tracked using relative vorticity at $925 \mathrm{hPa}$, thermal structure parameters are used to separate the subtropical ones. For the present climate, RegCM4s and GCMs simulate the main characteristics of the genesis and propagation of all cyclones and the subtropical ones. However, there are some positive impacts of downscaling. An important added value of downscaling is the greater ability of RegCM4s to capture the observed characteristics (phase and amplitude of the annual cycle, intensity and winds close to the surface) of cyclones initiated in regions far from the domain's borders, such as RG1 and RG2; and also in the identification of the subtropical cyclones in eastern southeast Brazil. In addition, RegCM4s time series present smaller (higher) biases (correlation) in relation to reanalyses, improving the representation of all cyclones and of stronger ones for the whole southwestern South Atlantic. In terms of impact, there is greater agreement between RegCM4s and reanalyses regarding the magnitude and location of stronger winds associated with intense cyclones starting in RG1 and RG2 and subtropical cyclones. For intense cyclones in the future climate, it is projected an intensification of near surface winds near the coast (south-southeast Brazil and south Argentina) and a shift to the south of the upper-level polar jet. Furthermore, there is a clear trend of decrease in 
the number of cyclogenesis in each hot-spot region, indicating that each intense cyclone will be associated with stronger low level winds near the eastern coast in the far future climate. For subtropical cyclones, both RegCM4s and GCMs also project a negative trend in the frequency of events and intensification of associated low level winds.

Key words: climate projections, cyclones, subtropical cyclones, GCM, RCM, South Atlantic, winds. 


\section{LISTA DE SIGLAS}

AOGCM - Atmosphere-Ocean Coupled General Circulation Model

BATS - Biosphere-Atmosphere Transfer Scheme

CCCMA - Canadian Center for Climate Modeling and Analysis

CCSR - Center for Climate Studies and Research

CFSR - Climate Forecast System Reanalysis

CLM - Community Land Model

CMIP5 - Climate Model Intercomparison Project

CPS - Cyclone Phase Space

CREMA - CORDEX RegCM4 hyper-MAtrix experiment

CSIRO - Commonwealth Scientific and Industrial Research Organization

ECMWF - European Centre for Medium-Range Weather Forecasts

GCM - Global Climate Model

GCMs - Global Climate Models

GFDL - Geophysical Fluids Dynamic Laboratory

IPCC - Intergovernmental Panel on Climate Change

MERRA - Modern Era Retrospective-Analysis for Research and Applications

NCAR - National Center for Atmospheric Research

NCEP - National Center for Environmental Prediction

NIES - National Institute for Environmental Studies

NOAA - National Oceanic and Atmospheric Administration

RCM - Regional Climate Model

RCMs - Regional Climate Models

RCP - Representative Concentration Pathways

RegCM4 - Regional Climate Model version 4

SCS - Software para classificação automática dos ciclones subtropicais

TSM - Temperatura da Superfície do Mar

WRF - Weather Research and Forecasting 



\section{LISTA DE FIGURAS}

Figura 2.1.1 - Localização geográfica do desenvolvimento de ciclones (taxa de crescimento $>0,1$ dia $^{-1}$ ) para 30 anos (dezembro 1981 a novembro 2011) no Hemisfério Sul (coluna esquerda) e Hemisfério Norte (coluna a direita) nas estações de: (a)-(b) verão, (c)-(d) outono, (e)-(f) inverno e (g)-(h) primavera para ciclones tropicais (vermelho), extratropicais (azul) e subtropicais (verde). Fonte: Yanase et al. (2014).

Figura 2.3.1 - Coeficiente angular da tendência anual de ciclones extratropicais no Hemisfério Sul para o período 1980-2010. As linhas azuis e vermelhas indicam, respectivamente, tendências negativas e positivas. A significância estatística com $90 \%$ de confiança só é encontrada próximo de $70^{\circ} \mathrm{S}$ e $110^{\circ} \mathrm{E}$, conforme destacado pela seta preta. Fonte: Reboita et al. (2015)......

Figura 3.3.1 - Domínio e topografia (sombreado) de simulação do CREMA-RegCM4 (linha azul), área efetiva de rastreamento de ciclones (linhas vermelhas, $15-57^{\circ} \mathrm{S} ; 81^{\circ}$-21W) e delimitação das

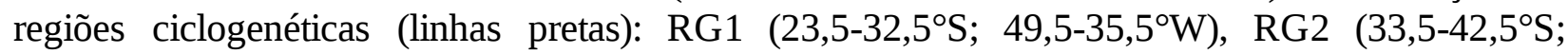
$\left.59,5-45,5^{\circ} \mathrm{W}\right)$ e RG3 (43,5-52,5요 $\left.67,5-53,5^{\circ} \mathrm{W}\right)$, como definidas em Reboita et al. (2010).........55

Figura 4.1.1 - Climatologia anual (1979-2005) da densidade ciclogenética (sombreado) para os conjuntos a) reanálise, b) GCMs e c) RegCM4s. A unidade de densidade é ciclones por área $\left(\mathrm{km}^{2}\right)$ x $10^{6}$ por ano. A média anual e desvio padrão para todo domínio da Figura é apresentada no canto superior direito de cada painel.

Figura 4.1.2 - Climatologia anual (1979-2005) da densidade de trajetória dos ciclones (sombreado) e de densidade ciclogenética (linhas pretas) para ciclones iniciados na RG1 (a, b, c - topo), RG2 (d, e, f - médio) e RG3 (g, h, i - base): a, d, g) reanálise; b, e, h) GCMs; e c, f, i) RegCM4s. A unidade de densidade é ciclones por área $\left(\mathrm{km}^{2}\right)$ x $10^{6}$ por ano. A média anual e desvio padrão de ciclogêneses em cada região ciclogenética é apresentada no canto superior direito de cada painel. .66

Figura 4.1.3 - Ciclo anual da média mensal (linhas) e desvio padrão (sombreado) de ciclogêneses no clima presente (1979-2005) para: a) RG1, b) RG2, c) RG3 e d) domínio do Atlântico Sul. As correlações e RMSEs entre reanálise e simulações para o ciclo anual estão indicadas em cada painel.

Figura 4.1.4 - Distribuição de frequência anual da vorticidade relativa (x10-5 $\left.\mathrm{s}^{-1}\right)$ no horário da ciclogênese para o clima presente (1979-2005) : a) RG1, b) RG2, c) RG3 e d) domínio do Atlântico Sul.....................................................................70

Figura 4.1.5 - Composições para o clima presente (1979-2005) do vento médio anual (vetores e intensidade em sombreado, $\mathrm{m} \mathrm{s}^{-1}$ ) em $1000 \mathrm{hPa}$ associado com os ciclones intensos na RG1 (a, b, c - superior), RG2 (d, e, f - meio) e RG3 (g, h, i - inferior) para: a, d, g) reanálises; b, e, h) GCMs; c, f, i) RegCM4s. Os retângulos indicam as áreas usadas para calcular a velocidade média do vento. 
Figura 4.1.6 - Composições para o clima presente (1979-2005) do vento médio anual (vetores e intensidade em sombreado, $\mathrm{m} \mathrm{s}^{-1}$ ) em $300 \mathrm{hPa}$ associado com os ciclones intensos na RG1 (a, b, c superior), RG2 (d, e, f - meio) e RG3 (g, h, i - inferior) para: a, d, g) reanálises; b, e, h) GCMs; c, f, i) RegCM4s. Os retângulos indicam as áreas usadas para calcular a velocidade média do

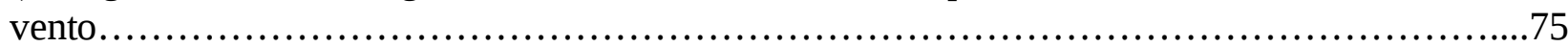

Figura 4.2.1 - Tendências das densidades de trajetórias (futuro "menos" presente) para o clima futuro a,b,e,f,i,j) próximo (2020-2050) e c,d,g,h,k,l) distante (2070-2099) para os GCMs e RegCM4s na a,b,c,d) RG1, e,f,g,h) RG2 e i,j,k,l) RG3. A unidade de densidade é ciclone por área

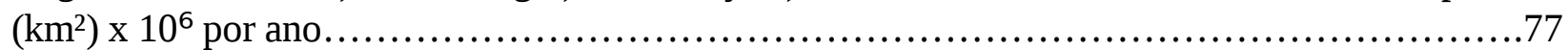

Figura 4.2.2 - Composição da diferença (futuro “menos” presente) da velocidade do vento em $1000 \mathrm{hPa}$ associada com ciclones intensos para o clima futuro a,b,e,f,i,j) próximo (2020-2050) e c,d,g,h,k,l) distante (2070-2099) para os GCMs e RegCM4s na a,b,c,d) RG1, e,f,g,h) RG2 e i,j,k,l) RG3. Os retângulos indicam as regiões de ventos mais fortes para cada região ciclogenética no clima presente.

Figura 4.2.3 - Composição da diferença (futuro “menos” presente) da velocidade do vento em 300 hPa associado com ciclones intensos para o clima futuro a,b,e,f,i,j) próximo (2020-2050) e c,d,g,h,k,l) distante (2070-2099) para os GCMs e RegCM4s na a,b,c,d) RG1, e,f,g,h) RG2 e i,j,k,l) RG3. O retângulo indica as regiões de ventos fortes associados com cada região/ponto quente no

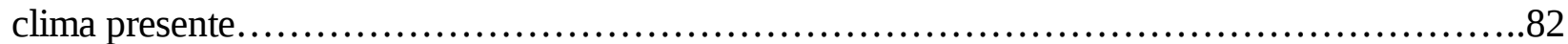

Figura 4.3.1 - Frequência absoluta anual e tendência (retas) de ciclogêneses da reanálise (1979-2005) e simuladas (1979-2099) na RG1 (cores avermelhadas), RG2 (cores azuladas) e RG3 (cores esverdeadas). As linhas retas indicam a tendência.

Figura 4.3.2 - Frequência absoluta anual e tendência de ciclogêneses observadas (1979-2005) e simuladas (1979-2099) em todo o domínio do Atlântico Sul (área delimitada na Figura 3.3.1). As linhas em negrito indicam a tendência.

Figura 4.3.3 - Vento médio em 1000 hPa associado às ciclogêneses intensas e tendência para a reanálise (1979-2005) e simulações (1979-2099) considerando ciclones iniciados na RG1 (cores avermelhadas), RG2 (cores azuladas) e RG3 (cores esverdeadas). Estas médias foram calculadas na área de velocidade do vento máximo associado com os ciclones intensos no clima presente (caixas nas Figuras 4.1.5 e 4.2.2). .86

Figura 5.1.1 - Densidade média anual de ciclogêneses subtropicais para o período 1979-2005 em a) Gozzo (2014) e b) SCS. A unidade é ciclone por área $\left(\mathrm{km}^{2}\right) \times 10^{6}$ por ano .89

Figura 5.1.2 - Densidade média anual de trajetórias de ciclones subtropicais para o período 1979-2005 em a) Gozzo (2014) e b) SCS. A unidade é ciclone por área $\left(\mathrm{km}^{2}\right)$ x10 $10^{6}$ por ano......90 
Figura 5.1.3 - a) Média mensal (linhas) e desvio padrão (sombreado) climatológico e b) duração (dias) dos ciclones subtropicais obtidos por Gozzo (2014; vermelho) e SCS (azul) para o período de 1979-2005.

Figura 5.1.4 - Série temporal do número anual (linhas cheias) e valor médio anual (linhas tracejadas) de ciclones subtropicais obtidos por Gozzo (2014; vermelho) e SCS (azul) no período 1979-2005 obtida da reanálise ERA-Interim.

Figura 5.1.5 - Campos espaciais médios anuais no período 1979-2005, obtidos da reanálise ERA-Interim, dos parâmetros a,b) $\mathrm{B}(\mathrm{m}), \mathrm{c}, \mathrm{d}) \mathrm{V}_{\mathrm{T}}^{\mathrm{L}}\left(\mathrm{m}^{3} / \mathrm{kg}\right)$ e e,f) $\mathrm{V}_{\mathrm{T}}{ }^{\mathrm{U}}\left(\mathrm{m}^{3} / \mathrm{kg}\right)$ associados às trajetórias dos ciclones subtropicais obtidas por a,c,e) Gozzo (2014) e b,d,f) SCS (azul). 95

Figura 5.2.1 - Densidade média anual de ciclogêneses subtropicais no período 1979-2005 obtidas em a) reanálise ERA-Interim, b) GCMs e c) RegCM4s. Os valores no canto superior direito indicam a média anual e o respectivo desvio padrão de ciclogêneses subtropicais. A unidade é ciclone por área $\left(\mathrm{km}^{2}\right) \times 10^{6}$ por ano

Figura 5.2.2 - Densidade média anual de trajetória (sombreado) e gênese (linhas pretas, valores de 2,5 e 6,5) dos ciclones subtropicais para o período de 1979-2005. (a) ERA-Interim (b) GCMs e c) RegCM4s. A unidade é ciclone por área $\left(\mathrm{km}^{2}\right) \times 10^{6}$ por ano.

Figura 5.2.3 - Vento médio (vetores e magnitude em sombreado; m/s) em $1000 \mathrm{hPa}$ associado às ciclogêneses subtropicais para o período 1979-2005: a) reanálise ERA-Interim, b) GCMs e c) RegCM4s. O retângulo preto indica a região de gênese dos ciclones subtropicais.

Figura 5.2.4 - Vento médio (vetores e magnitude em sombreado; m/s) em $300 \mathrm{hPa}$ associado às ciclogêneses subtropicais para o período 1979-2005: a) reanálise ERA-Interim, b) GCMs e c) RegCM4s.

Figura 5.3.1 - Tendência da densidade de trajetória dos ciclones subtropicais para o RCP8.5 no a,b) futuro próximo (2020-2050) e c,d) futuro distante (2070-2099) nos GCMs e RegCM4s, respectivamente. A unidade é ciclone por área $\left(\mathrm{km}^{2}\right) \times 10^{6}$ por ano.........................98

Figura 5.3.2 - Composições da tendência dos ventos (vetores e magnitude em sombreado; m/s) em $1000 \mathrm{hPa}$ associados às ciclogêneses subtropicais para o RCP8.5 no a,b) futuro próximo (2020-2050) e c,d) futuro distante (2070-2099) nos GCMs e RegCM4s, respectivamente.........100

Figura 5.3.3 - Composições da tendência dos ventos (vetores e magnitude em sombreado; m/s) em $300 \mathrm{hPa}$ associados às ciclogêneses subtropicais para os climas a,b) futuro próximo (2020-2050) e c,d) futuro distante (2070-2099) nos GCMs e RegCM4s, respectivamente. 101

Figura 5.3.4 - Série temporal da frequência absoluta anual, juntamente com a reta de tendência, de ciclogêneses subtropicais nos GCMs (linha vermelha), RegCM4s (linha verde) para o período 1979-2099 e reanálise ERA-Interim (linha azul) entre 1979-2005. 
Figura 5.3.5 - Série temporal da velocidade média anual (m/s) em $1000 \mathrm{hPa}$ associada às ciclogêneses subtropicais nos GCMs (linha vermelha), RegCM4s (linha verde) para o período 1979-2099 e reanálise ERA-Interim (linha azul) entre 1979-2005. As médias foram calculadas na região indicada na Figura 5.2.3 (retângulo preto). 103

Figura 5.3.6 - Campo espacial médio anual dos parâmetros a,b,c) B (m), d,e,f) $V_{T}{ }_{T}^{L}\left(\mathrm{~m}^{3} / \mathrm{kg}\right)$ e g,h,i) $\mathrm{V}_{\mathrm{T}}^{\mathrm{U}}\left(\mathrm{m}^{3} / \mathrm{kg}\right)$ associados às trajetórias dos ciclones subtropicais no período 1979-2005 para SCS, GCMs

e RegCM4s, respectivamente 106

Figura 5.3.7 - Composições da tendência do parâmetro B (m; sombreado) considerando toda trajetória e da densidade ciclogenética (ciclone por área $\left(\mathrm{km}^{2}\right) \times 10^{6}$ por ano; linhas pretas cheias valores positivos e tracejadas valores negativos) dos ciclones subtropicais para o a,b) futuro próximo (2020-2050) e c,d) futuro distante (2070-2099) nos GCMs e RegCM4s.................108

Figura 5.3.8 - Composições da tendência do parâmetro $\mathrm{V}_{\mathrm{T}}{ }^{\mathrm{L}}$ (sombreado) em toda a trajetória e da densidade ciclogenética (linhas pretas cheias valores positivos e tracejadas valores negativos) associados aos ciclones subtropicais para os climas a,b) futuro próximo (2020-2050) e c,d) futuro distante (2070-2099) nos GCMs e RegCM4s, respectivamente. .. 110

Figura 5.3.9 - Composições da tendência do parâmetro $\mathrm{V}_{\mathrm{T}}^{\mathrm{U}}$ (sombreado) em toda a trajetória e da densidade ciclogenética (linhas pretas cheias valores positivos e tracejadas valores negativos) associados aos ciclones subtropicais para os climas a,b) futuro próximo (2020-2050) e c,d) futuro distante (2070-2099) nos GCMs e RegCM4s, respectivamente. 


\section{LISTA DE TABELAS}

Tabela 3.2.1- GCMs utilizados como condições iniciais e de fronteira para as quatro regionalizações do RegCM4-CREMA . O espaçamento horizontal de grade (em graus) dos GCMs

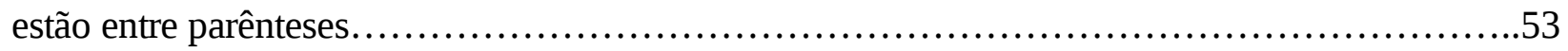

Tabela 3.4.1 - Limiares dos parâmetros do CPS propostos por Gozzo et al. (2014) e utilizados nesse estudo para identificar ciclones subtropicais.........................................57

Tabela 3.5.1 - Limiares externos dos parâmetros do CPS utilizados para identificar ciclones

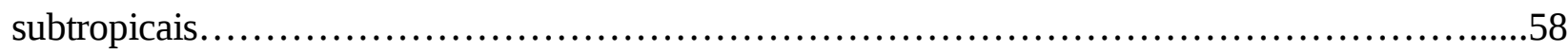

Tabela 4.1.1 - Limiares do percentil de $25 \%$ de vorticidade relativa inicial $\left(x 10^{-5} \mathrm{~s}^{-1}\right)$ para identificar

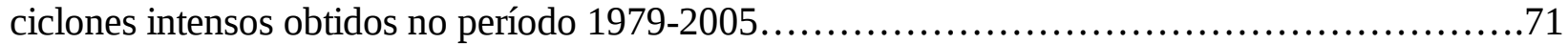

Tabela 5.3.1 - Número médio anual, com respectivo desvio padrão, e tendência relativa (\%) de ciclones totais e de subtropicais no período histórico (1979-2005), futuro próximo (2020-2050) e futuro distante (2070-2099) na RG1. As tendências estatisticamente significativas ao nível de 90\% confiança estão em negrito............................................................... 104 



\section{Sumário}

Introdução $\quad 24$

$\begin{array}{ll}1.1 \text { Objetivos } & 25\end{array}$

2. Revisão bibliográfica $\quad 26$

2.1 Ciclones e classificação $\quad 26$

2.2 Cenários de mudanças climáticas 33

2.3 Tendências climáticas: ciclones e ciclones subtropicais $\quad 37$

$\begin{array}{ll}\text { Mudanças climáticas e ciclones } & 40\end{array}$

Mudanças climáticas e ciclones subtropicais $\quad 44$

3. Metodologia $\quad 49$

3.1 Dados 49

3.2 Modelo RegCM4 49

3.2.1 Regionalizações com o RegCM4 - Projeto CREMA

3.3 Rastreamento de ciclones 53

3.4 Espaço de fase dos ciclones (Cyclone Phase Space - CPS) 55

3.5 Software para classificação automática dos ciclones subtropicais (SCS) 58

3.6 Ciclones: climatologia, tendência e ventos associados 60

4. Ciclones no Atlântico Sul e ventos associados: clima presente e tendências climáticas

4.1 Ciclones no clima presente $\quad 62$

Densidade e características dos ciclones $\quad 62$

Ventos associados aos ciclones intensos $\quad 71$

4.2 Tendências climáticas: futuros próximo e distante 75

Trajetórias $\quad 75$

Ventos em baixos e altos níveis $\quad 77$

4.3 Tendências médias de longo prazo: ciclogêneses e ventos 82

5. Ciclones Subtropicais no Atlântico Sul: validação, clima presente e tendências $\begin{array}{ll}\text { climáticas } & \mathbf{8 7}\end{array}$

5.1 Validação do método automático de classificação dos ciclones subtropicais 87

Densidade, trajetória e variabilidade 88

Parâmetros do CPS: VTU, VTL e B $\quad 91$

5.2 Simulação de ciclones subtropicais no clima presente (1979-2005) 93

5.3 Tendências futuras dos ciclones subtropicais $\quad 97$

5.4 Estrutura dos ciclones subtropicais baseada nos parâmetros CPS 104

$\begin{array}{ll}\text { VTU, VTL e B - clima presente } & 104\end{array}$ 


$$
\text { VTU, VTL e B - tendência }
$$

6. Conclusões

\subsection{Sugestões para estudos futuros}

119

7. Referências

121

Apêndice A 


\section{Introdução}

Os ciclones de escala sinótica são sistemas importantes para a caracterização do tempo e clima. Ciclones mais intensos estão associados a tempestades severas, ventos fortes e podem acarretar uma série de transtornos à população em geral e também às atividades humanas (economia, saúde, etc.). Sobre os oceanos os ventos associados aos ciclones são em geral mais intensos e possuem um forte controle nos processos de troca de energia atmosfera-oceano e nas correntes oceânicas, e também causam prejuízos às atividades econômicas (navegação, extração de petróleo, etc.) e à população próximo à costa (storm surges, ondas intensas, etc.).

No contexto de mudanças no clima, a climatologia de ciclones pode sofrer alteração, tais como, mudanças na intensidade, número de eventos, precipitação e outros fenômenos de tempo associados, e que contribuem para a definição do tempo e clima em todo o globo.

Na América do Sul, três principais regiões ciclogenéticos são encontradas ao longo da costa leste (sul da Argentina, Uruguai e sul-sudeste do Brasil; Gan e Rao, 1991; Reboita et al., 2018). Os ciclones que se formam nessas áreas causam importantes impactos econômicos e sociais através de tempestades (Muis et al., 2016; Ribeiro et al., 2019; Reboita et al., 2010; 2019), ondas altas (Cecilio e Dillenburg, 2019), ventos intensos e precipitação (Machado et al., 2016; Utsumi et al., 2017; Reboita et al., 2018; Reboita et al., 2019). Na região ciclogenética mais próxima ao sudeste do Brasil, área mais populosa e importante economicamente do país, uma categoria especial de ciclones, os subtropicais, representa cerca de 30\% de todos os ciclones (Gozzo et al., 2014) e muitas vezes estão associados com ventos e chuvas fortes próximo à costa (Brasiliense et al., 2018; Reboita et al., 2019; Cardoso, 2019).

Avaliar com mais clareza as tendências futuras dos ciclones em geral e dos ciclones subtropicais na costa leste da América do Sul em um clima mais quente é crucial para preparar a população e criar planos de mitigação para impactos futuros. Ao aplicar a abordagem multi-modelos, utilizando tanto projeções de modelos climáticos globais (GCMs) como regionais (RCMs), as análises de tendências climáticas de todos ciclones e dos subtropicais têm como objetivo adicionar informações sobre cenários futuros e incertezas associadas. 


\subsection{Objetivos}

O objetivo geral deste trabalho é estudar tendências climáticas de ciclones em geral e subtropicais utilizando um multi-conjunto de projeções climáticas de GCMs e RCMs tendo como foco o sudoeste do Oceano Atlântico Sul. Os objetivos específicos são:

a) avaliar como três GCMs e as respectivas regionalizações climáticas com o RegCM4 representam a climatologia de todos os ciclones e dos subtropicais no clima presente;

b) analisar tendências de todos os ciclones e dos subtropicais nas projeções climáticas do RegCM4 e GCMs para o cenário Representative Concentration Pathways 8.5 (RCP8.5;

c) desenvolver e validar um algoritmo para classificação automática de ciclones subtropicais;

d) obter a climatologia dos ventos associados aos ciclones mais intensos e estudar tendências avaliando possíveis mudanças em cenários de mudanças climáticas;

e) obter a climatologia e analisar tendências climáticas dos ventos associados aos ciclones subtropicais.

Portanto, além de entender mudanças futuras dos ciclones, este trabalho irá avaliar mudanças nos ventos de níveis inferior e superior associados aos ciclones, uma análise fundamental para entender os impactos de mudanças no clima, especialmente no contexto regional (Catto et al., 2019; Zappa, 2019), sendo esta a primeira abordagem nesses tópicos na América do Sul. 


\section{Revisão bibliográfica}

\subsection{Ciclones e classificação}

Desde a década de 90 ocorreram algumas mudanças conceituais sobre as características e desenvolvimento de ciclones de escala sinótica. A ideia principal é entender os ciclones como um contínuo, ou seja, os ciclones não seriam classificados apenas como extratropicais ou tropicais, sendo necessário considerar a existência de fase intermediária ou tipo, denominada subtropical (Beven, 1997). Desta forma, os ciclones podem ser entendidos como um contínuo e ao longo do seu ciclo de vida podem adquirir características de ciclones tropicais, subtropicais ou extratropicais (Beven, 1997;Hart, 2003; da Rocha et al., 2018; Cavichia et al., 2020).

Em termos de características principais, ciclones denominados tropicais formam-se preferencialmente em regiões próximas ao equador a partir de um distúrbio ciclônico inicial na baixa troposfera. Como sua formação acontece sobre os oceanos tropicais com temperaturas da superfície do mar (TSM) elevadas, normalmente a evaporação da superfície do mar para atmosfera predomina durante sua fase de crescimento e alimenta nuvens convectivas profundas, com consequente liberação de calor latente e aquecimento da atmosfera nas imediações de seu centro. Além disso, os ciclones tropicais são caracterizados por núcleo quente em toda a troposfera e estão associados com ventos fortes próximo da superfície, que diminuem de intensidade nos níveis superiores. Esse conjunto de fatores caracterizam o desenvolvimento desses ciclones, que não apresentam estrutura frontal e o sistema de baixa pressão encontra-se alinhado verticalmente desde a superfície até a troposfera superior (Charney e Eliassen, 1964). A presença de alto teor de umidade na baixa troposfera é também um elemento importante para o desenvolvimento de furacões, a partir da evolução de um ciclone tropical (Charney e Eliassen, 1964). As fortes chuvas e ventos nos ciclones tropicais ocasionam muitas vezes grandes estragos em infra-estrutura e perdas de vidas. 
Em latitudes médias, formam-se principalmente os ciclones extratropicais que possuem como fonte de energia os fortes gradientes horizontais de temperatura, que por sua vez estão diretamente relacionados à presença de jatos de oeste de altos níveis. As ciclogêneses extratropicais ocorrem principalmente através de uma perturbação em altos níveis e seu desenvolvimento depende da retirada de energia do escoamento médio, sua estrutura vertical é inclinada (baroclínica) indicando que o sistema cresce a partir da energia potencial disponível (Bjerknes, 1922; Holton, 2004). Uma característica importante é que ciclones extratropicais são sistemas de núcleo frio em toda a troposfera. Nos ciclones extratropicais a liberação de calor latente tem papel secundário para os desenvolvimentos atuando principalmente na intensificação dos mesmos. A disponibilidade de umidade na troposfera diminui o comprimento de onda do modo mais instável e aumenta a instabilidade das ondas baroclínicas, dessa maneira, atuando na intensificação dos ciclones extratropicais (Mak, 1982). Gutowski et al. (1992) analisaram como os processos envolvendo vórtices transientes contribuem para a manutenção da circulação de grande escala e clima. Os autores mostraram que a presença de umidade na baixa troposfera, aliada ao crescimento acelerado do sistema, intensifica os movimentos verticais, acelerando assim o processo de conversão de energia potencial disponível do escoamento médio em cinética do sistema. Ciclones extratropicais, além de produzirem queda acentuada de temperatura, estão associados à chuvas intensas, nevascas, ventos fortes, ondas oceânicas altas, entre outros fenômenos adversos de tempo.

Simpson (1951), ao estudar um ciclone no leste do Oceano Pacífico no período de inverno, denominou este sistema de ciclone subtropical levando em conta sua evolução, ou seja, o sistema iniciou-se com um núcleo frio e em estágios posteriores desenvolveu características de ciclones tropicais, que apresentam núcleo quente. Este ciclone foi nomeado pelo autor como Kona Low ou tempestade Kona, e ao longo de seu ciclo de vida causou alto índice de precipitação nas ilhas do Havaí. Guishard (2009) mostrou que a disponibilidade de umidade em baixos níveis é indispensável para o desenvolvimento dos ciclones subtropicais. Em geral os ciclones subtropicais apresentam estrutura vertical com núcleo frio em altos níveis, como os extratropicais, e quente em baixos níveis, como os tropicais, sendo também denominados de sistemas ou ciclones híbridos (da Rocha et al., 2019). 
Nos últimos anos têm aumentado o número de investigações sobre ciclones subtropicais que são mais frequentes no cinturão de latitude entre $15^{\circ}$ e $40^{\circ} \mathrm{S}$ (Yanase et al., 2014). Estes sistemas podem se formar diretamente como subtropical ou então representar uma fase de transição de extratropical para tropical ou vice-versa (da Rocha et al., 2019). Quando não há transição, a gênese dos ciclones subtropicais pode ocorrer associada à divergência de massa à jusante de um cavado ou vórtice ciclônico em níveis médios/altos da troposfera e fraca baroclinia em superfície (Guishard, 2006; Evans e Braun, 2012; da Rocha et al., 2019).

Os rastreamentos automáticos de sistemas ciclônicos em reanálises e modelos numéricos têm permitido ampliar o conhecimento sobre os ciclones em geral no Hemisfério Sul e América do Sul (Hoskins e Hodges, 2005; Sinclair, 2006; Reboita et al., 2010; Gramcianinov et al., 2019; Crespo, 2019) e as suas diversas fases/categorias (Hodges et al., 2017; Ramsay et al., 2018; Yanase et al., 2014; Guishard, 2006; Cavichia et al. 2018, 2020; Evans e Braun, 2012; Gozzo et al., 2014). Em particular na América do Sul, vários rastreamentos utilizando vorticidade relativa encontraram três regiões ciclogenéticas principais na parte centro-leste do continente - sul/sudeste do Brasil, Uruguai e sul da Argentina - (Hoskins e Hodges, 2005; Reboita et al., 2010; Reboita et al., 2019; Gramcianinov et al., 2019; Crespo et al., 2020), ou as duas últimas quando se utiliza pressão ao nível médio do mar em análise subjetiva (Gan e Rao, 1991), ou ainda apenas uma usando pressão e rastreamento automático (Mendes et al., 2010).

A Figura 2.1.1, retirada de Yanase et al. (2014), ilustra a climatologia sazonal das diferentes fases dos ciclones de escala sinótica para os Hemisférios Norte e Sul. Destaca-se a predominância de ciclones tropicais e extratropicais, respectivamente, em latitudes tropicais e extratropicais em ambos hemisférios, com os subtropicais ocupando latitudes intermediárias. Na costa leste da América do Sul, os ciclones subtropicais representam uma pequena porcentagem do total de ciclones nesta região, sendo as estações do verão e outono o período de maior ciclogênese subtropical.

Para a região da América do Sul, as duas principais climatologias que separaram de todos os ciclones aqueles denominados subtropicais são recentes e utilizaram metodologias e dados ligeiramente diferentes (da Rocha et al., 2019). Com a reanálise ERA-40 (resolução horizontal de 1,25 graus de latitude por longitude) e impondo vento sustentando mínimo de $17 \mathrm{~m} / \mathrm{s}$ em $925 \mathrm{hPa}$ 
para caracterizar ciclone subtropical, Evans e Braun (2012) obtiveram frequência de um evento por ano sobre o sudoeste do Oceano Atlântico Sul. Para essa mesma região, utilizando a ERA-Interim (Dee et al., 2011) e o NCEP-2 (Kanamitsu et al., 2002) e não impondo mínimo de velocidade do vento sustentada nem baixa fechada em $500 \mathrm{hPa}$, relaxando o $\mathrm{V}_{\mathrm{T}}^{\mathrm{L}}$ e retirando os ciclones em excesso, Gozzo et al. (2014) encontraram uma média 7,2 sistemas subtropicais por ano em ambas as reanálises. Em linhas gerais, a ERA-Interim e o NCEP-2 apresentam características similares para a climatologia dos ciclones subtropicais no Atlântico Sul, tais como, frequência anual, sazonalidade, região preferencial de ciclogêneses e ciclólises (Gozzo et al., 2014). É importante lembrar que estas duas reanálises são de centros meteorológicos diferentes, que utilizam diferentes modelos e resolução espacial (resolução horizontal, respectivamente, de 1,5 e 2,5 graus de longitude por latitude na ERA-Interim e NCEP-2). 
(a) SH summer (DJF)

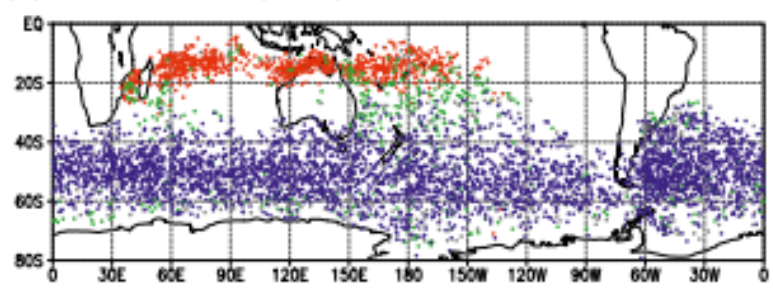

(c) SH autumn (MAM)

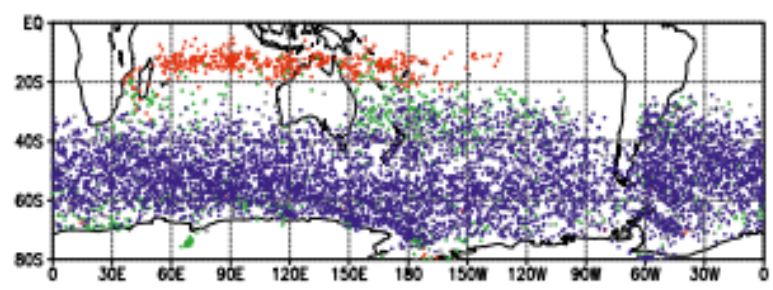

(e) SH winter (JJA)

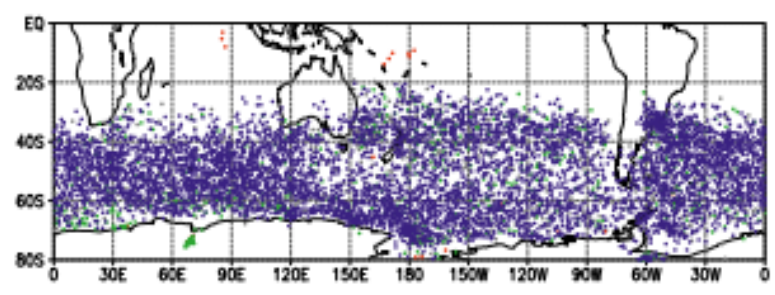

(g) SH spring (SON)

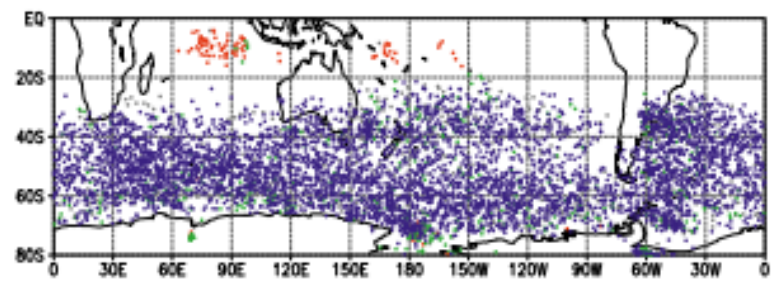

(b) NH summer (JJA)

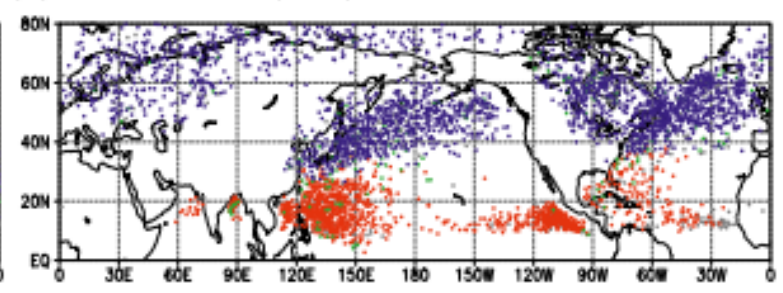

(d) NH autumn (SON)

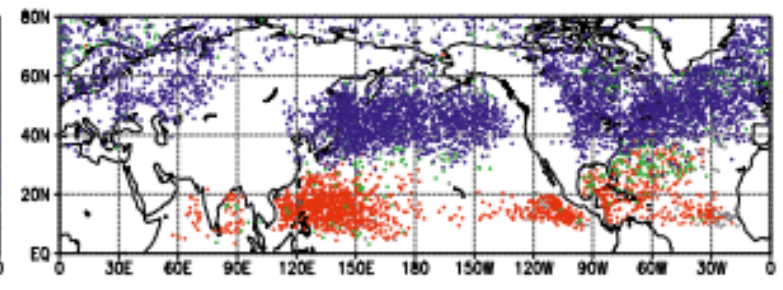

(f) $\mathrm{NH}$ winter (DJF)

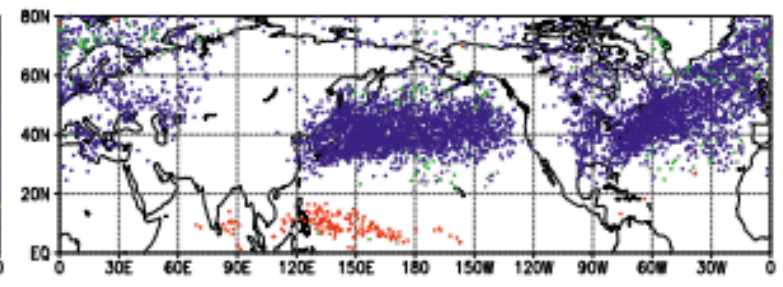

(h) NH spring (MAM)

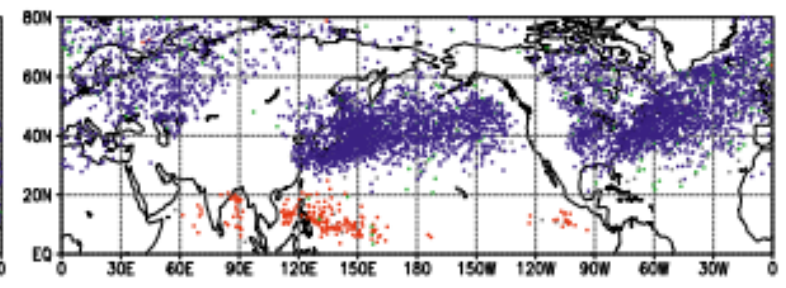

Figura 2.1.1 - Localização geográfica do desenvolvimento de ciclones (taxa de crescimento $>0,1$ dia $^{-1}$ ) para 30 anos (dezembro 1981 a novembro 2011) no Hemisfério Sul (coluna esquerda) e Hemisfério Norte (coluna a direita) nas estações de: (a)-(b) verão, (c)-(d) outono, (e)-(f) inverno e (g)-(h) primavera para ciclones tropicais (vermelho), extratropicais (azul) e subtropicais (verde). Fonte: Yanase et al. (2014).

A climatologia de Evans e Braun (2012) não apresenta a região preferencial de formação dos ciclones subtropicais. Por outro lado, Gozzo et al. (2014) mostraram maior frequência de ciclones subtropicais formando-se próximo à costa sul-sudeste do Brasil ( $\sim 45^{\circ} \mathrm{W}$ e $\left.\sim 25^{\circ} \mathrm{S}\right)$ tanto na ERA-Interim como no NCEP-2. As ciclólises ocorrem em duas regiões principais, a primeira praticamente coincide com a região de formação e a segunda, em aproximadamente $10^{\circ} \mathrm{W}$ e $42^{\circ} \mathrm{S}$, corresponde à região central do Oceano Atlântico Sul. Essa “quase” coincidência entre a região de 
gênese e fim dos sistemas indica o carácter semi-estacionário de muitos ciclones subtropicais. Uma pequena diferença é notada entre a ERA-Interim e NCEP-2, ou seja, no NCEP-2 existe um maior número de eventos sofrendo ciclose em área similar à de formação do que na ERA-Interim. Em termos de sazonalidade, Gozzo et al. (2014) encontraram maior frequência de ciclones subtropicais no verão seguido do outono, e menor no inverno. Essa sazonalidade foi encontrada tanto na ERA-Interim como no NCEP-2. Na climatologia de Evans e Braun (2012), os ciclones subtropicais ocorrem mais no inverno seguido do outono, e menos no verão. A diferença de sazonalidade entre Gozzo et al. (2014) e Evans e Braun (2012) resulta principalmente de diferenças metodológica (imposição de vento sustentado mínimo) do que da reanálise utilizada, desde que Gozzo et al. (2014) encontraram sazonalidade similar em duas reanálises diferentes (ERA-Interim e NCEP-2).

De acordo com alguns autores (Dias Pinto et al., 2013; Dutra et al., 2017; Reboita et al., 2019; da Rocha et al., 2019), as principais características sinóticas dos ciclones subtropicais no sudoeste do Atlântico Sul são semelhantes àquelas descritas para tais sistemas no Oceano Atlântico Norte (Guishard et al., 2009), na costa leste da Austrália (Dowdy et al., 2011; Pepler et al., 2016) e no mar Mediterrâneo (Tous e Romero, 2013). No entanto, outros fatores locais atuam caracterizando as principais regiões de formação destes sistemas. Segundo Evans e Braun (2012) uma hipótese para maior frequência de ciclogênese subtropicais próximo da costa leste do Brasil seria explicada por ciclogênese à sotavento dos Andes e valores elevados de temperatura da superfície do mar (TSM) na corrente do Brasil. Um outro fator importante para as ciclogêneses subtropicais na costa sudeste do Brasil foi apresentado por Gozzo et al. (2014), onde o transporte de umidade pelos ventos de nordeste no setor oeste do anticiclone subtropical do Atlântico Sul, juntamente com a evaporação local, são fundamentais para alimentar a atividade convectiva dos ciclones subtropicais e caracterizar a costa sudeste do Brasil com maior frequência destes sistemas.

A importância de classificar os ciclones reside no fato que diferentes eventos de tempo estão associados a cada fase/categoria ao longo do ciclo de vida dos sistemas. Além disso a ocorrência de transição entre as diversas categorias dificulta tanto a previsão subjetiva como numérica de eventos extremos, como aconteceu, por exemplo, para o ciclone tropical Catarina ocorrido em março de 2004 no Atlântico Sul sudoeste (McTaggart-Cowan et al., 2006; Pezza e Simmonds, 2005; Vianna et al., 2010) e para o furacão Sandy, que transicionou para subtropical e devastou a costa leste 
norte-americana em 2012 (Galarneau et al., 2013). As previsões numéricas não indicavam a formação do ciclone tropical Catarina e os meteorologistas tiveram dificuldades na previsão subjetiva do mesmo desde que por muito tempo a bacia do Atlântico Sul foi considerada como desfavorável para o desenvolvimento de ciclones tropicais (forte cisalhamento vertical do vento horizontal e TSM relativamente fria; Pezza e Simmonds, 2005). A ocorrência do furacão Catarina nas proximidades da costa sul do Brasil mostrou que, sob certas condições, mesmo nesta região, ciclogêneses tropicais são possíveis. O ciclone tropical Catarina apresentou um ciclo de vida bastante peculiar, ou seja, formou-se a partir de um ciclone extratropical que fez transição para subtropical, e a seguir, no momento em que decresceu o cisalhamento vertical do vento fez transição para tropical, mesmo estando sobre TSM relativamente fria (McTaggart-Cowan et al., 2006; Pezza e Simmonds, 2005; Vianna et al., 2010). Quando adquiriu características tropicais, o Catarina moveu-se para oeste, atingindo a costa sul do Brasil com ventos e chuvas intensas e impactos diversos, inclusive na população local de pássaros marítimos (Bugoni et al., 2007).

Como mostrado por Gozzo et al. (2014), o leste do sudeste/sul do Brasil (desde o Espírito Santo até o Paraná) destaca-se como região preferencial de formação e deslocamento dos ciclones subtropicais no Atlântico Sul. Desta forma, a percepção da importância dos sistemas subtropicais para eventos extremos de vento e precipitação sobre o sudeste do Brasil e oceano adjacente tem aumentado nos últimos anos. Após o ciclone subtropical Anita, em março de 2010, o Centro Hidrográfico da Marinha do Brasil começou a acompanhar e atribuir nomes aos ciclones tropicais e subtropicais que ocorrem no centro-oeste do Oceano Atlântico Sul. De acordo com da Rocha et al. (2017) e Reboita et al. (2019), de 2010 a 2016, foram nomeados seis ciclones subtropicais (Anita, Arani, Bapo, Cari, Deni, Eçaí). Esses ciclones se desenvolveram próximo do sudeste do Brasil e, durante a maior parte de seus ciclos de vida, foram responsáveis por ventos fortes em 925 hPa (excedendo $20 \mathrm{~m} \mathrm{~s}^{-1}$ por mais de 12 horas) e chuva intensa na costa sudeste do Brasil (Reboita et al., 2019). Para a bacia sudoeste do Atlântico Sul, Cardoso (2019) analisou a relação entre ciclones subtropicais e extremos de vento próximo à superfície utilizando reanálises no período 1979-2014. Considerando como extremo velocidades acima do percentil de 95\%, Cardoso (2019) mostrou que os extremos associados aos ciclones subtropicais são mais comuns no verão e outono e ocorrem 
com mais frequência na região com maior densidade destes eventos, ou seja, no leste do sudeste do Brasil.

Ainda em termos de extremos, um vórtice ciclônico de janeiro de 2000, com características subtropicais, foi associado por Brasiliense et al. (2018) com a ocorrência de precipitação extrema sobre a bacia do rio Paraíba do Sul, que se estende desde o leste do estado de São Paulo até o norte do Rio de Janeiro. A excepcionalidade desse mesmo período de chuvas intensas, início de janeiro de 2000, foi analisado por Sugahara et al. (2010) em termos de período de retorno de evento extremo para chuvas no leste do sudeste do Brasil ( sul de Minas Gerais, leste de São Paulo e Rio de Janeiro). Sugahara et al. (2010) classificaram a precipitação acumulada observada durante cinco dias de janeiro de 2000 (que em uma estação específica chegou a 522 mm) como um evento extremamente raro para a região, ou seja, com probabilidade de ocorrência menor que 1\% para a maioria das estações analisadas.

\subsection{Cenários de mudanças climáticas}

Segundo o Painel Intergovernamental de Mudanças Climáticas (IPCC, 2007) a ação antropogênica vem proporcionando aumento da concentração de gases do efeito estufa, entre eles o $\mathrm{CO}_{2}$. Este aumento faz com que uma maior quantidade de radiação de onda longa permaneça na troposfera terrestre e, como resposta, resulta no aumento de temperatura média do planeta. Para entender como o aumento da concentração de gases do efeito estufa poderá alterar o clima futuro, o IPCC (2007, 2013) coordena um esforço de vários grupos de pesquisa no desenvolvimento e aplicações de modelos globais de circulação geral acoplados oceano-atmosfera (AOGCMs) em cenários futuros do clima. Por exemplo, para o relatório do IPCC-2007 foram construídos vários cenários de emissões futuras, e entre eles, Nakicenovic (2000) propôs e analisou o B1 (baixa emissão de gases de efeito estufa), A1B (média emissão) e A2 (alta emissão). Ao analisar as projeções nestes cenários para metade do século XXI (2046-2065) em comparação com o clima presente, tem-se um aumento da temperatura média global para os cenários B1, A1B e A2 de, respectivamente, $+1,3^{\circ} \mathrm{C},+1,8^{\circ} \mathrm{C}$ e $+1,7^{\circ} \mathrm{C}$. Estes modelos também indicaram que no geral deverá 
aumentar a precipitação nas regiões tropicais, em particular sobre o Pacífico Tropical. Também são projetados aumentos da precipitação em latitudes altas com consequente intensificação do ciclo hidrológico global, enquanto as projeções apontam para um decréscimo da chuva nos subtrópicos.

O IPCC (2013) propôs novos cenários, os quais são identificados pela forçante radiativa e concentração de $\mathrm{CO}_{2}$ em partes por milhão (ppm) denominados RCPs: RCP2.6 (475 ppm; 2,6 W/m²), RCP4.5 (630 ppm; 4,5 W/m²), RCP6.0 (800 ppm; 6,0 W/m²) e RCP8.5 (1313 ppm; 8,5 $\mathrm{W} / \mathrm{m}^{2}$ ). Nesses cenários a temperatura do ar próximo à superfície global pode sofrer aumento no final do século XXI, ultrapassando $1,5^{\circ} \mathrm{C}$, exceto no cenário RCP2.6. Nos dois cenários mais alarmantes de concentração de $\mathrm{CO}_{2}$, RCP6.0 e RCP8.5, os aumentos projetados de temperatura ultrapassam $2,0^{\circ} \mathrm{C}$. Para o período de 2016-2035, a temperatura média sazonal e anual poderá sofrer aumento nos trópicos e subtrópicos, já no período de 2081-2100, projeta-se que a temperatura na região do Ártico vai aumentar mais rapidamente do que a média global. Ainda segundo o IPCC (2013), em altas latitudes e Pacífico equatorial as simulações indicam um aumento na precipitação média anual, enquanto nas regiões de médias latitudes e subtrópicos projeta-se decréscimo na precipitação média. O oceano global vai continuar aquecendo durante o século XXI, com o calor penetrando desde a superfície até níveis mais profundos e afetando a circulação oceânica. Nessas estimativas uma camada com profundidade de cerca de cem metros poderá aquecer de $0,6^{\circ} \mathrm{C}(\mathrm{RCP} 2.6)$ até $2,0^{\circ} \mathrm{C}(\mathrm{RCP} 8.5)$.

Para uma avaliação de tendências no clima futuro na América do Sul, principalmente sobre o Brasil, Marengo (2006) utilizou os cenários de alta emissão dos gases do efeito estufa (A2) de cinco GCMs acoplados (AOGCMs) do IPCC AR5 (IPCC, 2013): HadCM3 do Hadley Center da Inglaterra, Canadian Center for Climate Modeling and Analysis (CCCMA) do Canadá, Australia's Commonwealth Scientific and Industrial Research Organization (CSIRO) da Austrália, Center for Climate Studies and Research SCSR/National Institute for Environmental Studies NIES (SCSR/NIES) do Japão e Geophysical Fluids Dynamic Laboratory (GFDL) da National Oceanic and Atmospheric Administration (NOAA) dos Estados Unidos. Em uma análise da média dos cinco AOGCMs, a comparação entre o período presente, 1961-1990, e o futuro, 2071-2100, indica para o inverno intensas anomalias negativas de precipitação sobre o norte da América do Sul e positivas no sul do Brasil. Já no verão, as anomalias negativas concentram-se sobre o oeste da 
Amazônia, e as positivas sobre o nordeste, sudeste e sul do Brasil. Estes AOGCMs projetam ainda aumento de temperatura em toda a América do Sul no verão e inverno. Em uma análise regional, Marengo (2006) comparou o ciclo sazonal da precipitação para o século XXI com o clima presente na Amazônia e bacia do Prata. Na Amazônia, projeta-se um período maior de estação seca (junho até setembro) na maioria dos modelos do que na análise, indicando que em cenários futuros a estação seca poderá ter maior duração. Na Bacia do Prata, o ciclo anual mostra que no cenário A2 as projeções para o clima futuro são similares ao presente, ou seja, as mudanças seriam menores.

Torres e Marengo (2013) apresentaram uma comparação de GCMs do CMIP3 (cenários B1, A1B e A2) e CMIP5 (cenários RCP 2.6, 4.5, 6.0 e 8.5) para avaliar projeções climáticas para o final do século (2071 - 2100) comparado com o clima presente (1961 - 1990). No verão e inverno as projeções do CMIP3 indicam aumento de temperatura sobre todo o continente sul americano. Já para a precipitação, no verão as projeções mostram aumento na bacia do Prata e oeste da Amazônia, enquanto no inverno indicam redução de precipitação no nordeste, centro-oeste, sudeste e leste da Amazônia, e aumento sobre o sul da região Sul do Brasil. Os GCMs do CMIP5 projetam aumento de precipitação na bacia do Prata e norte da Amazônia no verão, já no inverno projeta-se redução de precipitação nas mesmas regiões já indicadas pelos GCMs do CMIP3. As projeções de temperatura mostram padrão espacial de aumento similar nos GCMs do CMIP3 e CMIP5.

A necessidade de informações mais detalhadas no tempo e no espaço aumentou a necessidade de usar RCMs, com maior resolução espacial, para avaliar cenários de mudanças climáticas também na América do Sul. Conforme sintetizado por Ambrizzi et al. (2019), alguns projetos envolvendo vários países do continente fizeram avançar esta linha de pesquisa. Por exemplo, no contexto do projeto PROBIO-MCT-Brasil, com um conjunto de três RCMs (Eta CCS, RegCM3 e HadRM3P) aninhados no GCM HadAM3 para os cenários A2 e B2, Marengo et al. (2010) analisaram mudanças climáticas no Brasil. Essas projeções, considerando os três RCMs, indicaram tendência de decréscimo da chuva no futuro no nordeste do Brasil e centro-leste e sul da Amazônia, enquanto para temperatura indicaram maior aquecimento na região equatorial (entre $5^{\circ} \mathrm{N}-15^{\circ} \mathrm{S}$ ) onde o aumento pode chegar a $6-8^{\circ} \mathrm{C}$.

Para os cenários A2 e B2 do GCM HadAM3 regionalizados pelo RCM RegCM3 (Pal et al., 2007), Krüger et al. (2012) compararam o período futuro 2071-2085 com o presente 1975-1989 
sobre a América do Sul e Oceano Atlântico Sul. Para o verão essas projeções mostraram tendência de anomalias positivas de precipitação posicionadas sobre o Peru, oeste e sul do Brasil, Uruguai e centro-norte da Argentina mais intensas no cenário A2 do que no B2. No inverno, nos cenários A2 e B2 a precipitação tem padrão similar, ou seja, anomalias negativas sobre o sul do Brasil, Paraguai e sobre o oceano cobrindo praticamente toda a costa leste do Brasil. No cenário B2 projeta-se aumento da chuva no oeste da Argentina. Sobre a América do Sul, as projeções indicam aumento de temperatura nos dois cenários, sendo no cenário A2 maior em comparação com o cenário B2. Estes resultados são similares aos de Marengo et al. (2010) que utilizaram três RCMs.

Recentemente, Llopart et al. (2014) regionalizaram com RegCM4 (Regional Climate Model version 4; Giorgi et al., 2012) o cenário RCP8.5 do IPCC (2013) para a América do Sul. Estas projeções mostraram para o cenário RCP8.5 que existe tendência de seca sobre o centro da América do Sul associada com o início tardio e término precoce do sistema de monção. Em uma análise sazonal, Llopart et al. (2014) destacaram que na Amazônia as projeções indicam decréscimo da precipitação sazonal, enquanto na bacia do Prata projetam um aumento da precipitação durante a estação úmida (novembro-maio) e decréscimo durante a estação seca. Em geral, é aparente nas projeções um padrão de dipolo, ou seja, decréscimo de precipitação sobre uma ampla área na Amazônia-nordeste do Brasil e aumento sobre a região sudeste da América do Sul. No entanto, os autores ressaltam que existe um alto nível de incertezas das projeções para a região de estudo, sendo necessário investir na melhoria dos modelos buscando reduzir as incertezas.

Chou et al. (2014) avaliaram tendências climáticas com o RCM Eta forçado pelos modelos globais HadGEM2 e MIROC5 nos cenários RCP8.5 e 4.5. Temperaturas mais altas no futuro são projetadas por esses modelos em todo o continente, com maior amplitude quando o Eta é forçado pelo HadGEM2 no cenário RCP8.5. No verão nas regiões Norte, Sudeste e Centro-Oeste do Brasil as projeções indicam intensa redução de precipitação, enquanto na bacia do Prata a precipitação poderá aumentar no futuro. Embora com diferenças de intensidade, esse padrão espacial de mudança na chuva também foi encontrado por outros estudos (Marengo et al., 2010; Kruger et al., 2009; Reboita et al., 2014; Llopart et al., 2014; Llopart et al., 2020) conforme sintetizado em Ambrizzi et al. (2019). 


\subsection{Tendências climáticas: ciclones e ciclones subtropicais}

Como já mencionado, a maior disponibilidade de análises observacionais (reanálises) e resultados de modelos de cobertura global e regional tem ampliado o número de estudos sobre ciclones no clima presente e suas tendência futuras ao redor do globo. Os métodos de rastreamentos, variável utilizada para rastrear (vorticidade, pressão, altura geopotencial, etc.) e a base de dados (diferentes reanálises e resultados de modelos) levam a algumas incertezas relacionadas tanto com a climatologia como com as tendências. Estas fontes de incertezas estão documentadas em Leonard et al. (1999) e Neu et al. (2013). Em especial, Neu et al. (2013) mostram que no Hemisfério Sul o número total de ciclones no inverno pode variar de 4000 e 14000 em função do algoritmo, desde que se utilizou a mesma reanálise como base de dados. Portanto, várias análises recentes têm comparado climatologias e tendências de ciclones em diferentes reanálises com algoritmos diversos.

Para um período de 7 anos (1980-1986) de análises do ECMWF, Sinclair (1994) empregou um esquema automático para determinar a distribuição espacial e temporal dos centros de circulação ciclônica no Hemisfério Sul através de mínimos de vorticidade relativa geostrófica. Essa variável tem potencial para incluir centros móveis adicionais em latitudes médias $\left(45-55^{\circ} S\right)$, capturando atividade ciclônica transiente. Uma desvantagem pode ser em relação aos extremos de vorticidade que são mais sensíveis a erros de análise e dependentes do espaçamento horizontal de grade. $\mathrm{O}$ autor obteve alta frequência de centros de vorticidade relativa geostrófica ao sul de $60^{\circ} \mathrm{S}$ e em zonas continentais de latitudes médias, que incluem uma mistura de centros móveis e fixos. Com a mesma metodologia e dados, Sinclair (1995) avaliou o ciclo de vida dos ciclones no Hemisfério Sul. Obteve que a maioria dos ciclones forma-se ou intensifica-se em latitudes médias e migra para leste. As principais regiões ciclogenéticas incluem as costas leste da Austrália e da América do Sul no inverno; e sobre o oceano os ciclones no inverno se formam e intensificam principalmente próximo às zonas de forte gradiente de TSM (temperatura da superfície do mar). 
Uma climatologia mais longa (1958-1997) e utilizando pressão ao nível do mar para identificar ciclones na reanálise do NCEP (Kalnay et al., 1996) foi elaborada por Simmonds e Keay, 2000a). Encontraram maior ocorrência de sistemas entre $50^{\circ} \mathrm{S}-70^{\circ} \mathrm{S}$, com máximo de ciclogênese em torno de $60^{\circ} \mathrm{S}$ e ciclólise acontecendo preferencialmente ao sul deste cinturão de latitudes, próximo à costa Antártica. Os autores mostraram ainda que a taxa de ciclogênese excede a de ciclólise ao norte de $\sim 50^{\circ} \mathrm{S}$ em todas estações do ano, enquanto o oposto ocorre ao sul desta latitude, e que os ciclones mais profundos encontram-se em torno de $60^{\circ} \mathrm{S}$.

Em termos de tendência, Simmonds e Keay (2000b) encontraram uma redução no número de ciclones ao sul de $40^{\circ} \mathrm{S}$, e aumento ao norte dessa latitude. Em termos percentuais, obtiveram um decréscimo de cerca de $10 \%$ nas ciclogêneses entre $30^{\circ} \mathrm{S}-70^{\circ} \mathrm{S}$ entre as décadas de 70 e 90 . Utilizando pressão ao nível do mar para identificar ciclones na reanálise do NCEP entre 1973-1996, Pezza e Ambrizzi (2003) concentraram-se na análise de tendências de ciclones no inverno do Hemisfério Sul. Encontraram, basicamente, um decréscimo do número de sistemas ciclônicos, principalmente no final da década de 70, devido ao menor número de sistemas fracos e predomínio de sistemas com maior intensidade. Através do mesmo algoritmo e dados utilizados por Pezza e Ambrizzi (2003), mas considerando um período mais longo (1980-2012), Reboita et al. (2015) analisaram a tendência de ciclones no Hemisfério Sul para todas as estações do ano. Reboita et al. (2015) obtiveram um resultado oposto ao de Pezza e Ambrizzi (2003), ou seja, identificaram uma tendência positiva do total de ciclones no Hemisfério Sul. Essa diferença deve-se à maior extensão temporal da série utilizada por Reboita et al. (2015). Os autores discutem ainda que o aumento no total de ciclones resultaria da forte tendência positiva dos eventos mais intensos, como também encontraram Pezza e Ambrizzi (2003) para ciclones no inverno.

Diversos autores encontraram tendência de aumento de ciclones no Hemisfério Sul. Por exemplo, através de 4 reanálises (ERA40, ERAI, NCEP2, JRA25) entre 1979-2008, Allen et al. (2010) obtiveram tendência positiva na frequência de ciclones intensos no Hemisfério Sul, que foram identificados através de pressão ao nível médio do mar. Para o total de ciclones, Wang et al. (2013) e Wang et al. (2016), também utilizando a pressão ao nível médio do mar porém diferentes períodos (1951-2010; 1979-2001 e 1901-2008) e reanálises (NCEP e NCEP-20C; ERA-20C, NCEP20C, JRA55, MERRA, CFSR, ERAI, ERA40, NCEPI, NCEP2), obtiveram tendência de 
aumento de ciclones no Hemisfério Sul e sinais diferentes de tendência de ciclones nas reanálises centenárias tanto no Hemisfério Norte como no Hemisfério Sul.

Embora no Hemisfério Sul se encontre usualmente tendência positiva do total de ciclones em vários estudos, a Figura 2.3.1, extraída de Reboita et al. (2015), mostra que existem diferenças regionais importantes. Por exemplo, no Atlântico Sul, especificamente no leste do Uruguai e sul da Argentina, nota-se tendências, respectivamente, positiva e negativa no total de ciclones. Reboita et al. (2015) ressalta que ambas as tendências não são estatisticamente significativas ao nível de 90\%.

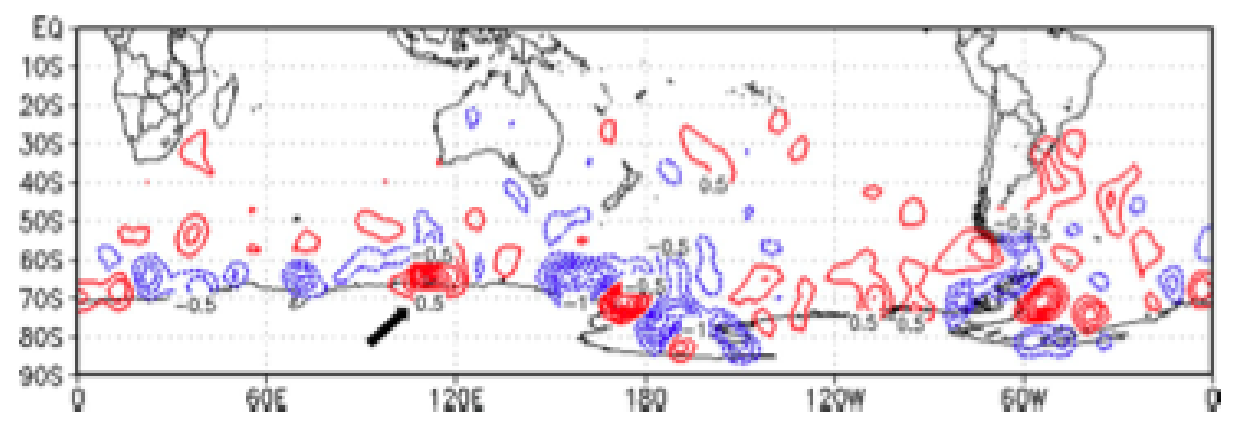

Figura 2.3.1 - Coeficiente angular da tendência anual de ciclones extratropicais no Hemisfério Sul para o período 1980-2010. As linhas azuis e vermelhas indicam, respectivamente, tendências negativas e positivas. A significância estatística com 90\% de confiança só é encontrada próximo de $70^{\circ} \mathrm{S}$ e $110^{\circ} \mathrm{E}$, conforme destacado pela seta preta. Fonte: Reboita et al. (2015).

As tendências observadas, com discrepâncias em função de vários fatores ( algoritmo, reanálise e período), no clima apontam para possíveis alterações na atuação dos ciclones. Desta forma, existe a necessidade de entender mudanças na atuação dos sistemas sinóticos e eventos de tempo associados em cenários de mudanças climáticas. Além disso, estas mudanças podem indicar também mudanças em eventos extremos, servindo também para alertar a sociedade sobre a necessidade de adequação. Nesse sentido, muitos estudos têm procurado entender como a atuação dos ciclones em geral, e em particular os subtropicais, pode ser alterada em cenários climáticos futuros.

Os relatórios do IPCC (2007; 2013) indicam um aumento de temperatura no decorrer do século XXI, enquanto os sinais de mudanças na chuva são mais incertos e dependentes da região do globo. Alguns autores estudaram o comportamento dos ciclones pelo globo para saber quais 
alterações estes sistemas podem sofrer em sua intensidade, número de eventos, região de atuação, entre outras características importantes associadas.

\section{a) Mudanças climáticas e ciclones}

A maior disponibilidade de umidade na atmosfera e as modificações nos gradientes meridionais de temperatura em resposta às mudanças climáticas (Watterson, 2006; Tierney et al., 2018) podem modificar o desenvolvimento de ciclones e as trajetórias da tempestades (storm tracks) em todo o mundo. Portanto, é fundamental que os modelos numéricos de circulação atmosférica sejam capazes de representar a climatologia e as características dos ciclones no clima atual, dando confiança para explorar suas mudanças nos cenários futuros. A maioria dos estudos individuais utilizando uma ampla gama de GCMs, dos mais simplificados aos mais complexos, também mostra que é esperada uma mudança no caminho das tempestades nos dois hemisférios (Fyfe, 2003; Bengtsson et al., 2005; Wu et al., 2011; Tamarin-Brodsky e Kaspi, 2017; Mbengue e Schneider, 2017; Zappa, 2019). Essa mudança estaria associada a um deslocamento dos ventos de oeste de nível superior em direção ao pólo e a uma expansão da célula de circulação de Hadley. No entanto, também existem estudos mostrando uma mudança em direção ao equador do caminho de tempestades devido aos forçantes antropogênicos (Ming et al., 2011; Pfahl et al., 2015). Shaw et al. (2016) analisaram a complexidade dessa discussão, apontando que a resposta termodinâmica da atmosfera ao aquecimento global pode ter efeitos opostos no gradiente meridional de temperatura, levando a diferentes deslocamentos possíveis nos caminhos de tempestade no futuro.

A fim de estudar o efeito do aumento dos gases de efeito estufa na frequência de ciclones no verão e inverno, Lambert (1995) realizou simulações utilizando a segunda geração do GCM Canadian Climate Centre (CCC): uma controle com $1 \mathrm{X} \mathrm{CO}_{2}$ e outra dobrando o conteúdo de $\mathrm{CO}_{2}$ na atmosfera. $\mathrm{O}$ autor obteve que ao dobrar o $\mathrm{CO}_{2}$, diminui o número total de ciclones no no inverno em ambos os hemisférios, enquanto a frequência de ciclones mais intensos aumenta. Este padrão mostra-se mais significativo no Hemisfério Norte do que no Hemisfério Sul. Baseado em um cenário de mudanças climáticas Zang e Wang (1997) obtiveram redução da atividade dos ciclones a nível global, que foram atribuídas a três diferentes mecanismos físicos: 1) decréscimo do 
gradiente meridional de temperatura, 2) redução do contraste continente-oceano na costa oeste dos continentes Asiático e América do Norte e 3) aumento do fluxo meridional de calor latente.

Com o GCM do CCCma, Fyfe (2003) estudou mudanças climáticas para o período 1850-2100. O autor mostrou que no oceano sub-Antártico o número de ciclones apresenta uma tendência drástica de decréscimo, enquanto projeta-se pequeno aumento na frequência dos ciclones sobre o oceano Antártico. Também investigando tendências de ciclones, Geng e Sugi (2003) utilizaram simulações de mudanças climáticas até o ano 2050 com um GCM da Japan Meteorological Agency. Em termos de frequência de ciclones extratropicais, os autores obtiveram tendência de decréscimo no número total de ciclones em médias latitudes nos hemisférios Norte e Sul durante o verão e inverno. O decréscimo na densidade de ciclones no Hemisfério Sul no poderá chegar a 7\% e 10\%, respectivamente, no verão e inverno, já no Hemisfério Norte no inverno a diminuição poderá atingir 3\%. Ao estudar os ciclones extratropicais mais intensos, os autores obtiveram que a densidade destes sistemas aumenta no verão e inverno sobre a costa leste da Ásia e América do Norte. Da mesma maneira, no Hemisfério Sul também projetou-se que a frequência dos ciclones mais intensos pode aumentar na costa sudeste da África e da América do Sul. Bengtsson et al. (2005) utilizando o GCM acoplado do Max Planck Institut (MPI - ECHAM5) avaliaram mudanças climáticas nos ciclones e também encontraram que as regiões dos caminhos de tempestades em ambos os Hemisférios deverão se deslocar em direção aos pólos. Particularmente no Hemisfério Sul esse deslocamento para o pólo deverá acontecer em todas as estações do ano. Em experimentos numéricos com GCMs considerando o aumento dos gases estufa, Lambert e Fyfe (2005) obtiveram que o número de ciclones ao redor do globo no período de inverno poderá diminuir, enquanto projeta-se aumento do número de eventos mais intensos. Estes resultados reforçam a hipótese de deslocamento dos caminhos de tempestades para os pólos também encontrada em outros trabalhos (Fyfe, 2003; Kushner et al., 2001; Geng e Sugi, 2003; Yin 2005; Chang et al., 2012; Tamarin-Brodsky e Kaspi, 2017).

Além de entender mudanças na frequência de ciclones, também é um fator de interesse entender mudanças de intensidade e fenômenos de tempo associados (chuva, vento, etc.) aos ciclones em um clima mais aquecido. Com os GCMs CSIRO-Mark2 (baixa resolução espacial) e CSIRO-Mark3 (alta resolução espacial) para simular o clima futuro (2071-2100), Watterson (2006) 
investigou a precipitação associada aos ciclones extratropicais. No cenário A2, o CSIRO-Mark2 simula aumento da temperatura global em 3,5 K e um pequeno decréscimo no número de ciclones em médias latitudes, enquanto em altas latitudes pode ocorrer um pequeno aumento desses sistemas. Ao aumentar a resolução espacial no CSIRO-Mark3 obtém-se aumento da temperatura global menor (3,1 K) e a precipitação associada com os ciclones em superfície sofre um grande aumento no futuro. Também investigando impactos nos fenômenos de tempo, Bengtsson et al. (2008) identificaram uma redução no número de ciclones e mudança nos extremos de vento e vorticidade associados em ambos os Hemisférios, mas essa tendência não apresentou significância estatística. No entanto, encontraram mudanças significativas na precipitação ao longo das trajetórias dos ciclones, onde o acumulado aumenta em até 11\% em comparação com o clima presente. Para o Hemisfério Sul, Chang (2016) mostrou, através de GCMs do CMIP5, projeções de aumento na frequência dos sistemas extremos e também de ventos extremos associados aos ciclones em cenários futuros do clima.

Em escala regional, alguns estudos têm procurado entender mudanças nos ciclones e eventos de tempo associado utilizando RCMs. Para a América do Sul, Kruger et al. (2012) utilizaram o RegCM3 aninhado ao HadAM3 nos cenários futuros A2 e B2 e compararam o clima presente e futuro (2071-2085). Nesses cenários, o RegCM3 apresentou tendência de decréscimo no total de ciclones de $-7,2 \%$ e $-4,7 \%$, respectivamente, nos cenários A2 e B2. Uma redução mais acentuada na frequência de ciclones foi obtida considerando os eventos mais intensos, chegando a -20,9\% e -11,3\% nos cenários A2 e B2, respectivamente.

Focando no total de ciclones (sem separar em tropicais, subtropicais e extratropicais), Reboita et al. (2018) avaliaram o desempenho do GCM HadGEM2-ES e da regionalização do RegCM4 sobre o sudoeste do Oceano Atlântico Sul. Esta análise mostrou que os modelos simulam as principais características da distribuição de densidade ciclogenética, ou seja, apresentam os três principais núcleos ciclongenéticos do sudoeste do Oceano Atlântico Sul (costa sudeste do Brasil; sul do Brasil-Uruguai; sudeste da Argentina). No entanto, no sudeste da Argentina o HadGEM2-ES superestima a frequência de ciclogêneses, enquanto o RegCM4 corrige esse erro e aproxima-se mais das observações. Este resultado indica que o RegCM4 agrega valor ao HadGEM2-ES ao simular o padrão espacial da ciclogênese mais próximo ao observado. Para o 
fim do século XXI no cenário RCP8.5, Reboita et al. (2018) encontraram projeções de diminuição em até -11,4\% nas ciclogêneses sobre o sudoeste do Atlântico Sul.

As incertezas nas projeções climáticas surgem do conhecimento teórico limitado dos processos físicos, da descrição incompleta de alguns processos físicos nos modelos ou de deficiências nas parametrizações de fenômenos de pequena escala (Knutti et al., 2010). A abordagem de utilizar um conjunto composto de vários modelos têm sido frequentemente considerada para discutir tendências climáticas. Isso permite considerar um espectro de incertezas através da combinação de diversos modelos que forneça projeção climática e o espalhamento associado ao conjunto. Para o Hemisfério Norte, análises de conjuntos de GCMs e RCMs corroboram a significativa tendência de redução na frequência de ciclones durante o inverno e o verão no clima futuro (McDonald, 2011; Zappa et al., 2013). Embora menos frequentes, os ciclones de verão no futuro tendem a ser maiores e mais intensos (Lehmann et al., 2014; Akperov et al., 2019). As projeções de conjuntos de modelos também indicam uma diminuição nos ventos extremos em baixos níveis associados aos ciclones extratropicais em escala hemisférica ou em toda a bacia analisada (Zappa et al., 2013; Chang et al., 2018). No entanto, em escala regional é possível identificar sinal oposto, ou seja, de tendência de aumento da velocidade do vento associada ao total de ciclones (Leckebusch e Ulbrich, 2004; Zappa et al., 2013) e também dos "sting jets" dentro dos ciclones do tipo Shapiro-Keyser (Martínez-Alvarado et al., 2018). Considerando a troposfera superior, Mizuta (2012) mostrou que muitos modelos do CMIP5 (Taylor et al., 2012) projetam um jato polar mais intenso no futuro, levando à formação de ciclones em superfície mais intensos, especialmente no Pacífico Norte. O aumento da frequência de ciclones mais intensos e decréscimo do total também foram encontrados por Grieger et al. (2014) ao analisarem um conjunto composto de projeções climáticas de nove GCMs acoplados oceano e atmosfera.

No contexto de investigar um conjunto de modelos, Reboita et al. (2020) utilizou regionalizações do RegCM4 aninhadas em três GCMs do CMIP5 e identificaram tendências de decréscimo na frequência de ciclones na África, Austrália e América do Sul no cenário RCP8.5. Além disso, os autores encontraram que a intensidade média da precipitação associada com os ciclones apresentou tendência de aumento no clima futuro, o que estaria de acordo com outras análises para outras regiões (Hawcroft et al., 2018; Kodama et al., 2019). Portanto, as projeções 
analisadas por Reboita et al. (2020) indicam que no clima futuro poderá ocorrer uma expansão da chuva mais intensa nas imediações das principais regiões ciclogenéticas do Hemisfério Sul.

\section{b) Mudanças climáticas e ciclones subtropicais}

Modelos numéricos apresentam dificuldades em simular as diferentes categorias/fases de ciclones, pois enquanto a instabilidade baroclínica, que desponta como principal mecanismo para ciclogênese extratropical, é relativamente bem simulada, a forma e intensidade dos ciclones subtropicais dependem de características locais que ainda não são totalmente conhecidas (Guishard, 2006; da Rocha et al., 2019). Por exemplo, Gozzo et al. (2017) discutiram a importância do transporte de umidade, de nordeste para sudeste, realizado pelo anticiclone subtropical do Atlântico Sul para a formação de ciclones no leste do sudeste do Brasil. As fontes diabáticas de calor, associadas tanto à mudança de fase durante a formação de nuvens/chuva como a transferência turbulenta de energia e momento na interface superfície-atmosfera, também exercem papel importante na formação destes sistemas (Reed et al., 2001; Homar et al., 2003; Dutra et al., 2017; Gozzo et al., 2017). Estas fontes normalmente são incluídas nos modelos numéricos na forma paramétrica e representam uma das principais fontes de incertezas nas simulações numéricas (Llopart et al., 2014). Por exemplo, para a bacia do Atlântico Sul, Abreu e da Rocha (2015) realizaram vários experimentos numéricos com o Weather Research and Forescasting (WRF) para identificar o tempo de antecedência e parametrização física mais apropriados para previsão do ciclone subtropical Anita, ocorrido em março de 2010 (Dias Pinto et al., 2013; Dutra et al., 2017). Estes experimentos mostraram que dependendo da parametrização convectiva utilizada o ciclone simulado pode apresentar intensidade e executar trajetória bastante distintas da observada.

No contexto de entender a habilidade dos modelos numéricos em simular as diversas categorias de ciclones, em especial, os subtropicais, vários estudos têm realizado simulações nas bacias do globo onde são mais frequentes (da Rocha et al., 2019). 
Para a região oceânica no leste da Austrália, Di Luca et al. (2016) analisaram um conjunto de 15 RCMs para entender a habilidade dos mesmos em simular a climatologia de ciclones subtropicais, denominados localmente de ciclones da costa leste australiana. Os autores concluíram que o espalhamento do conjunto de RCMs sofre influência tanto da versão do RCM e como da análise usada como fronteira lateral, o que aponta para a importância de usar ambos (diferentes RCMs e dados de fronteira) para obter um conjunto capaz de representar a climatologia observada desses ciclones.

Os ciclones subtropicais no mar Mediterrâneo normalmente são referidos como Medicanes, por apresentarem características híbridas de ciclones tropicais e extratropicais. Através de vários experimentos numéricos, Cavicchia e von Storch (2012) concluíram que utilizando um RCM com alta resolução espacial é possível simular Medicanes. Basicamente, os autores encontraram que tanto as variáveis em superfície como a estrutura vertical dos sistemas foram adequadamente representadas pelo RCM. Considerando 11 eventos de Medicanes, Akhtar et al. (2014) mostraram que o acoplamento de um RCM, utilizando grade horizontal bastante refinada, com um modelo oceânico simulou ciclones subtropicais com características mais próximas das observadas. Os autores destacaram que o comprimento da trajetória, a temperatura próximo ao centro do ciclone e os ventos associados aos sistemas apresentaram erros menores na simulações acopladas comparadas com aquelas que utilizaram apenas a componente atmosférica.

A importância de utilizar RCMs com grades em alta resolução espacial também foi apontada por Gaertner et al. (2016) como um dos fatores para obter uma frequência mais próxima da observada de Medicanes. No entanto, Gaertner et al (2016) também chamam atenção que mesmo com grade horizontal mais refinada, os ciclones subtropicais simulados continuam sendo mais fracos (pressão central maior do que a observada) do que mostram as observações, o que indicaria que outros processos físicos associados aos ciclones híbridos ainda não estão sendo representados pelos RCMs.

Na bacia do Atlântico Sul, o ciclone subtropical Anita de março de 2010 (Dias Pinto et al., 2013; Dutra et al., 2017), já foi estudado numericamente com RCM por Abreu e da Rocha (2015) e Reboita et al. (2019). Os dois estudos utilizaram grade horizontal relativamente refinada, ou seja, com espaçamento entre pontos de grade na horizontal de $25 \mathrm{~km}$. Abreu e da Rocha (2015), como 
mencionado anteriormente, concluíram que os menores erros na intensidade e trajetória do ciclone Anita ocorreram com a simulação iniciada 24 horas antes da formação, utilizando o esquema convectivo de Betts-Miller (Betts e Miller, 1996). Com o mesmo RCM, esta mesma parametrização de convecção também mostrou-se mais apropriada para simular outros eventos de ciclones subtropicais na bacia do Atlântico Sul (Gozzo et al., 2017; Reboita et al., 2019).

Conforme hipotetizado por Dias Pinto et al. (2013), Reboita et al. (2019) realizaram experimentos de sensibilidade com um RCM modificando a TSM para entender a possibilidade do ciclone subtropical Anita sofrer transição para tropical. Os experimentos numéricos mostraram que duas condições de TSM mais quente seriam favoráveis à transição tropical do ciclone Anita. Na primeira a TSM deveria ser aquecida em $2^{\circ} \mathrm{C}$ durante todo o tempo de vida do Anita, e na segunda seria necessário um aquecimento de $6^{\circ} \mathrm{C}$ a partir do momento em que o ciclone apresentou caráter semi-estacionário próximo à costa sul do Brasil. Essa possibilidade de transição tropical também na bacia do Atlântico estaria de acordo com a ocorrência do furacão Catarina em 2004 (Pezza e Simmonds, 2005; McTaggart-Cowan et al., 2006) e com as análises de Roberts et al. (2014), que encontraram ciclones de núcleo quente próximo à região sudeste do Brasil em simulações com grade mais refinada em GCMs do CMIP5.

O número de projeções climáticas para as diversas bacias oceânicas de ocorrência de ciclones subtropicais ainda é pequeno. Para o leste da Austrália, Ji et al. (2015) analisaram simulações de quatro GCMs que foram utilizados para forçar três diferentes RCMs. Essa estratégia forneceu um conjunto de projeções climáticas formado por 12 membros composto de GCMs e RCMs no cenário de emissões A2 do CMIP3/SRES. Com este conjunto, Ji et al. (2015) mostraram que existem projeções de decréscimo, tanto na frequência anual (podendo atingir até -36\%) quanto no tempo de vida, dos ciclones subtropicais durante o inverno na costa leste australiana nos períodos futuros de 2020-2039 e 2070-2099. No entanto, para a estação quente a incerteza é muito maior em função da resposta diversa dos membros do conjunto.

Ainda considerando o leste da Austrália, a mudança futura na atividade ciclônica, considerando as características térmicas do núcleo dos ciclones (quente, frio ou híbrido), foi 
investigada por Cavichia et al. (2020). Os autores utilizaram um conjunto com 12 membros, composto por 4 GCMs do CMIP3 e três regionalizações climáticas com o WRF (50 km de grade horizontal), para avaliar o clima presente (1990-2009) e tendências futuras (2060-2079) no cenário climático A2. Para entender as tendência dos diferentes tipos de ciclones é necessário primeiro obter todos os ciclones e depois classificá-los de acordo com a estrutura térmica do núcleo (quente, frio ou híbrido). Assim como Pepler et al. (2016), Cavichia et al. (2020) obtiveram uma tendência futura de decréscimo na frequência do total de ciclones na costa leste da Austrália. No entanto, este decréscimo não é uniforme, ou seja, a tendência negativa engloba ciclones de núcleo frio e quente, enquanto ciclones com estrutura híbrida (núcleo quente em baixos níveis e frio em altos níveis) tendem a aumentar. $\mathrm{O}$ aumento de ciclones híbridos no futuro também irá impactar o vento e a chuva próximo da costa leste da Austrália

Para a bacia do Mediterrâneo, Tous e Romero (2013) utilizaram três GCMs (CSIRO-MK3.0, ECHAM5/MPI-OM e GFDL-CM2.1) para estudar tendências climáticas de Medicanes. Estas projeções indicaram que no final do século (2081-2100) no cenário A2 poderá ocorrer uma diminuição geral na frequência de Medicanes no inverno boreal. Para este mesmo cenário, Romero e Emanuel (2013) encontraram em quatro GCMs (GFDL, CSIRO, MIROC e ECHAM) um decréscimo acentuado, entre 10-40\%, na frequência de Medicanes para o final do século XXI. Além de analisar o total de eventos, Romero e Emanuel (2013) consideraram tendências em função da intensidade do evento e obtiveram um aumento na frequência de Medicanes mais violentos/intensos no futuro. A projeção de decréscimo na frequência de Medicanes também é encontrada em simulações de modelos regionais (Walsh et al., 2014; Romero et al., 2017; Tous et al., 2016). Em face destes resultados, Romero e Emanuel (2017) discutiram que não existe um sinal muito claro de tendências futuras desde que o número total de tempestades muda muito pouco, enquanto as projeções de forma repetida indicam uma maior frequência de Medicanes nas categorias entre moderado a violento.

Para a bacia do Atlântico Sul há análises de projeções climáticas investigando o total de ciclones (Kruger et al., 2012; Reboita et al., 2018; Gramcianinov, 2018; Reboita et al., 2020) ou então de ciclones tropicais (Roberts et al., 2014). Em particular, Roberts et al. (2014) classificou ciclones tropicais nos GCMs do CMIP5, encontrando em GCMs com grade mais refinada ciclones 
tropicais no leste do sudeste do Brasil. Em cenários de mudanças climáticas estes GCMs não indicam mudança significativa da atividade desses ciclones na região. No entanto, especificamente na bacia do Atlântico Sul, ainda não se conhece como os GCMs e RCMs simulam a climatologia de ciclones subtropicais no clima presente e nem tendências climáticas futuras em cenários de aquecimento global. 


\section{Metodologia}

\subsection{Dados}

As reanálises ERA-Interim (Dee et al., 2011) do European Centre for Medium-Range Weather Forecasts (ECMWF) e CFSR (Climate Forecast System Reanalysis) do National Center for Environment Prediction (NCEP; Saha et al., 2010) são utilizadas para a validação das simulações no clima presente. Além disso, a média desse conjunto, ERA-Interim e CFSR, fornecerá a climatologia observada do total de ciclones e da circulação atmosférica, que será referida como reanálise ou observação. A classificação dos ciclones em ciclones subtropicais utilizará, no entanto, apenas a ERA-Interim já que a validação do algoritmo automático desenvolvido neste trabalho baseia-se na climatologia prévia de Gozzo (2014) obtida da ERA-Interim.

As reanálises ERA-Interim e CFSR possuem espaçamento de grade horizontal, respectivamente, de aproximadamente $1,5^{\circ}$ e 0,5 e dados (temperatura, vento, umidade específica) da estrutura tridimensional da atmosfera a cada 6 horas (00, 06, 12, e 18 UTC).

\subsection{Modelo RegCM4}

O modelo regional RegCM foi originalmente desenvolvido pelo National Center for Atmospheric Research - Pennsylvania State University (NCAR-PSU). A primeira versão deste modelo, RegCM1, foi lançada em 1989 e desde então passou por diversas atualizações, em 1993 (RegCM2), 1999 (RegCM2.5), 2006 (RegCM3) e em 2010 (RegCM4). Esta última versão trouxe atualizações significativas na estrutura do código, nos pré e pós-processamentos, juntamente com a inclusão de novas parametrizações físicas.

O RegCM4 (Giorgi, 2012) é um modelo de área limitada, que resolve as equações em uma atmosfera compressível, hidrostática e em coordenada vertical sigma-pressão. As equações no 
modelo são discretizadas através do método de diferenças finitas na grade B de Arakawa-Lamb e também possui um algoritmo para reduzir a difusão horizontal na presença de intensos gradientes de topografia (Giorgi, 1993 a,b).

As simulações do RegCM4 utilizadas neste trabalho foram realizadas por Llopart et al. (2014) com parametrizações de precipitação convectiva utilizando os esquemas Grell (1993) e Emanuel (1991), e de interação superfície-atmosfera Biosphere-Atmosphere Transfer Scheme (BATS; Dickinson et al., 1989) e Community Land Model (CLM, Dai et al., 2003) descritas sinteticamente a seguir:

\section{Parametrização convectiva de Grell}

Grell (1993) propôs um esquema cumulus onde a convecção é representadas por duas circulações estacionárias, as descendentes (downdraft) e ascendentes (updraft). Em ambas correntes o fluxo de massa não varia com a altura. A parametrização de cumulus é ativada quando a parcela após ascender atinge a adiabática úmida. O cálculo da água condensada nas correntes ascendentes considera que não ocorre troca de massa com o ar fora da nuvem, e o fluxo de massa na corrente descendente é o mesmo da corrente ascendente.

\section{Parametrização convectiva Emanuel e Zivkovic-Rothman}

Na parametrização de convecção proposta por Emanuel (1991) e aprimorada por Emanuel e Zivkovic-Rothman (1999), a precipitação é disparada quando o nível de condensação por levantamento é menor do que o nível de flutuação neutra, considerado como sendo a base da nuvem. A fração da mistura condensada e o ar ascendente entre os níveis de condensação por levantamento e nível flutuação neutra formam a nuvem e ao mesmo tempo a precipitação. Após a formação da nuvem, o gradiente vertical de flutuação dentro da mesma determina as taxas de entranhamento e desentranhamento.

Biosphere-Atmosphere Transfer Scheme - BATS 
O esquema BATS foi desenvolvido por Dickinson et al. (1993) para resolver a interação entre a atmosfera e interface solo-planta nas trocas turbulentas de momento, energia e vapor d'água. O BATS possui uma camada de vegetação, uma de neve e três camadas de solo com diferentes profundidades. As três camadas de solo são divididas em: camada superficial com 10 centímetros de espessura, zona de raízes com espessura variável de acordo com o tipo de vegetação e camada de solo profundo com 3 metros. A solução para o ciclo hidrológico utiliza equações prognósticas do conteúdo de água nas três camadas de solo. Por fim, o fluxos de vapor d’água, calor e momento na superfície são calculados em função dos coeficientes de arrasto obtidos da teoria da similaridade aplicada à camada superficial.

\section{Community Land Model - CLM}

O CLM (Dai et al., 2003) resolve os processos de interação solo-planta-atmosfera baseado nas componentes físicas de três diferentes modelos de superfície: o Land Surface Model - LSM (Bonan, 1996), o BATS (Dickinson, 1993) e o modelo de neve de Dai e Zeng (1996). O CLM foi construído considerando os melhores aspectos dos três modelos citados e incluiu ainda um módulo de vegetação dinâmica, ou seja, a vegetação muda ao longo do tempo em função de mudanças no clima. No CLM as variáveis de superfície são calculadas utilizando uma camada de vegetação, um modelo de fotossíntese, dez camadas de solo e condutância estomática acoplada, cinco camadas de neve sobre o solo. Sobre o oceano, os fluxos superficiais são calculados utilizando os coeficientes de transferência vertical turbulenta do tipo bulk. O CLM inclui patches para calcular separadamente os fluxos verticais turbulentos de superfície de cada tipo de cobertura vegetal. Com essa habilidade adicional, é possível separar a água e a energia para cada patch como descrito em Koster e Suarez (1992). Especificamente, o RegCM4 utilizado neste estudo conta com a versão 3.5 do CLM, ou seja, CLM3.5 (Tawfik e Steiner, 2011; Llopart et al., 2014).

\subsubsection{Regionalizações com o RegCM4 - Projeto CREMA}


As simulações do RegCM4 utilizadas neste estudo fazem parte do projeto CREMA (CORDEX REgCM4 hyper-MAtrix experiment) descrito por Giorgi et al. (2014). CREMA representa um mini-conjunto de regionalizações climáticas do RegCM4 para diferentes domínios do CORDEX considerando dois cenários RCPs (4.5 e 8.5; Riahi et al., 2011) e três GCMs do CMIP5 como condições inicial e de fronteira. Especificamente para a América do Sul, as regionalizações RegCM4-CREMA utilizaram $\sim 50 \mathrm{~km}$ de espaçamento de grade horizontal, 18 níveis sigma-pressão e as simulações cobriram todo o período 1970-2100.

Os três GCMs do CMIP5 utilizados no CREMA são: HadGEM2-ES (Martin et al., 2011), MPI-ESM-MR (Giorgetta et al., 2013), GFDL-ESM2M (Dunne et al., 2012). Estes modelos possuem espaçamento horizontal de grade variando entre aproximadamente 1,25 to 2,5 $5^{\circ}$ (Tabela 1 ). Das simulações do RegCM4-CREMA, as quatro utilizadas neste trabalho diferem em termos do GCM forçante e parametrização física como sintetizado na Tabela 1. Todas as simulações do RegCM4 analisadas utilizaram as seguintes parametrizações: radiação de onda curta e longa parametrizadas segundo NCAR-CCM3 (National Center for Atmospheric Research-Community Climate Model version 3; Kiehl et al., 1996), Holtslag et al. (1990) para resolver os processos na camada limite e SUBEX para calcular a precipitação na escala da grade (Pal et al., 2000). Conforme a Tabela 1, para processos na superfície utilizou-se BATS ou CLM3.5, e para convecção, Emanuel ou a combinação Grell-Emanuel.

As análises utilizaram apenas o RCP8.5, cenário de alta emissão de gases do efeito estufa, desde que somente este cenário possui quatro membros do RegCM4, enquanto o RCP4.5 possui apenas um membro no projeto CREMA-América do Sul (Llopart et al., 2014; da Rocha et al., 2014).

As quatro simulações CREMA-RegCM4 e as três dos GCMs serão mediadas para fornecer, respectivamente, as médias de conjuntos RegCM4 e GCMs denominadas, respectivamente, RegCM4s e GCMs. 
Tabela 3.2.1- GCMs utilizados como condições iniciais e de fronteira para as quatro regionalizações do RegCM4-CREMA . O espaçamento horizontal entre pontos de grade (em graus) dos GCMs estão entre parênteses.

\begin{tabular}{|c|c|c|}
\hline GCM forçante do RegCM4 & $\begin{array}{c}\text { Interação } \\
\text { superfície-atmosfera }\end{array}$ & Parametrização convectiva \\
\hline MPI-ESM-M $(1,875 \times 1,875)$ & CLM & Emanuel \\
\hline GFDL-ESM2M $(2,0225 \times 2,6)$ & CLM & Emanuel \\
\hline HadGEM2-ES $(1,25 \times 1,875)$ & CLM & $\begin{array}{c}\text { Emanuel sobre o oceano e Grell sobre o } \\
\text { continente }\end{array}$ \\
\hline HadGEM2-ES $(1,25 \times 1,875)$ & BATS & \\
\hline
\end{tabular}

\subsection{Rastreamento de ciclones}

O rastreamento dos ciclones utilizou o algoritmo inicialmente desenvolvido por Sugahara (2000) e aprimorado por Reboita et al. (2010). Este algoritmo identifica ciclones através de mínimos de vorticidade relativa (ciclônica no Hemisfério Sul) e é semelhante ao utilizado por Sinclair (1994, 1995 e 1997). Neste trabalho os ciclones foram identificados através do campo de vorticidade relativa calculada a partir do campo de vento em $925 \mathrm{hPa}$, diferentemente de Reboita (2008) que rastreou os ciclones no campo de vorticidade do vento a $10 \mathrm{~m}$ de altura.

Inicialmente, o algoritmo suaviza o campo de vorticidade utilizando o esquema de Cressman (Cressman, 1959). A aplicação da suavização de Cressman permite reduzir ruídos em zonas de cisalhamento alongado e a eliminar centros espúrios de vorticidade (Sinclair, 1997; Reboita et al., 2010).

Após a suavização do campo de vorticidade, o algoritmo identifica os mínimos de vorticidade através do método do vizinho mais próximo (nearest-neighbor search), ou seja, compara a vorticidade em cada ponto de grade com os vizinhos mais próximos. Um ponto de grade é considerado centro do ciclone se possuir vorticidade relativa menor que dos pontos vizinhos e ao mesmo tempo menor ou igual ao limiar de $-1,5 \times 10^{-5}\left(\mathrm{~s}^{-1}\right)$ estabelecido no início do rastreamento. Após identificar o mínimo, aplica-se uma correção na posição do centro do ciclone interpolando o 
campo de vorticidade para uma grade de análise para alta resolução. Neste processo, existe um refinamento espacial da posição do centro do ciclone. Para encontrar a próxima posição do ciclone, o algoritmo repete a etapa inicial, isto é, busca por um mínimo de vorticidade relativa na baixa resolução nos oito pontos vizinhos e interpola para alta resolução para refinar a localização do centro do ciclone. Este processo é repetido até que o ciclone deixe de existir, ou seja, quando o limiar de vorticidade relativa não é mais observado. A trajetória do ciclone é definida desde o primeiro mínimo de vorticidade relativa até o seu desaparecimento. O tracking considera também um tempo de vida mínimo de 24 horas e um tempo de vida máximo de até 10 dias.

A utilização de vorticidade relativa para rastrear ciclones é mais vantajoso em comparação com o método que utiliza a pressão (Sinclair, 1994; Hoskins e Hodges, 2005), pois o método que utiliza a pressão em superfície depende de encontrar isóbaras fechadas para identificar ciclones. Com isso, surge uma limitação na identificação de alguns ciclones, pois muitas vezes intensos gradientes meridionais de pressão sobrepostos aos sistemas ciclônicos transientes não permitem o fechamento de isóbaras, impedindo a identificação do sistema.

O algoritmo de rastreamento fornece data, hora, posição (latitude e longitude), vorticidade relativa e pressão ao nível do mar central dos ciclones. Tanto as reanálises como as simulações, originalmente com diferentes projeções e espaçamentos de grade, foram interpoladas para uma grade horizontal com espaçamento regular em latitude-longitude de 1,5 x 1,5 graus. Em seguida, o rastreamento de ciclones foi realizado na área delimitada pelo retângulo de linhas vermelhas destacado na Figura 4.2.1. Esta figura apresenta os limites geográficos (retângulos menores) das regiões ciclogenéticas RG1, RG2 e RG3, seguindo a definição proposta por Reboita et al. (2010) 


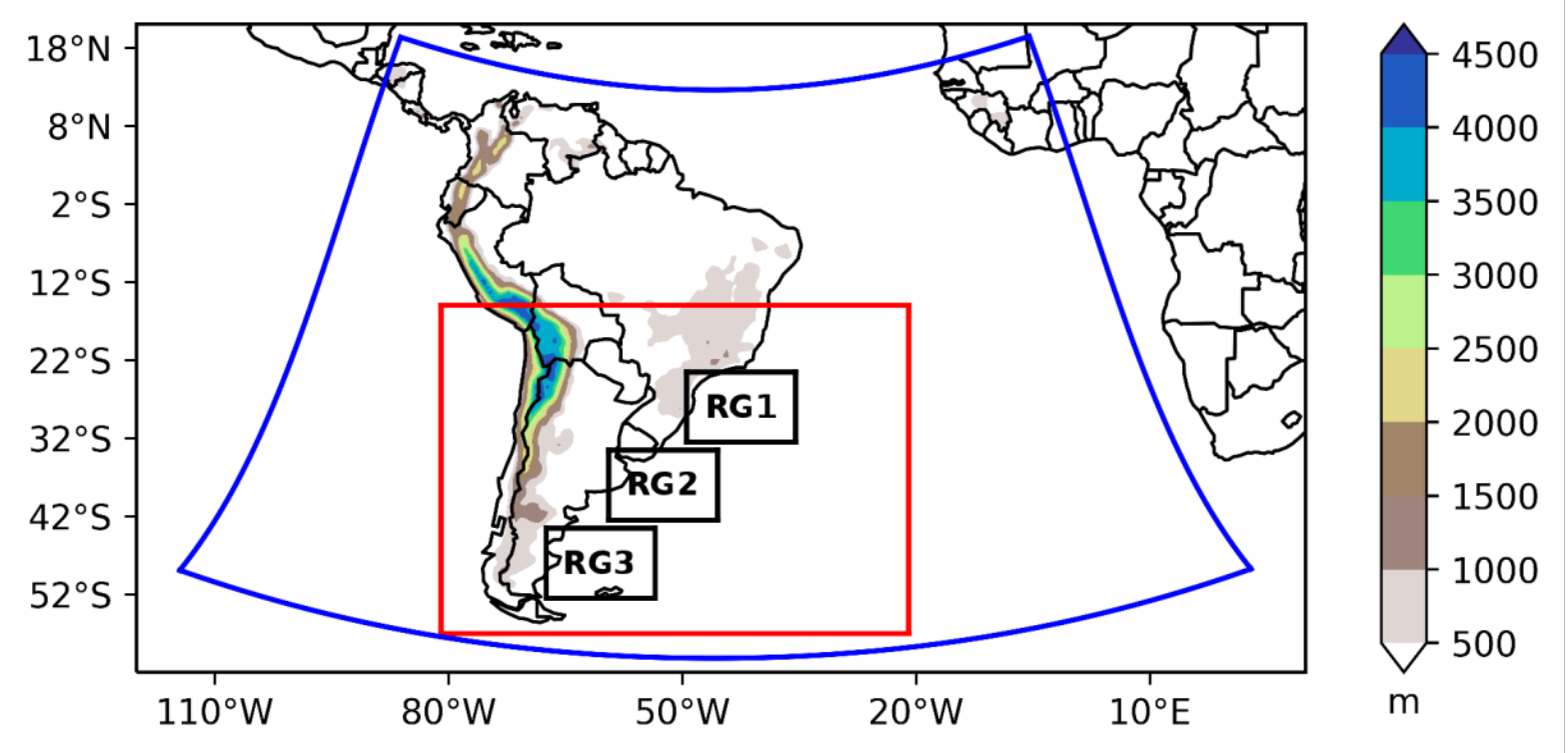

Figura 3.3.1 - Domínio e topografia (sombreado) de simulação do CREMA-RegCM4 (linha azul), área efetiva de rastreamento de ciclones (linhas vermelhas, $15-57^{\circ} \mathrm{S}$; $81^{\circ}-21 \mathrm{~W}$ ) e delimitação das

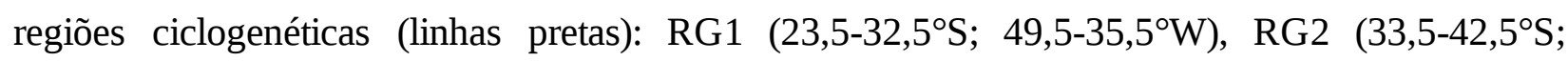

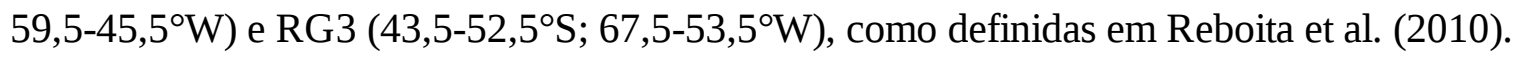

\subsection{Espaço de fase dos ciclones (Cyclone Phase Space - CPS)}

Desenvolvido por Hart (2003), o espaço de fase dos ciclones, conhecido por sua sigla em inglês - CPS (Cyclone Phase Space), identifica as diferentes fases tropical, subtropical e extratropical dos ciclones. Para realizar esta classificação, o CPS considera parâmetros de simetria térmica e de anomalia da temperatura na horizontal próximo ao núcleo desses sistemas em baixos até altos níveis da troposfera. Estes três parâmetros são obtidos conhecendo somente o campo tridimensional de altura geopotencial que irá fornecer as seguintes variáveis: simetria térmica ou espessura do ciclone (B), vento térmico em baixos níveis $\left(-\left|V_{T}^{L}\right|\right)$ e vento térmico em altos níveis ( $\left.-\left|V_{T}^{U}\right|\right)$

A simetria térmica do ciclone medida pelo parâmetro B é calculada como:

$$
B=h\left(\left.\overline{Z_{600 h P a}-Z_{900 h P a}}\right|_{D}-\left.\overline{Z_{600 h P a}-Z_{900 h P a}}\right|_{E}\right)
$$


onde Z é a altura geopotencial, h é +1 no Hemisfério Norte e -1 no Hemisfério Sul, $D$ representa o semicírculo do lado direito e $E$ o semicírculo do lado esquerdo, sendo que ambos semicírculos possuem raio de $500 \mathrm{~km}$ a partir do centro do ciclone. A equação (3.3.1) mostra que o parâmetro B representa a diferença de espessura da camada 900-600 hPa entre o semicírculo do lado direito e do lado esquerdo do centro ciclone. Fisicamente, o parâmetro B informa sobre a inclinação na vertical do sistema e se o ciclone possui frente fria associada (extratropical) ou não (tropical). Segundo Guishard (2006), os ciclones tropicais apresentam parâmetro de simetria térmica dentro do intervalo $-10 \mathrm{~m}<\mathrm{B}<10 \mathrm{~m}$, nos extratropicais B $>10 \mathrm{~m}$ e nos subtropicais os valores de B não são muito elevados. Para o Oceano Atlântico Norte, Guishard (2009) obteve na climatologia de ciclones subtropicais o valor médio de B de 11,1 \pm 13,9.

A determinação da estrutura vertical de temperatura próximo ao núcleo dos ciclones é

obtida a partir do cálculo dos parâmetros de vento térmico em baixos (-|V $\left.V_{T}^{L} \mid\right)$ e altos $\left(-\left|V_{T}^{U}\right|\right)$ níveis:

$$
\begin{aligned}
& -\left|V_{T}^{L}\right|=\left.\frac{\partial\left(Z_{\max }-Z_{\min }\right)}{\partial \ln p}\right|_{900} ^{600} \\
& -\left|V_{T}^{u}\right|=\left.\frac{\partial\left(Z_{\max }-Z_{\min }\right)}{\partial \ln p}\right|_{600} ^{300}
\end{aligned}
$$

Nos ciclones tropicais o vento térmico em baixos e altos níveis é positivo, indicando que o núcleo deste tipo de sistema é quente em toda a coluna vertical. Comparativamente, os valores de vento térmico em baixos níveis são maiores do que em altos níveis nos ciclones tropicais. Este padrão se deve aos maiores fluxos de calor latente e sensível próximo à superfície. Os ciclones tropicais formam-se sobre o oceano e têm como principal fonte de energia os fluxos de calor latente 
mais elevados, que transferem umidade para atmosfera alimentando e organizando as nuvens convectivas.

Nos ciclones extratropicais, o vento térmico em baixos e altos níveis é negativo, mostrando que estes sistemas apresentam núcleo frio em toda a coluna vertical. Já os ciclones subtropicais são híbridos, ou seja, apresentam núcleo quente em baixos níveis $\left(-\left|V_{T}^{L}\right|>0\right)$ e núcleo frio em altos níveis $\left(-\left|V_{T}^{U}\right|<0\right)$.

Gozzo et al. (2014) propuseram novos limiares para o parâmetro de vento térmico em baixos e altos níveis para a América do Sul, objetivando a identificação de ciclones subtropicais. Os limiares propostos pelos autores são: $-\left|V_{T}^{L}\right| \geq-50$ e $-\left|V_{T}^{U}\right| \leq-10$. Isto porque o vento térmico em baixos níveis pode fornecer valores baixos, ou até negativos, mesmo para ciclones tropicais de categoria 1 e, por outro lado, este parâmetro é bastante sensível à resolução horizontal e vertical dos dados utilizados em seu cálculo. Assim, o limiar mais abrangente proposto por Gozzo et al. (2014) garante que um maior número de sistemas subtropicais seja identificado. Para incluir na climatologia ciclones rasos que não estão associados a ventos intensos, os autores não utilizaram os critérios de vento mínimo sustentado de $17 \mathrm{~m} / \mathrm{s}$ e baixa desprendida em $500 \mathrm{hPa}$. Dessa forma, a tabela 3.4.1 apresenta os valores dos parâmetros utilizados para identificar ciclones subtropicais a partir do rastreamento de todos os ciclones.

Tabela 3.4.1 - Limiares dos parâmetros do CPS propostos por Gozzo et al. (2014) e utilizados nesse estudo para identificar ciclones subtropicais.

\begin{tabular}{|c|c|}
\hline Parâmetro & Limiares \\
\hline $\mathrm{B}$ & $<25 \mathrm{~m}$ \\
\hline$-\left|V_{T}^{L}\right|$ & $\geq-50 \mathrm{~m}^{3} / \mathrm{kg}$ \\
\hline$-\left|V_{T}^{U}\right|$ & $\leq-10 \mathrm{~m}^{3} / \mathrm{kg}$ \\
\hline
\end{tabular}




\subsection{Software para classificação automática dos ciclones subtropicais (SCS)}

Gozzo et al. (2014) utilizaram os parâmetros do CPS e limiares específicos (os valores da Tabela 3.4.1 momentaneamente denominados como limiares internos para melhor entendimento) para classificar os ciclones subtropicais a partir dos cálculos efetuados pelo CPS. O método aplicado pelos autores, além de considerar os limiares da Tabela 3.4.1, inclui na climatologia aqueles ciclones subtropicais que extrapolam os limiares pré-estabelecidos por até dois passos de tempo não necessariamente consecutivos ao longo de 36 horas de ciclo de vida,. Dessa forma, como os parâmetros (simetria térmica, vento térmico em altos e baixos níveis) se mostraram muito sensíveis ao longo do ciclo de vida dos ciclones subtropicais, durante o desenvolvimento do algoritmo adotou-se o seguinte critério: se o sistema extrapolar limiares dos três parâmetros em no máximo dois passos de tempo no período de 36 horas, desde que não ultrapassem os limiares apresentados na Tabela 3.5.1 e estiver sobre o oceano, o mesmo é classificado como ciclone subtropical. A classificação destes sistemas foi realizada sazonalmente, sendo aplicados os limiares externos da tabela 3.5.1. As estações do verão e outono têm limiares externos mais relaxados devido à TSM mais altas nestas estações (Gozzo et al., 2014) impactando diretamente o $\mathrm{V}_{\mathrm{T}}^{\mathrm{L}}$. Em adição, pela maior sensibilidade do parâmetro $\mathrm{V}_{\mathrm{T}}^{\mathrm{L}}$ nestas estações, foram permitidos até três ultrapassagens do limiar interno.

Tabela 3.5.1 - Limiares externos dos parâmetros do CPS utilizados para identificar ciclones subtropicais.

\begin{tabular}{|c|c|}
\hline Verão e Outono & Inverno e Primavera \\
\hline$-50<\mathrm{B}<50$ & $-35<\mathrm{B}<35$ \\
\hline$-\left|V_{T}^{L}\right|<-127.6$ & $-\left|V_{T}^{L}\right|<-75.0$ \\
\hline$-\left|V_{T}^{U}\right|>17.5$ & $-\left|V_{T}^{U}\right|>11.0$ \\
\hline
\end{tabular}


Como neste trabalho a classificação de ciclones é realizada em um grande conjunto de dados (análises e simulações), desenvolveu-se um software (linguagem Fortran 90), denominado SCS (Software para classificação automática dos ciclones subtropicais), partindo dos parâmetros fornecidos pelo CPS (simetria térmica, vento térmico em baixos e altos níveis). Em uma primeira etapa, o SCS reposiciona o ciclone em uma grade com espaçamento horizontal 0,125 $\mathrm{x} 0,125^{\circ}$, em uma posição idêntica à máscara continente/oceano obtida da ERA-Interim. Esta máscara permite posicionar e identificar a formação dos ciclones como continental ou oceânica. A formação dos ciclones subtropicais ocorre preferencialmente próximo à costa sudeste do Brasil sobre o Oceano Atlântico Sul e a utilização da máscara permitiu descartar as ciclogêneses continentais.

Embora a máscara represente uma boa aproximação para a posição central do ciclone, as dimensões de um ciclone subtropical (escala horizontal $1000 \mathrm{~km}$ ) fazem com que sua posição inicial seja difícil de determinar com exatidão. A avaliação se o ciclone é continental ou oceânico não pode ser realizada de uma forma direta apenas com a máscara, pois a escala do ponto central dos ciclones é desprezível em comparação com a escala da área do sistema. Sendo assim, é necessário adotar uma metodologia para minimizar essa discrepância. Desta forma, foram adotados os seguintes critérios para ciclogênese oceânica:

1. Se a posição central da ciclogênese coincide com a parte oceânica da máscara, o ciclone é oceânico;

2. Se a posição central da ciclogênese coincide com a parte continental da máscara, outra checagem é efetuada. Como a grade da máscara é de $0,125^{\circ}$ x $0,125^{\circ}$, ou 13 x $13 \mathrm{~km}$ aproximadamente, foram consideradas oceânicas as ciclogêneses onde o ponto cerca de 180 $\mathrm{km}$ mais a leste (ou equivalente a 14 pontos de grade) do ponto central, estiver sobre o oceano.

O critério 2 considera que o ciclone tenha no mínimo 30\% de sua área total sobre o oceano . Dessa forma, se o centro do ciclone estiver aproximadamente $180 \mathrm{~km}$ a oeste do centro, ele será considerado um ciclone que se iniciou no oceano.

A partir da identificação se a formação do ciclone é sobre o continente ou oceano, a classificação subsequente em ciclone subtropical utiliza os mesmos limiares propostos no trabalho 
de Gozzo et al (2014). Estes limiares foram nomeados como limiares internos excepcionalmente neste subcapítulo para melhorar a descrição do método utilizado para desenvolvimento do SCS.

\subsection{Ciclones: climatologia, tendência e ventos associados}

As informações contidas no rastreamento de ciclones permitem o cálculo de várias quantidades, dentre elas as frequências de ciclogênese (a primeira posição dos ciclones) e de trajetórias (todas as posições dos ciclones durante seu ciclo de vida), mapas de densidades de ciclogênese e trajetória de ciclones, características dos ciclones (intensidade, tempo de vida, etc.) e tendência na frequência e densidade dos ciclones. Neste estudo, as densidades são calculadas usando a localização do ciclone (latitude e longitude) projetada em uma grade de $3^{\circ} \times 3^{\circ}$ de longitude-latitude e, em seguida, o número de sistemas é dividido pela área desta malha $\left(\mathrm{km}^{2}\right)$ e multiplicado por $10^{6}$. Para avaliar a tendência dos ciclones em regiões selecionadas ("hot-spots") são construídas séries anuais de frequência de ciclones para todo o período de simulação (1979-2099) e mapas de diferença entre os climas futuros próximo (2020-2050) e distante (2070-2099) e o clima presente (1979-2005).

Além disso, conhecendo a posição dos ciclone, é possível analisar mudanças no vento associadas aos ciclones mais intensos. Para identificar estes eventos considerou-se apenas ciclones com vorticidade ciclônica (negativa no Hemisfério Sul) inicial menor ou igual ao percentil 25 de cada conjunto de dados. Embora o rastreamento do ciclone utilize o vento em 925 hPa, a análise de composição do vento associado aos extremos considerou o nível de 1000 hPa para representar baixos níveis, pois é o nível mais próximo da superfície com impactos diretos nas atividades econômicas e sociais próximos às regiões costeiras. Mudanças do vento em níveis superiores (300 hPa) também foi considerado nesta análise, para avaliar como a atividade dos jatos de altos níveis associados a formação de ciclones intensos poderá mudar em cenários futuros.

Análises semelhantes foram conduzidas para avaliar as características no clima presente e tendências dos ciclones subtropicais. No entanto, em função da menor ocorrência desses sistemas 
61

na análise de tendência do vento foram utilizados todos os eventos disponíveis e não só os mais intensos como para quando se considera todos os ciclones. 


\section{Ciclones no Atlântico Sul e ventos associados: clima presente e tendências climáticas}

Este capítulo apresenta a validação das simulações no clima presente e tendências futuras de todos os ciclones, independente das fases que podem adquirir, no sudoeste do Atlântico Sul. Ambas análises consideram os ciclones a partir de três núcleos ciclogenéticos principais (denominados RG1, RG2 e RG3) ao longo da costa leste da América do Sul. Como descrito no Capítulo 3, a validação no clima presente utiliza valores médios de duas reanálises (ERA-Interim e CFSR) no período entre 1979-2005, enquanto os conjuntos de simulações GCMs e RegCM4s possuem, respectivamente, três e quatro membros e foram obtidos através do projeto CREMA (Coppola et al., 2014).

Tanto o estudo de Llopart et al. (2014) como da Rocha et al. (2014) avaliaram a climatologia e tendência de chuva no clima futuro das simulações do projeto CREMA. Estas avaliações indicaram que tanto os GCMs como os RegCMs reproduzem as principais características climatológicas observadas da chuva e de sua variabilidade interanual sobre a América do Sul. Partindo desse conhecimento, o presente estudo irá se concentrar na análise da climatologia e tendências de ciclones e ventos associados.

\subsection{Ciclones no clima presente}

\section{a) Densidade e características dos ciclones}

A Figura 4.1.1 apresenta a climatologia de densidade ciclogenética anual no período histórico (1979-2005) dos conjuntos de reanálise e simulações. Como mostra a Figura 4.1.1, o fator principal na atividade ciclogenética é a presença de três núcleos ciclogenéticas mais intensos localizados nas costas: sudeste da Argentina (RG3), sul do Brasil-Uruguai (RG2) e sudeste do 
Brasil (RG1). Essa característica está presente nas simulações tanto dos GCMs como dos RegCMs (Figura 4.1.1b,c).

Conforme apresentado no Capítulo 2, as três regiões ciclogenéticas no leste da América do Sul (Figura 4.1.1) são normalmente identificadas em estudos que utilizam vorticidade para rastrear ciclones (Hoskins and Hodges 2005; Reboita et al. 2010; 2018; Gramcianinov et al. 2019; Crespo et al., 2020). Do ponto de vista de mecanismos que conduzem à ciclogênese existem algumas diferenças entre essas regiões. Sabe-se que a região mais ao norte (RG1) é caracterizada pela formação de ciclones subtropicais sobre o Atlântico Sul, correspondendo a 33\% dos ciclones formados na região (Gozzo et. al., 2014; da Rocha et al., 2019). Trabalhos mostraram que a ciclogênese subtropical necessita da presença de distúrbios ciclônicos em baixos níveis provenientes do transporte umidade e umidade existente na região (Gozzo et al. 2014), em conjunto com a presença de moderado cisalhamento do vento associado à presença de regiões frontais (Guishard, 2006). A formação de ciclones extratropicais na RG1 ocorre na presença de gradiente de temperatura e umidade em baixos níveis em conjunto com a aproximação de cavados transientes em altos níveis (Reboita, 2008), esta é uma região onde convergem os fluxos de umidade transportado pelo jato de baixos níveis e os ventos do anticiclone subtropical do Atlântico Sul (Gozzo et al., 2014; 2017). Na costa do Uruguai e leste da Argentina (RG2), a presença de gradiente de temperatura em conjunto com o transporte de calor e umidade pelo jato de baixos níveis proveniente da Amazônia (Mendes et al., 2007; Reboita et al., 2012) e a propagação de cavados em altos provenientes do Pacífico Sul (Gan e Rao, 1992; Vera et al., 2002; Reboita et al., 2008; Gramcianinov et al., 2019) contribuem para formação dos ciclones extratropicais nesta região. No sul da Argentina (RG3), a ocorrência de ciclogênese está mais associada aos cavados de altos níveis se deslocando do Pacífico em direção ao Atlântico (Gan e Rao, 1994) e ao efeito a sotavento dos Andes (Sinclair, 1995).

Os conjuntos GCMs e RegCM4s (Figura 4.1.1b,c) são hábeis em simular a densidade de ciclones em localizações similares às da reanálise (Figura 4.1.1a). No entanto, para todas as áreas do sudoeste do Atlântico Sul (linha vermelha na Figura 3.3.1) enquanto os GCMs tendem a subestimar (-18\%) o número de ciclones por ano, os RegCM4s apresentam uma pequena superestimativa da quantidade anual de sistemas (+6\%). Uma das fontes de superestimativa pelos 
RegCM4s pode resultar do maior espalhamento das ciclogêneses, desde a costa da Argentina estendendo-se para leste de $30^{\circ} \mathrm{W}$, quando comparado com os GCMs e a reanálise. Esse maior espalhamento da densidade de ciclones pelo oceano também foi encontrado por Reboita et al. (2012) e atribuído à maior intensidade dos fluxos de calor latente nas simulações. Por outro lado, os GCMs apresentam poucos ciclones à leste de $40^{\circ} \mathrm{W}$ no Atlântico Sul, o que é mais próximo do observado na reanálise. No entanto, para toda a área do sudoeste do Atlântico Sul o bias no RegCM4s é consideravelmente menor do que no GCMs, representando assim um valor agregado pela regionalização climática à climatologia de ciclones na região. Outro valor agregado importante dos RegCM4s, especialmente para estudar ciclones subtropicais, é maior similaridade com a reanálise próximo à costa do sudeste do Brasil. Os desvios padrões da média anual (topo da Figura 4.1.1) indicam que tanto os GCMs como os RegCM4s, com desvios padrões de 18 ciclones/ano, superestimam a variabilidade interanual de ciclones comparado com a reanálise (desvio padrão de $\sim 15$ ciclones/ano) quando se considera todo o domínio da Figura 4.1.1.
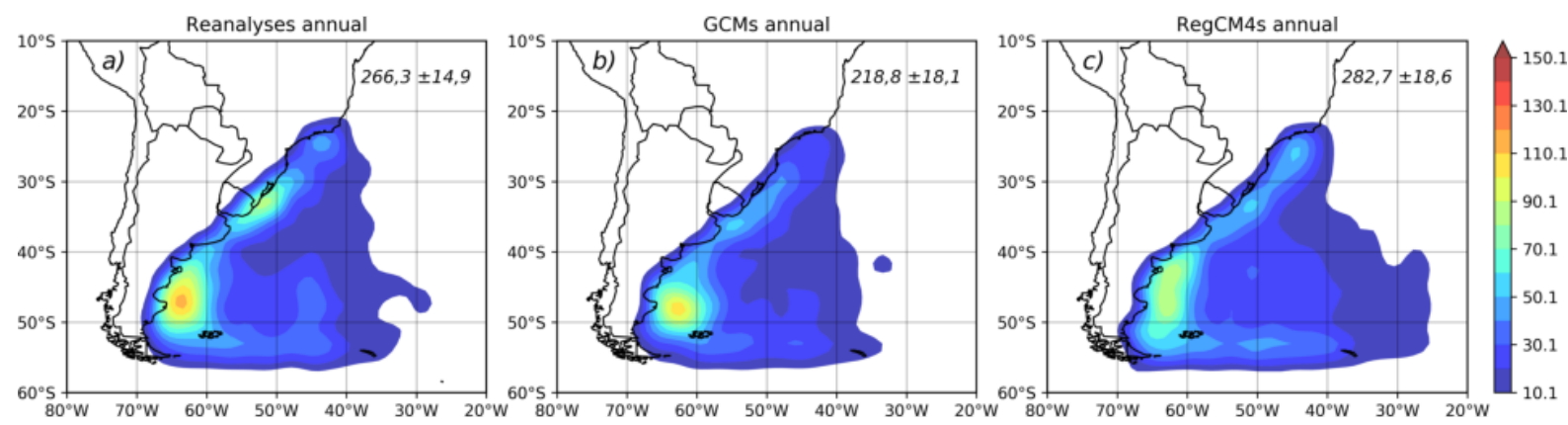

Figura 4.1.1 - Climatologia anual (1979-2005) da densidade ciclogenética (sombreado) para os conjuntos a) reanálise, b) GCMs e c) RegCM4s. A unidade de densidade é ciclones por área $\left(\mathrm{km}^{2}\right)$ x $10^{6}$ por ano. A média anual e desvio padrão para todo domínio da Figura é apresentada no canto superior direito de cada painel.

A Figura 4.1.2 apresenta a densidade de ciclogênese (linhas pretas) e de trajetória (sombreado) para os ciclones iniciados em cada região ciclogenética (RG1, RG2 e RG3). Para RG1, os GCMs (Figura 4.1.2b) e RegCM4s (Figura 4.1.2c) são hábeis para capturar as principais características das gêneses e trajetórias preferenciais dos ciclones apresentados nas reanálises 
(Figura 4.1.2a). Entretanto, enquanto os GCMs apresentam considerável subestimativa da frequência anual de ciclogênese $(26,6 \pm 4,6)$, os RegCM4s $(34,4 \pm 6,6)$ apresentam erro menor comparado com o conjunto de reanálises $(33,0 \pm 6,0)$. Considerando os desvios padrões, também a variabilidade interanual de ciclones na RG1 é melhor reproduzida pelos RegCM4s do que GCMs.

$\mathrm{Na}$ reanálise (Figura 4.1.2a), as trajetórias são mais concentradas próximo da RG1 durante a maior parte do tempo de vida dos ciclones. Isto é corretamente representado pelo GCMs e RegCM4s (Figuras 4.1.2b,c). A concentração de trajetórias indica características semi-estacionárias da maioria dos ciclones que se desenvolvem na RG1, uma característica também encontrada por Gozzo et al. (2014) quando analisou apenas os ciclones subtropicais que se iniciam nessa área. Além dos eventos semi-estacionários, um número considerável de eventos apresenta deslocamento preferencial para sudeste, um fator importante que também é encontrado nas simulações.

A região denominada RG2, situa-se perto da fronteira do Uruguai e sul do Brasil, e

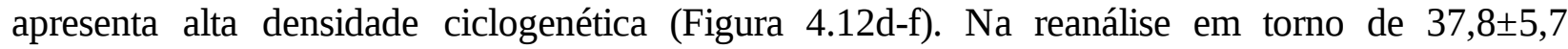
ciclogêneses por ano ocorrem nesta região. Nota-se também uma grande concentração de densidade de trajetórias sobre e próximo da RG2 e uma diminuição gradativa de trajetórias para sudeste (Figura 4.1.2d). Para RG2, o número anual de ciclogêneses da reanálise é subestimado pelos GCMs (-3,2 ciclones/ano) e ligeiramente subestimado (-2,2 ciclones/ano) pelos RegCM4s. Para a variabilidade interanual, encontra-se padrão semelhante de subestimativa e superestimativa, respectivamente, pelos GCMs e RegCM4. Em termos de densidades ciclogenética e de trajetórias, ambos os conjuntos simulam padrões similares aos das reanálises, mas com os GCMs (RegCM4s) subestimando (superestimando) a densidade nas regiões de máximo próximo a costa (entre $\left.30^{\circ}-20^{\circ} \mathrm{W}\right)$. A maior densidade de trajetórias concentra-se sobre e próximo da região de formação, RG2, e diminui mais lentamente para sudeste e mais rapidamente para norte. Essa característica está presente na reanálise e é simulada tanto pelos GCMs como RegCM4s (Figura 4.1.2d-f).

A região RG3 (Figura 4.1.2g), no sul da Argentina, apresenta o maior número de gênese de ciclones por ano $(62,3 \pm 7,4)$ da costa leste da América do Sul. Esse resultado está de acordo com outros estudos (Reboita et al. 2010; Krüger et al. 2012; Gramcianinov et al. 2019; Crespo et al., 2020). O caminho preferencial de ciclones formados na RG3 é para leste tanto na reanálise como nas simulações (Figura 4.1.2g,h,i). Apesar da densidade de trajetórias semelhantes nos três 
conjuntos, GCMs e RegCM4s subestimam o número de ciclogêneses por ano (56,3 e 56,1, respectivamente). No entanto, ambos conjuntos de simulações capturaram realisticamente a variabilidade interanual apresentada na reanálises com desvios padrões muito próximos (7,3 e 7,6, respectivamente) aos da reanálise e entre si. Nota-se nos conjuntos de simulações que a máxima densidade de ciclogêneses e de trajetórias encontra-se ligeiramente deslocada para oeste comparado com a reanálises (Figura 4.1.2g,h,i). Na RG3, as frequências e trajetórias de ciclones em ambos os conjuntos de simulações são muito mais próximas entre si do que nas RG1 e RG2. Isso seria explicado pela grande proximidade da RG3 com a borda sul do domínio do RegCM4, o que acarretaria em maior influência dos modelos globais nas variáveis simuladas pelo RegCM4 na região.
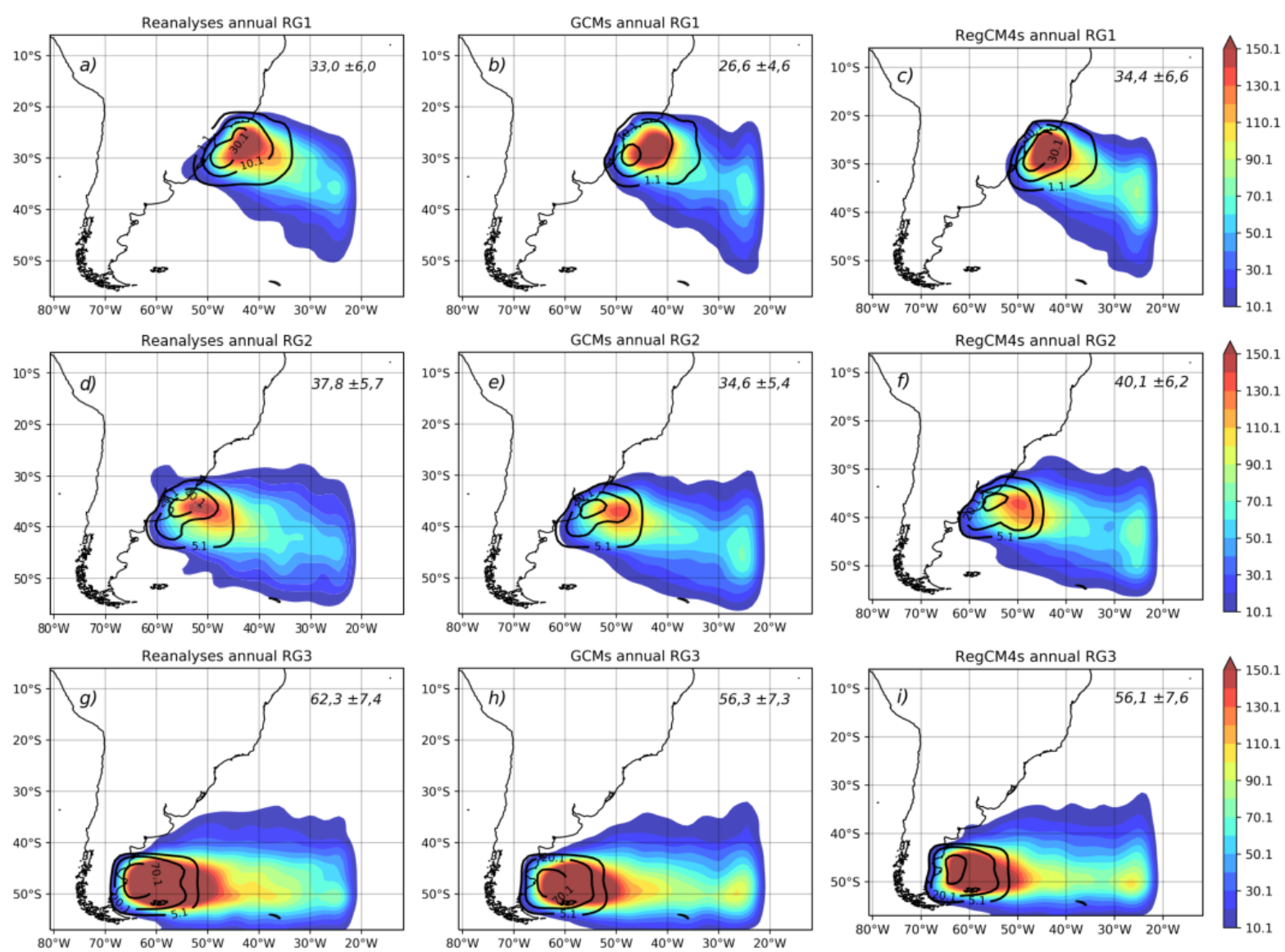

Figura 4.1.2 - Climatologia anual (1979-2005) da densidade de trajetória dos ciclones (sombreado) e de densidade ciclogenética (linhas pretas) para ciclones iniciados na RG1 (a, b, c - topo), RG2 (d, e, f - médio) e RG3 (g, h, i - base): a, d, g) reanálise; b, e, h) GCMs; e c, f, i) RegCM4s. A unidade de densidade é ciclones por área $\left(\mathrm{km}^{2}\right) \times 10^{6}$ por ano. A média anual e desvio padrão de ciclogêneses em cada região ciclogenética é apresentada no canto superior direito de cada painel. 
Para uma avaliação mais detalhada, a Figura 4.1.3 apresenta os ciclos anuais da frequência mensal de ciclogêneses nas três principais regiões ciclogenéticas. Para a RG1 (Figura 4.1.3a), a reanálise apresenta ciclo anual com fraca amplitude, entre 2 e 3,5 ciclones/mês, e caracterizado pela maior frequência de ciclones nos meses mais quentes do ano, dezembro-janeiro, enquanto o mês de março apresenta menor frequência. Para a maioria dos meses, tanto a fase como a amplitude da frequência de ciclones simulada pelos RegCM4s é mais próxima da reanálise do que dos GCMs (Figura 4.1.3a). Essa maior habilidade dos RegCM4s em reproduzir o ciclo anual de ciclogêneses observado na RG1 é sintetizado pelo alto coeficiente de correlação $(0,78)$ e baixa raiz quadrada do erro médio (RMSE de 0,47). Do ponto de vista de mecanismos de formação, na RG1 a maior frequência de ciclones no verão estaria principalmente associada com mecanismos termodinâmicos do que com forçantes dinâmicas, principalmente em função da maior disponibilidade e transporte de umidade para a região que alimentaria a atividade convectiva nesses ciclones (Reboita et al., 2010; 2012; Gozzo et al., 2014).

Os GCMs e RegCM4s mostram grande habilidade em simular a fase e amplitude observadas do ciclo anual de frequência de ciclogêneses na RG2, exceto pela subestimativa nos meses de pico (julho-agosto; Figura 4.1.3c). Essa habilidade se reflete nos índices estatísticos. Ao comparar as simulações com a reanálise nota-se altas correlações, com valores próximos entre si ( 0,77), e pequenos RMSEs para o ciclo anual de ciclogêneses na RG2. A subestimativa de ciclones em julho-agosto no RegCM4 pode estar associada à menor amplitude dos cavados em níveis médios nas simulações, como proposto por Reboita et al. (2010) que utilizando o RegCM3 (versão anterior do RegCM4) encontrou subestimativa similar e mostrou cavados de médios níveis mais suavizados na simulação comparado com a reanálise do NCEP. Em geral, o principal mecanismo forçante para as ciclogêneses na RG2 é a presença de um cavado transiente na média-alta troposfera se movendo desde o Pacífico Sul leste para o Atlântico Sul (Reboita et al. 2012; Crespo et al., 2020). Em especial, Crespo et al. (2020) mostrou que estes cavados são mais profundos e situados mais ao norte no inverno (junho-agosto), enquanto possuem menor amplitude e situam-se ao sul no verão (dezembro-fevereiro). Dessa forma, ao subestimar a amplitude desses cavados as simulações acabam subestimando também a frequência de eventos ciclônicos na RG2 
no inverno. No entanto, em alguns meses mais quentes do ano (outubro-novembro e janeiro-fevereiro) os RegCM4s simulam frequência de ciclones ligeiramente acima da reanálise, resultando assim na superestimativa anual de 2,2 eventos mostrada na Figura 4.1.2f.

Para RG3, ambos conjuntos simulam a maioria das características observadas do ciclo anual das ciclogêneses, ou seja, menor frequência de ciclones entre janeiro-março e maior entre maio-julho (Figura 4.1.3d). No entanto, nem os GCMs e RegCMs capturam os picos na frequência de ciclones em outubro e dezembro, refletindo em diminuição das correlações entre os ciclos anuais simulados e da reanálise para valores em torno de 0,4. A Figura 4.1.3d revela ainda que a subestimativa na frequência de ciclogêneses pelas simulações ocorre na maioria dos meses no ano, resultando na subestimativa do total anual apresentado na Figura 4.2.1h,j. Em termos de mecanismos de desenvolvimento, as ciclogêneses na RG3 resultam principalmente da regeneração dos sistemas se movendo no cinturão de latitudes médias de oeste para leste depois de cruzarem os Andes e instabilidade baroclínica (Gan e Rao 1991; Hoskins e Hodges 2005; Reboita et al. 2012). Crespo et al. (2020) apontou também a grande contribuição de perturbações na alta troposfera através de anomalias de vorticidade potencial para o desenvolvimento de ciclones na RG3 durante o verão.

Para todo o Atlântico Sul, a fase e amplitude observadas de ciclogêneses simuladas pelos RegCM4s são muito próximas da reanálise em comparação com os GCMs (Figura 4.13d). Com isso, as correlações para os ciclos anuais simulados e observados são altas e em torno de 0.73 . No entanto, o RMSE para os GCMs é muito alto em função da grande subestimativa de ciclogêneses em todos os meses do ano. Por outro lado, a menor subestimativa mensal de ciclogêneses implica em pequeno RMSE nos RegCM4s, representando também um importante valor adicionado da regionalização dinâmica. Comparando com estudos anteriores, os menores erros na fase e amplitude do ciclo anual de ciclogênese representa uma clara melhoria em relação ao RegCM3/CMIP3 (Krüger et al. 2012) e também à utilização de apenas um membro (RegCM4/HadGEM2-ES) do projeto CREMA (Reboita et al. 2018). 

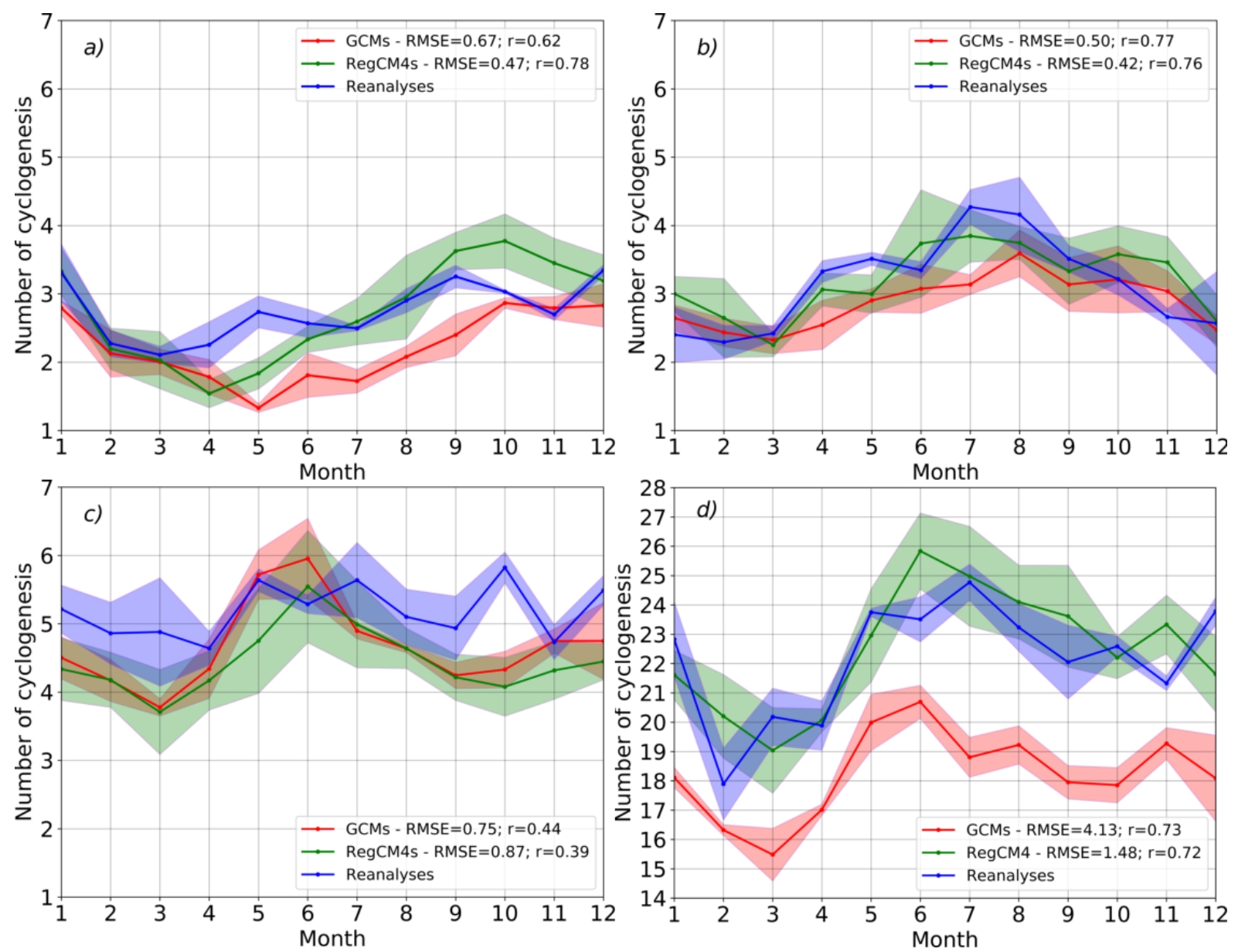

Figura 4.1.3 - Ciclo anual da média mensal (linhas) e desvio padrão (sombreado) de ciclogêneses no clima presente (1979-2005) para: a) RG1, b) RG2, c) RG3 e d) domínio do Atlântico Sul. As correlações e RMSEs entre reanálise e simulações para o ciclo anual estão indicadas em cada painel.

A Figura 4.1.4 apresenta os histogramas de vorticidade relativa no horário de ciclogênese para cada uma das três áreas ciclogenéticas e também para todo o Atlântico Sul. Em geral, os RegCM4s apresentam menores erros melhorando a representação da intensidade de ciclogênese em relação aos GCMs na RG1 (Figura 4.1.4a) e RG2 (Figura 4.1.4b). Nessas duas regiões, nota-se também uma maior concordância entre RegCM4s e a reanálise para frequências de ciclogêneses mais e menos intensas. Para RG3, a distribuição de intensidade das ciclogêneses simuladas pelos GCMs aproxima-se mais da reanálise, enquanto tem-se subestimativa para frequência de ciclogêneses com intensidade até $-3 \times 10^{-5} \mathrm{~s}^{-1}$ e superestimam eventos mais fortes nos RegCMs (Figura 4.1.4c). Quando se considera todo o domínio do Atlântico Sul, ambos conjuntos simulam frequências similares para ciclogêneses entre -3 e $-4 \times 10^{-5} \mathrm{~s}^{-1}$ como um reflexo do que ocorre em 
cada região (Figura 4.1.4d). Para ciclones inicialmente mais fracos $\left(-2 \times 10^{-5} \mathrm{~s}^{-1}\right)$ os erros na frequência são menores no GCMs do que nos RegCM4s, enquanto o oposto ocorre para eventos inicialmente mais intensos ( $\left.<-5 \times 10^{-5} \mathrm{~s}^{-1}\right)$. Destaca-se então, o melhor desempenho dos RegCM4s para simular ciclones inicialmente muito intensos (Figura 4.1.4d). Este tipo de ciclogênese foi fortemente subestimada em outras regionalizações climáticas na América do Sul utilizando o RegCM3 aninhado no CMIP3 (Krüger et al. 2012) e também à reanálise do NCEP (na RG2; Reboita et al. 2010).
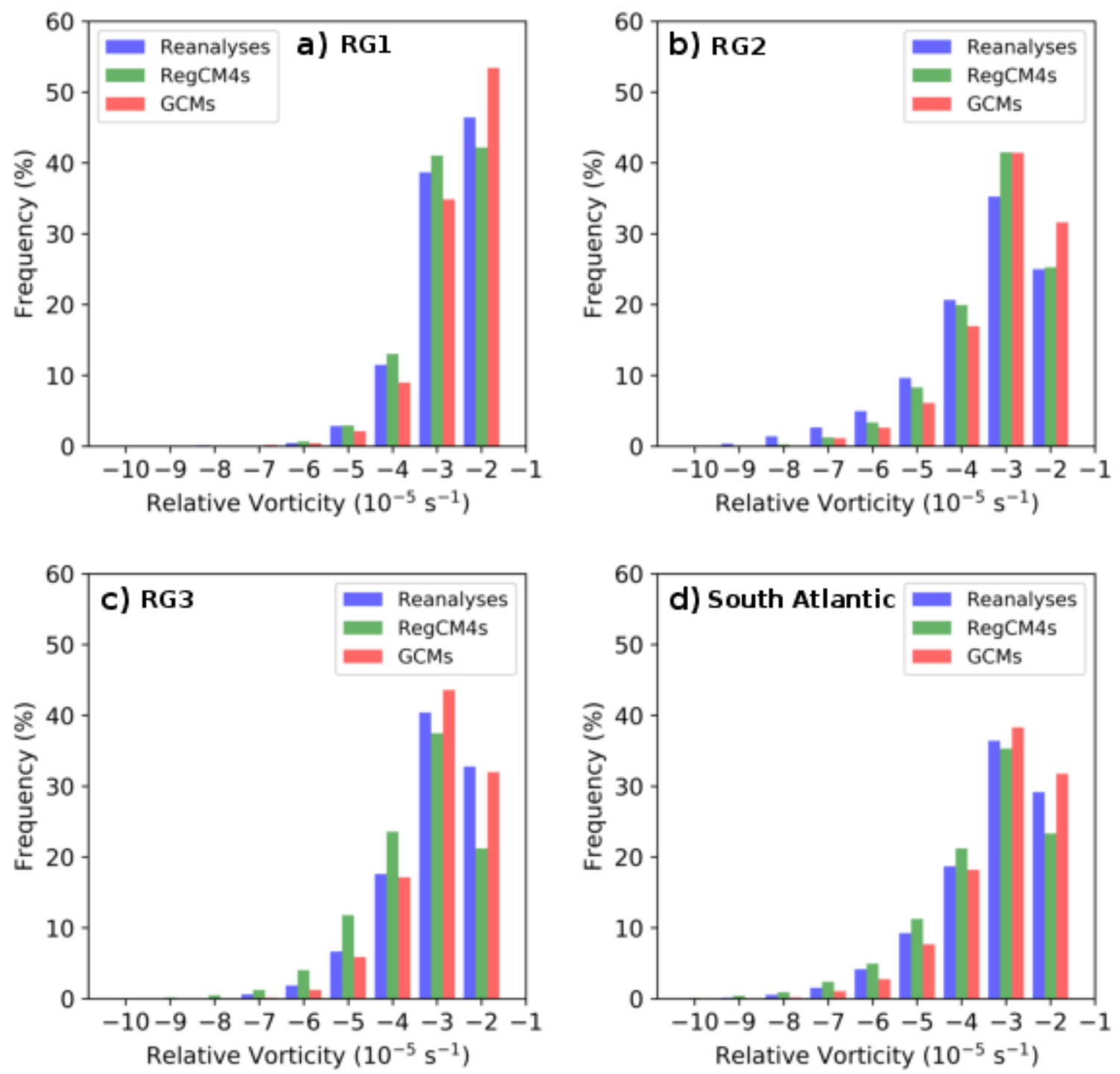

Figura 4.1.4 - Distribuição de frequência anual da vorticidade relativa (x10-5 $\left.\mathrm{s}^{-1}\right)$ no horário da ciclogênese para o clima presente (1979-2005) : a) RG1, b) RG2, c) RG3 e d) domínio do Atlântico Sul. 


\section{b) Ventos associados aos ciclones intensos}

Um fato bastante conhecido é a associação entre os ciclones extratropicais e a formação de uma ampla área no entorno com ventos intensos próximos à superfície e também a presença de correntes de jato em altos níveis ao longo dos ciclos de vida (Browning, 2004; Reboita et al., 2012; Dowdy et al., 2019; Domingues et al., 2019). Esta seção, apresenta uma avaliação climatológica dos ventos associados com os ciclones intensos nas três principais regiões ciclogenéticas. A Tabela 4.1.1 apresenta para cada região os limiares do percentil de 25\% de vorticidade inicial utilizados para caracterizar esses eventos. Os valores dos percentis de 25\% simulados pelo RegCM4s são mais próximos aos das reanálises nas regiões RG1 e RG2, e o oposto ocorre na RG3. Em consequência, comparando as três áreas, os ciclones inicialmente mais intensos na reanálise e GCMs ocorrem na RG2, enquanto nos RegCM4s na RG3.

Tabela 4.1.1 - Limiares do percentil de $25 \%$ de vorticidade relativa inicial $\left(\times 10^{-5} \mathrm{~s}^{-1}\right)$ para identificar ciclones intensos obtidos no período 1979-2005.

\begin{tabular}{c|c|c|c}
\hline Região ciclogenética & Reanálise & GCMs & RegCM4s \\
\hline RG1 & -2.61 & -2.44 & -2.68 \\
\hline RG2 & -3.65 & -3.07 & -3.34 \\
\hline RG3 & -3.09 & -2.99 & -3.63 \\
\hline
\end{tabular}

A Figura 4.1.5 apresenta as composições do vento em 1000 hPa para ciclogenêses intensas selecionadas utilizando os limiares de vorticidade para cada uma das regiões ciclogenéticas no clima presente (Tabela 4.1.1). A Figura 4.1.5 também destaca as áreas (retângulos) com ventos mais fortes onde foram calculadas as médias dos mesmos para obter as séries temporais das Figuras 4.3.1 e 4.3.3.

De acordo com a Figura 4.1.5, tanto os GCMs como os RegCM4s reproduzem os núcleos de ventos mais intensos associados com as ciclogêneses intensas na RG1. Tanto a localização quanto a intensidade simuladas são similares às da reanálises (Figura 4.1.5a,b,c). Para os ciclones mais intensos os ventos mais fortes são de norte-nordeste e ocupam o centro-leste da RG1. Outros 
aspectos observados na reanálise, que são também capturados pelos conjuntos de simulações, são os ventos mais fortes no setor noroeste da alta subtropical do Atlântico Sul e uma área com ventos de sul/sudeste desde a costa sul do Brasil até o nordeste da Argentina (Figura 4.15a,b,c).

A reanálise mostra um núcleo com ventos mais intensos, de nordeste/norte, associado com as ciclogêneses intensas na RG2 situado ao longo da costa, desde o sudeste do Brasil até o Uruguai (Figura 4.1.5d). A localização e intensidade dos ventos associados aos ciclones fortes são melhores reproduzidas pelas simulações RegCM4s. Em especial, os RegCM4s apresentam a região com ventos intensos em maior concordância com a reanálise, representando assim um importante valor adicionado aos GCMs (Figura 4.1.5e,f).

De acordo com a reanálise, durante as ciclogêneses intensas na RG3 os ventos fortes associados são de oeste/noroeste no sudeste da Argentina na faixa latitudinal $38-48^{\circ} S$ (Figura 4.1.5g), e a posição da área com ventos fortes é bem reproduzida pelas simulações (Figura 4.1.5h,i). Nota-se, no entanto, que os ventos são mais intenso nas simulações do que na reanálise.

Em geral, para as três regiões ciclogenéticas, a intensidade do vento em 1000 hPa é ligeiramente superestimada ( 1 a $2 \mathrm{~m} \mathrm{~s}^{-1}$ ) pelos conjuntos de simulações. Os RegCM4s mostram magnitude e localização dos ventos mais fortes associados com os ciclones intensos na RG1 e RG2 mais próximos da reanálise do que os GCMs. De acordo com estes resultados, a regionalização climática adiciona valor aos resultados dos GCMs na representação da circulação próximo à superfície associada às ciclogêneses intensas. Outra importante característica a partir da reanálise é que os ventos mais fortes são encontrados no setor quente dos ciclones incipientes, que está de acordo com outros estudos (Bengtsson et al., 2008) e é muito bem reproduzida pelas simulações. 

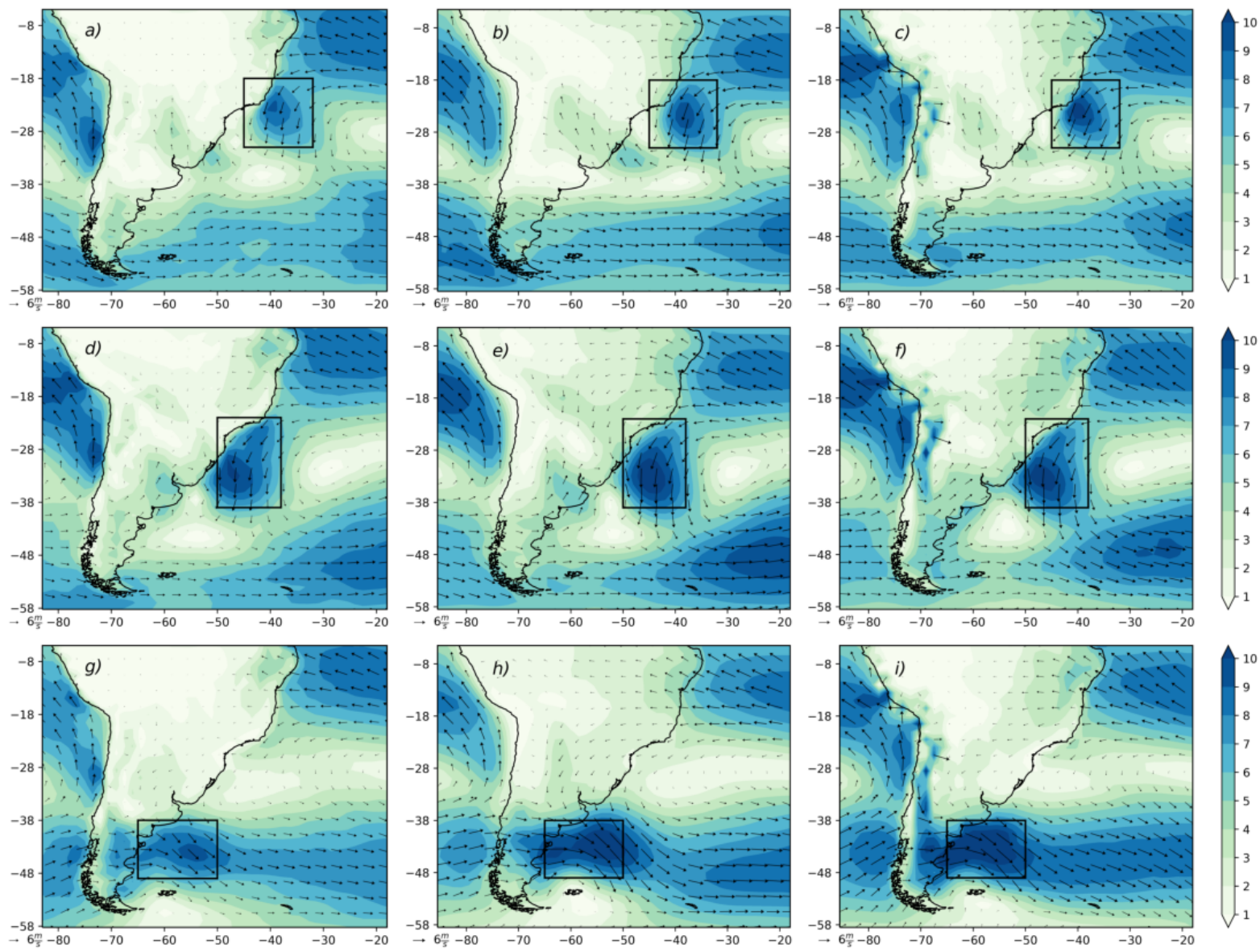

Figura 4.1.5 - Composições para o clima presente (1979-2005) do vento médio anual (vetores e intensidade em sombreado, $\mathrm{m} \mathrm{s}^{-1}$ ) em $1000 \mathrm{hPa}$ associado com os ciclones intensos na RG1 (a, b, c - superior), RG2 (d, e, f - meio) e RG3 (g, h, i - inferior) para: a, d, g) reanálises; b, e, h) GCMs; c, f, i) RegCM4s. Os retângulos indicam as áreas usadas para calcular a velocidade média do vento.

As composições anuais do vento em 300 hPa para as ciclogêneses intensas em cada região são mostradas na Figura 4.1.6. O jato de altos níveis associado às ciclogêneses intensas na RG1 situa-se ao sul da região de formação, com a gênese ocorrendo na entrada equatorial da corrente de jato (Figura 4.1.6a,b,c). De acordo com Crespo et al. (2020), o jato em altos níveis para as ciclogêneses ocorrendo na RG1 mostram forte sazonalidade, situando-se, em média, mais distante (perto) da região no verão (inverno). Contudo, a Figura 4.1.6 mostra o jato muito próximo da RG1 indicando assim uma influência maior da instabilidade baroclínica no desenvolvimento dos ciclones inicialmente mais fortes. As simulações apresentam o padrão de jato em altos níveis semelhante ao da reanálise, mas nas reanálises o jato é ligeiramente mais forte comparado aos conjuntos dos RegCM4 e GCMs (Figura 4.1.6a,b,c). 
Para ciclogêneses intensas, a reanálises mostra que o jato em altos níveis (com dois núcleos de velocidade máxima) situa-se sobre e corrente abaixo da RG2 (Figura 4.1.6d). A localização e intensidade do máximo de vento em altos níveis são simuladas tanto pelo RegCMs como GCMs em razoável concordância com a reanálise (Figura 4.1.6e,f). Nas simulações a corrente de jato é alongada desde o leste do Pacífico Sul, cruza o continente e chega ao Atlântico Sul.

Nas ciclogêneses intensas da RG3, o jato de altos níveis nos conjuntos de simulações apresenta padrão espacial similar ao da reanálise (Figura 4.1.6h,i,j), com os GCMs sendo mais próximo da reanálise nas vizinhanças da RG3. A proximidade do jato de altos níveis em relação à área de formação confirma a forte influência da instabilidade baroclínica nas ciclogêneses na RG3. É importante destacar, que tanto nas simulações como na reanálise, o jato situa-se sobre o centro-norte da área indicando que os ciclones que se formam na RG3 são favorecidos pela divergência de massa em altos níveis normalmente encontrada na saída polar do jato, conforme mostrado por Crespo et al. (2020) durante o inverno. Durante o verão, no entanto, Crespo et al. (2020) observaram a presença do jato sobre a região ciclogenética e uma quebra do núcleo do jato próximo dos Andes, mostrando uma forte influência dos streamers de vorticidade potencial para a formação de ciclones nesta estação. Vale ressaltar que em Crespo et al. (2020) a região ciclogenética próximo à Argentina situa-se mais a norte e abrangendo parte do continente.

As análises anteriores confirmam que as simulações reproduzem as principais características climatológicas observadas nas ciclogêneses (densidade, trajetória, intensidade e ventos associados) no leste da América do Sul, o que dá a confiança para uma avaliação dos cenários climáticos resultantes das mesmas. 

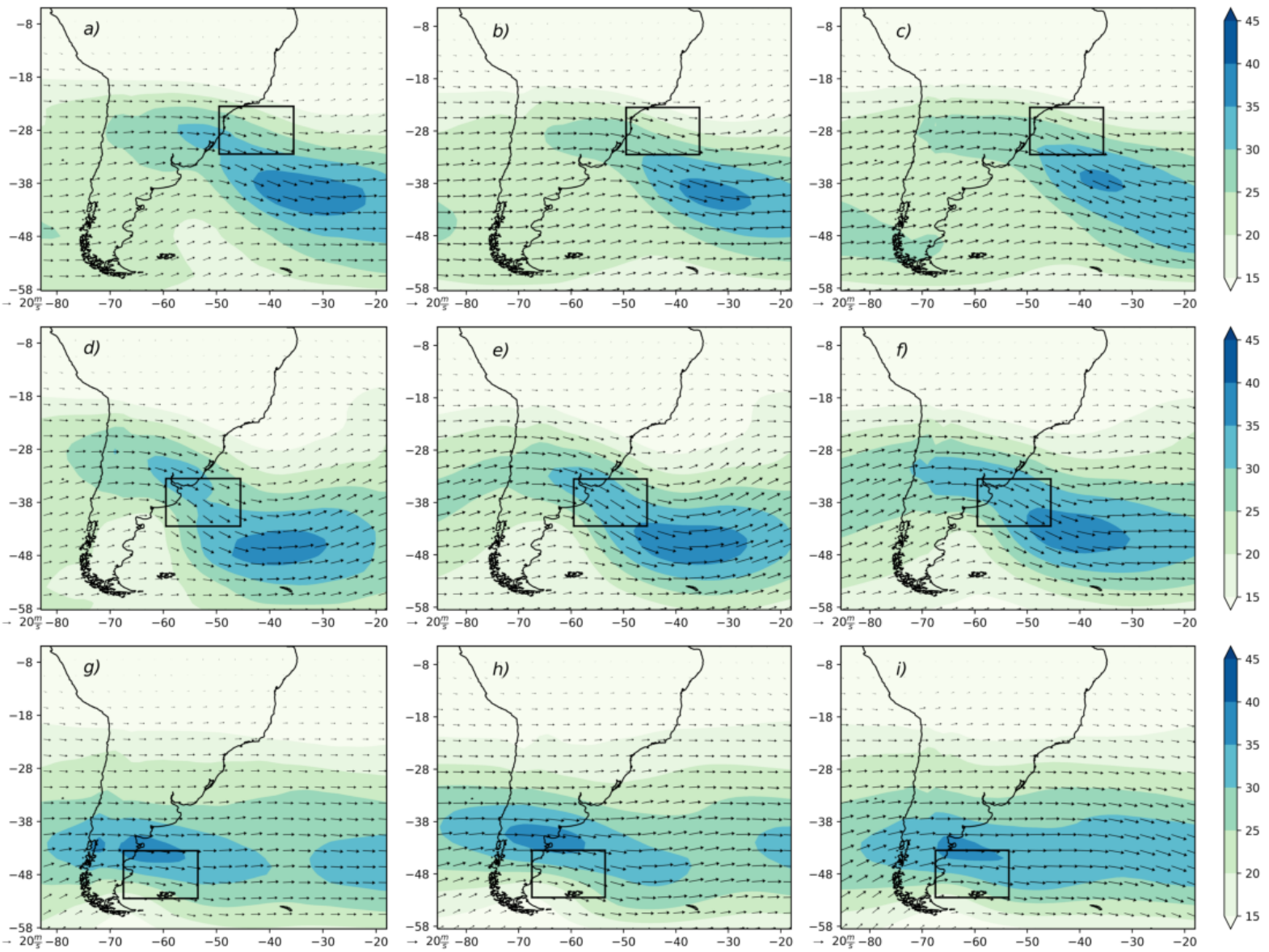

Figura 4.1.6 - Composições para o clima presente (1979-2005) do vento médio anual (vetores e intensidade em sombreado, $\mathrm{m} \mathrm{s}^{-1}$ ) em $300 \mathrm{hPa}$ associado com os ciclones intensos na RG1 (a, b, c superior), RG2 (d, e, f - meio) e RG3 (g, h, i - inferior) para: a, d, g) reanálises; b, e, h) GCMs; c, f, i) RegCM4s. Os retângulos indicam as áreas usadas para calcular a velocidade média do vento.

\subsection{Tendências climáticas: futuros próximo e distante}

\section{a) Trajetórias}

A Figura 4.2.1 apresenta as tendências de densidade de trajetória ao longo do ciclo de vida dos ciclones que se formam nas três regiões ciclogenéticas. A tendência é calculada como a diferença entre a densidade de trajetória no clima futuro (próximo/distante) e clima presente. 
Para o futuro próximo, ambos os conjuntos de simulações indicam uma diminuição geral na atividade ciclônica perto do sudeste do Brasil e oceano adjacente (Figura 4.2.1a,b), que são os principais caminhos de ciclones com origem na RG1 (Figura 4.1.2). As tendências indicam também algumas áreas de aumento de densidade de trajetórias de ciclones nos arredores do principal núcleo negativo, principalmente à nordeste da RG1 nos RegCM4s (Figura 4.2.1b). Este aumento indicaria um pequeno deslocamento para norte do caminho preferencial dos ciclones iniciados na RG1 no clima futuro próximo. Para o futuro distante, o cenário muda completamente (Figura 4.2.1c,d), uma vez que predomina forte tendência negativa na densidade de trajetórias dos ciclones partindo da RG1. A tendência de decréscimo de densidade de trajetória é especialmente mais intensa em uma área maior nos GCMs (Figura 4.2.1d).

Os ciclones iniciados na RG2, no futuro próximo mostram tendência (positiva ou negativa) de densidade de trajetória mais fraca do que para os iniciados na RG1. Mesmo assim, para as ciclogêneses da RG2 nota-se predominância de núcleos indicando aumento na atividade de ciclones em uma ampla área sobre o Atlântico Sul adjacente à costa do Uruguai e Argentina (Figura 4.2.1e,f), enquanto restam poucas áreas com fraca tendência de diminuição no percurso dos ciclones. O padrão de tendência para o futuro próximo é similar entre os GCMs e RegCM4s. Utilizando apenas um membro do CREMA, Reboita et al. (2018) encontraram tendência consistente com as mostradas nas Figura 4.2.1e,f. Por outro lado, para o final do século, há uma predominância de tendência negativa nas densidades de trajetórias conjuntos GCMs e RegCM4s, mas com algumas diferenças espaciais (Figura 4.2.1g,h). Os GCMs (Figura 4.2.1g) projetam decréscimo maior do que o RegCM4s (Figura 4.2.1h) dos caminhos de ciclones sobre e perto da RG2. Uma outra indicação das projeções é a presença de uma "linha” noroeste-sudeste (iniciando no leste da Argentina em $\sim 40^{\circ} \mathrm{S}$ ) de aumento nas densidades de trajetórias nos GCMs, que também é notada ligeiramente ao norte (iniciando no leste da Argentina em 38ㅇ) nos RegCM4s (Figura 4.2.1g,h). Essa "linha" de aumento estaria indicando deslocamento para sul da principal trajetória dos ciclones iniciados na RG2.

Existe forte concordância entre as projeções em relação às tendências negativas de densidade de trajetória para os ciclones iniciados na RG3 (Figura 4.2.1i,j). Ambos indicam uma grande diminuição na atividade na densidade de trajetórias dos ciclones sobre o sul do Atlântico 
Sul, em torno de $45^{\circ}-50^{\circ} \mathrm{S}$, no futuro próximo (Figura 4.2.1i,j), que se intensificará no futuro distante (Figura 4.2.1k,l).

As tendências futuras mostradas na Figura 4.2.1, que considera cada região ciclogenética separadamente, concordam com a diminuição na frequência de ciclones sobre todo o sudoeste do Atlântico Sul e um pequeno aumento próximo ao Uruguai (Krüger et al., 2012; Reboita et al., 2018; 2019).
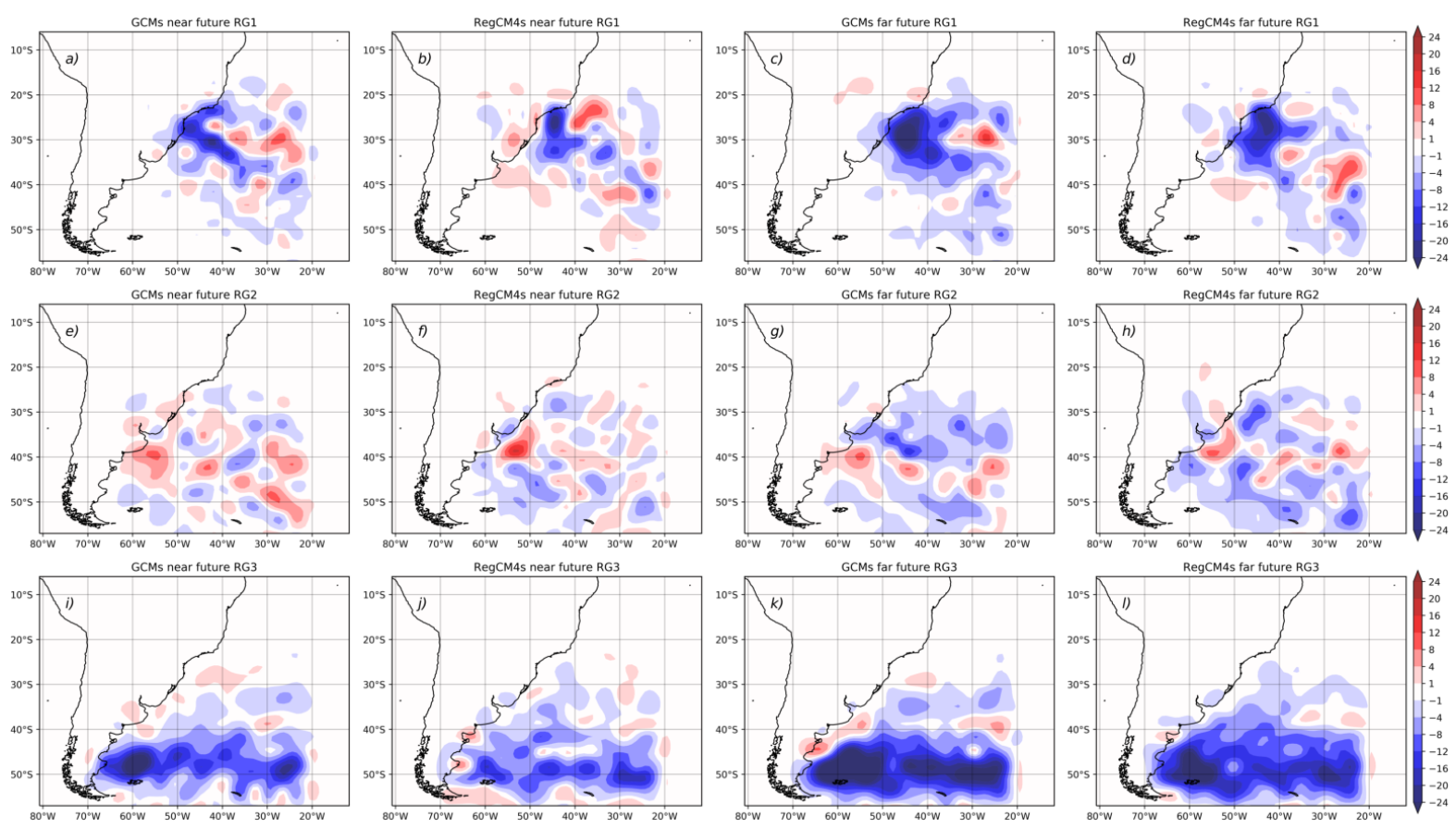

Figura 4.2.1 - Tendências das densidades de trajetórias (futuro "menos" presente) para o clima futuro a,b,e,f,i,j) próximo (2020-2050) e c,d,g,h,k,l) distante (2070-2099) para os GCMs e RegCM4s na a,b,c,d) RG1, e,f,g,h) RG2 e i,j,k,l) RG3. A unidade de densidade é ciclone por área $\left(\mathrm{km}^{2}\right) \times 10^{6}$ por ano.

\section{b) Ventos em baixos e altos níveis}

As projeções de circulação associada com os ciclones intensos no clima futuro foram avaliadas considerando as tendências (composições do clima futuro "menos" composições do clima presente) dos ventos nos níveis de $1000 \mathrm{hPa}$ (Figura 4.2.2) e $300 \mathrm{hPa}$ (Figura 4.2.3). Os limiares do 
percentil de 25\% para identificar ciclones intensos no clima futuro são os mesmos do clima presente mostrados na Tabela 4.1.1.

No futuro próximo, para as ciclogêneses intensas não se projetam grandes mudanças na circulação e intensidade dos ventos em 1000 hPa próximo à costa leste da América do Sul, com algumas exceções de tendências fracas. Entre essas: (a) para ciclones intensos originados na RG1, os GCMs projetam decréscimo de velocidade do vento em torno de $44^{\circ} \mathrm{S}$ (enfraquecimento dos ventos de oeste; Figura 4.2.2a); (b) para ciclones da RG2, os RegCM4s indicam aumento de velocidade no Atlântico Sul, perto do Uruguai $\left(36^{\circ} \mathrm{S}-58^{\circ} \mathrm{W}\right.$; Figura 4.2.2f); (c) projeções dos conjuntos de aumento de velocidade no sul da Argentina (Figuras 4.2.2i,j).

Para ciclones iniciados nas RG1 e RG2, tanto as projeções dos GCMs como as dos RegCM4s indicam o desenvolvimento de uma circulação anticiclônica em $1000 \mathrm{hPa}$, situada à sul/sudeste da RG1 (Figura 4.2.2a,b; centrada em 44 ${ }^{\circ} \mathrm{S}-35^{\circ} \mathrm{W}$ ) e RG2 (Figura 4.2.2 e,f) no futuro próximo. Essa circulação anômala representa um padrão recorrente de mudança na circulação na baixa troposfera sobre o Atlântico Sul encontrada em outros estudos (Rauscher et al., 2011;Krüger et al., 2012; Reboita et al., 2019). O estabelecimento desta circulação anticiclônica contribui para reforçar os ventos de oeste em médias latitudes (Figura 4.2.2a,b,e,f) e contribui para explicar a diminuição na densidade de trajetórias no clima futuro próximo para os ciclones iniciados na RG1 (Figura 4.2.1a,b). Na RG3, a mudança mais importante em baixos níveis é um pequeno fortalecimento dos ventos de oeste próximo à RG3 e o estabelecimento de uma circulação ciclônica à sudeste (Figura 4.2.2i,j). Estas mudanças apresentam maior intensidade nos GCMs (Figura 4.2.2i) do que nos RegCM4s (Figura 4.2.2j).

Para o futuro distante, as projeções indicam um aumento generalizado das velocidades dos ventos em 1000 hPa associados com as ciclogêneses intensas (Figura 4.2.2c-l). Por exemplo, para ciclogêneses intensas da RG1 os ventos de nordeste podem aumentar em até $~ 1,5 \mathrm{~m} \mathrm{~s}^{-1}$ na costa sudeste do Brasil no futuro distante (Figura 4.2.2c,d). Comparativamente, a área com anomalias positivas mais intensas projetada pelos RegCM4s é maior do que nos GCMs. Para ciclogêneses intensas na RG2, também se projeta aumento (até $1 \mathrm{~m} \mathrm{~s}^{-1}$ ) da velocidade do vento em $1000 \mathrm{hPa}$ perto da costa sudeste do Brasil (Figura 4.2.2g,h), isto é, ao norte dos ventos mais fortes associados às ciclogêneses intensas no clima presente (Figura 4.1.5d,e,f). Além disso, para a RG2, os GCMs e 
RegCM4s projetam um reforço das anomalias anticiclônicas sobre o Atlântico Sul (centrado em $\left.\sim 48^{\circ} \mathrm{S}-35^{\circ} \mathrm{W}\right)$.

A região de ventos fortes em baixos níveis associados com as ciclogêneses intensas na RG3 apresenta uma pequena diminuição na velocidade do vento no setor noroeste da RG3 nas projeções dos GCMs (Figura 4.2.2k). Ambos os conjuntos projetam a intensificação dos ventos em baixos níveis em regiões distantes da RG3, como ocorre na costa sudeste do Brasil (até $2 \mathrm{~m} \mathrm{~s}^{-1}$ ) e ao sul da RG3. Essa resposta remota na velocidade do vento resultaria da intensificação da circulação anticiclônica tanto sobre o Pacífico Sul como sobre o Atlântico Sul (Figura 4.2.2k,l). Não se nota tendência semelhante nas projeções para o futuro próximo (Figura 4.2.2i,j). Perto do sul do domínio, o aumento na intensidade do vento para ciclones intensos da RG3 seria uma resposta ao gradiente horizontal de pressão mais intenso no futuro distante (Reboita et al. 2019).

Independente da região ciclogenética considerada, uma característica comum nas projeções para o futuro distante é o desenvolvimento de uma circulação anticiclônica, centrada em $\sim 48^{\circ} \mathrm{S}$ e $30-35^{\circ} \mathrm{W}$, em baixos níveis que enfraquece e intensifica os ventos de oeste, respectivamente, no cinturão de $38-48^{\circ} \mathrm{S}$ e ao sul de $48^{\circ} \mathrm{S}$ (Figura 4.2.2). Além disso, o anticiclone anômalo reforça os ventos de leste-nordeste em 1000 hPa no leste do sul-sudeste do Brasil. 

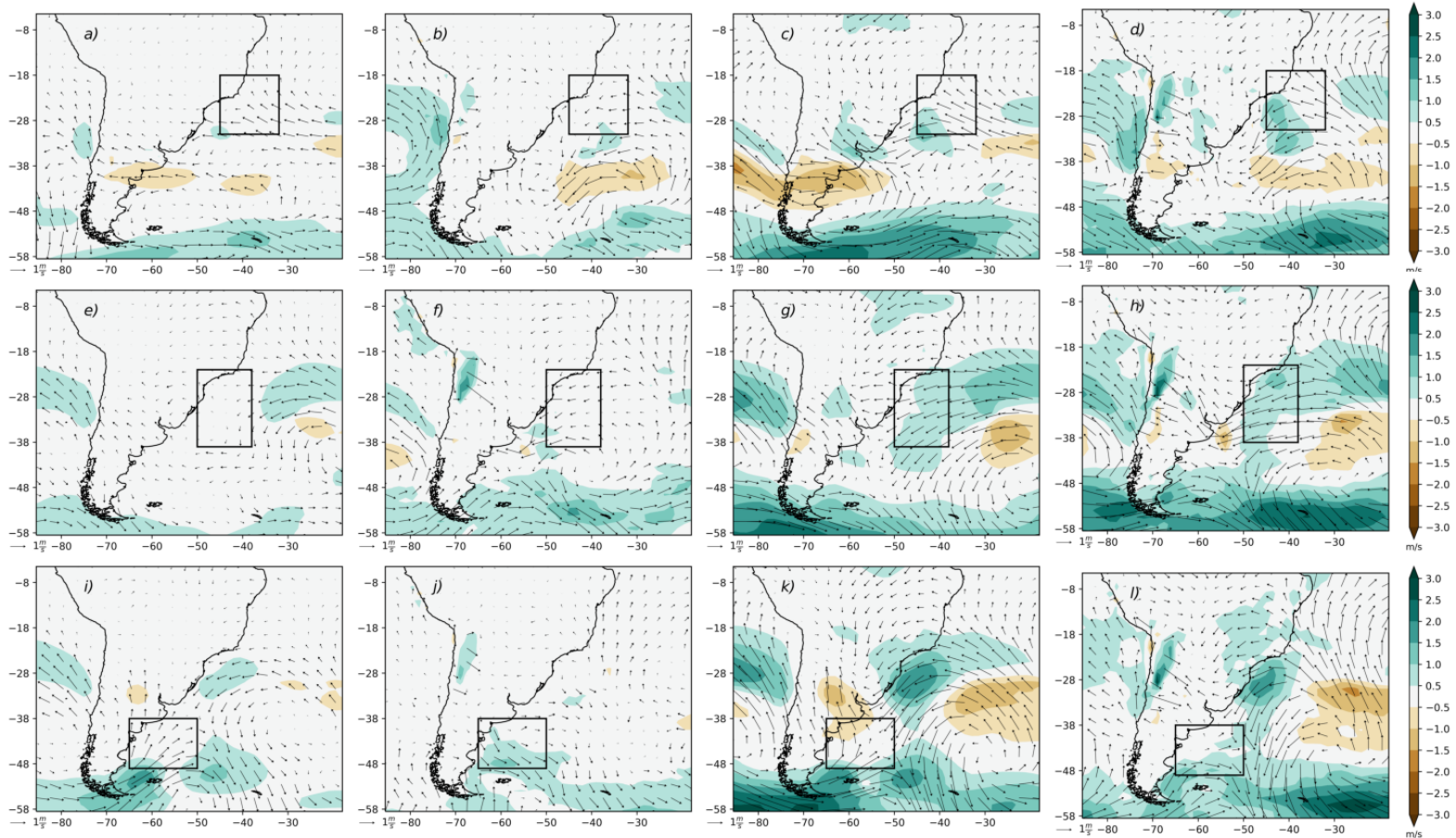

Figura 4.2.2 - Composição da diferença (futuro "menos” presente) da velocidade do vento em $1000 \mathrm{hPa}$ associada com ciclones intensos para o clima futuro a,b,e,f,i,j) próximo (2020-2050) e c,d,g,h,k,l) distante (2070-2099) para os GCMs e RegCM4s na a,b,c,d) RG1, e,f,g,h) RG2 e i,j,k,l) RG3. Os retângulos indicam as regiões de ventos mais fortes para cada região ciclogenética no clima presente.

A Figura 4.2.3 apresenta as composições das tendências dos ventos em 300 hPa para os climas futuro próximo e distante. Em altos níveis, as projeções do futuro próximo indicam aumento na velocidade na corrente de jato próximo das regiões ciclogenéticas RG1 e RG2, e diminuição ao sul. Associado com ciclogêneses intensas, esse padrão de tendência implicaria em pequeno enfraquecimento do jato polar ao mesmo tempo que o jato subtropical se intensifica em altos níveis (Figura 4.2.3a,b,e,f). Para RG3, apenas os GCMs (RegCM4s) projetam que a velocidade da corrente de jato deverá sofrer pequeno decréscimo ao norte próximo da RG3, onde normalmente está situado o jato associado às ciclogêneses intensas da RG3 (Figura 4.1.6). Para a região do jato subtropical $\left(\sim 28^{\circ} \mathrm{S}\right)$, as projeções indicam intensificação do mesmo no futuro próximo, bem como ao sul da RG3 (Figura 4.2.3i,j). Embora com diferenças de intensidade pequenas, nota-se algumas mudanças na circulação em altos níveis no futuro próximo.

Para o futuro distante, os padrões de mudança são semelhantes aos do futuro próximo, porém se intensificam (em módulo) as anomalias nas correntes de jato subtropical e polar 
associadas às três regiões ciclogenéticas (Figura 4.2.3c,d,h,k,l). Enquanto os GCMs apresentam tendências mais fortes para a RG1 (Figura 4.2.3c,d), nos RegCM4s isso ocorre para as anomalias das RG2 e RG3 (Figura 4.2.3g,h,k,l). Tanto a RG1 como RG2 sofrem influência de anomalias positivas de velocidade na corrente jato em altos níveis. A RG1 situa-se logo abaixo da região de entrada do jato que se intensificará no futuro distante (Figura 4.2.3c,d), enquanto a RG2 localiza-se abaixo da saída de um jato mais intenso também no futuro distante (Figura 4.2.3g,h). Esse padrão de intensificação do vento em altos níveis sugere que as ciclogêneses intensas (na RG1 e RG2) irão ocorrer sob jatos de altos níveis mais fortes no futuro, entretanto, para a RG3 este sinal não está claro (Figura 4.2.3k,l).

Em geral, projeções do futuro distante indicam 1) um maior enfraquecimento do jato polar na banda de latitude de $36^{\circ} \mathrm{S}-50^{\circ} \mathrm{S}$ e um reforço a sul, que é um padrão consistente com o deslocamento para sul da zona baroclínica climatológica; 2) um aumento de intensidade do jato subtropical, desde o leste do Pacífico Sul até o Atlântico Sul na banda latitudinal $18^{\circ} \mathrm{S}-36^{\circ} \mathrm{S}$. Este reforço no jato de altos níveis poderá aprofundar o cavado estacionário sobre os Andes e, como uma consequência, a formação de uma crista/anticiclone corrente abaixo $\left(20^{\circ} \mathrm{S}-40^{\circ} \mathrm{W}\right.$ para $50^{\circ} \mathrm{S}-30^{\circ} \mathrm{W}$ ), acima das anomalias anticiclônicas de baixos níveis (Figura 4.2.2), configurando portanto uma resposta barotrópica ao aquecimento global; e 3) um reforço dos ventos de leste em latitudes tropicais a norte de $18^{\circ} \mathrm{S}$. Estes padrões apresentam semelhanças aos encontrados por Reboita et al. (2018) para as projeções climáticas para o inverno, independente da ocorrência ou não de ciclogêneses, indicando uma predominância dos padrões relacionados com eventos intensos na definição da circulação no clima futuro. 

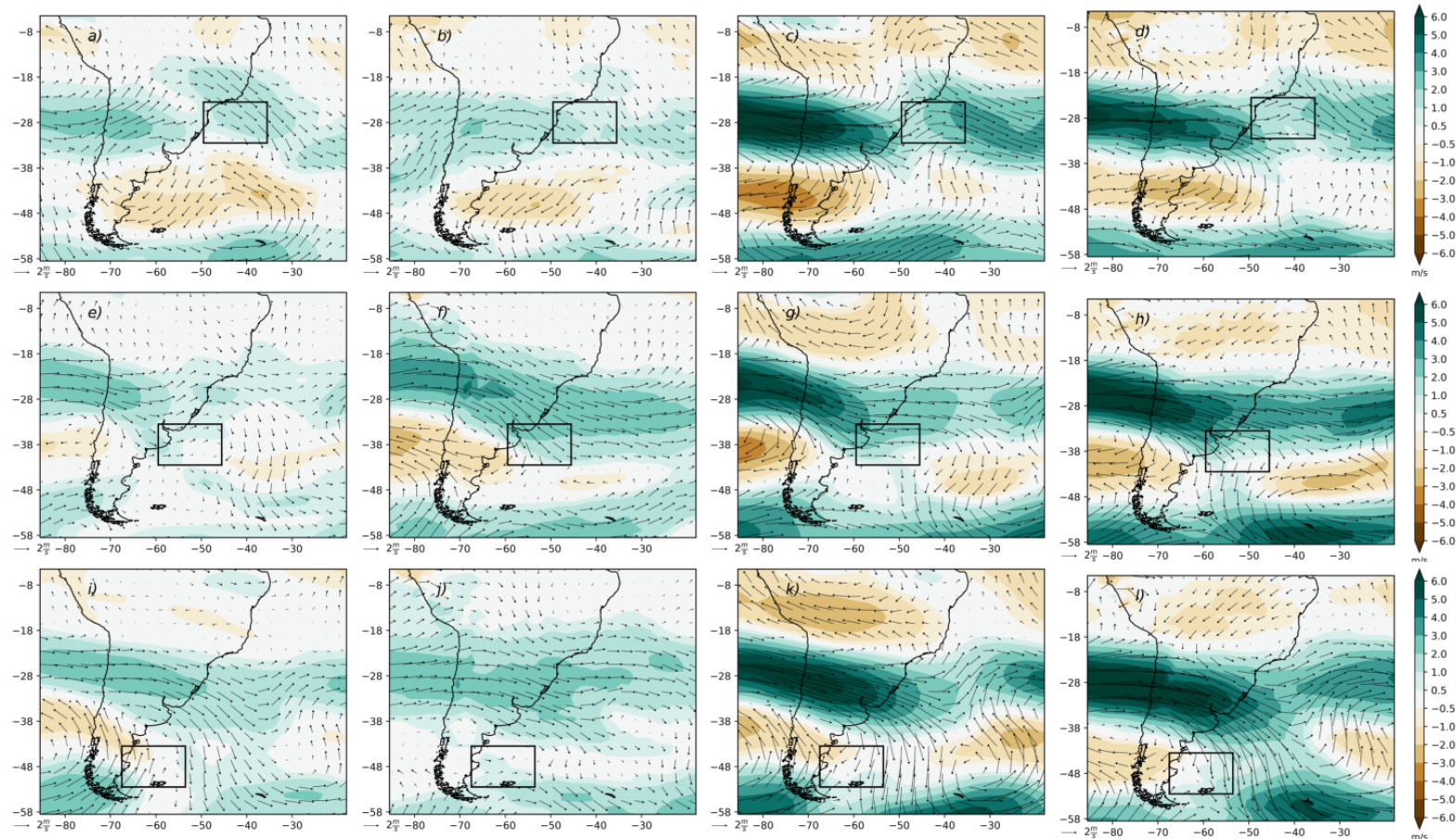

Figura 4.2.3 - Composição da diferença (futuro “menos” presente) da velocidade do vento em 300 hPa associado com ciclones intensos para o clima futuro a,b,e,f,i,j) próximo (2020-2050) e c,d,g,h,k,l) distante (2070-2099) para os GCMs e RegCM4s na a,b,c,d) RG1, e,f,g,h) RG2 e i,j,k,l) RG3. O retângulo indica as regiões de ventos fortes associados com cada região/ponto quente no clima presente.

\subsection{Tendências médias de longo prazo: ciclogêneses e ventos}

Outra maneira de avaliar as tendências de ciclogêneses nas regiões ciclogenéticas é através de séries temporais da frequência anual dos eventos apresentadas na Figura 4.3.1.

Como mostrado nos mapas espaciais, os RegCM4s simulam um número maior de ciclogêneses na RG1 e RG2 comparado à reanálise. E o oposto ocorre com os GCMs. De acordo com a Figura 4.3.1, na RG1 os RegCM4s mostram maior proximidade com a frequência observada de ciclones no clima presente, enquanto os GCMs apresentam forte subestimativa como já indicavam as Figuras 4.1.2 e 4.1.3. Os menores erros de simulação estariam associados à maior habilidade dos RCMs, e em particular o RegCM4s, em resolver fatores de mesoescala presentes 
durante as ciclogêneses de mesoescala, bem como processos diabáticos que são relevantes para a maioria das ciclogêneses na RG1 de acordo com Gozzo et al. (2014).

Para a RG2, apesar da proximidade entre as linhas de tendência do GCMs e reanálise, na média do clima presente nota-se um bias de intensidade similar mas de sinais opostos nos conjuntos de simulações (Figura 4.3.1), ou seja, os RegCM4s superestimam em +6\% e os GCMs subestimam em -8\% a frequência anual de ciclones. Entretanto, esses vieses são relativamente pequenos uma vez que não excedem $\pm 10 \%$. No clima presente, para a RG3 a subestimativa da frequência anual de ciclones é similar para ambos os conjuntos de simulações (Figura 4.3.1).

A Figura 4.3.1 revela uma clara tendência de diminuição na frequência de ciclones no clima presente para as três regiões ciclogenéticas. Entre as três regiões, a reanálise apresenta tendência negativa menos acentuada nas RG2 e RG3, e uma forte tendência negativa na RG1. Da mesma forma, os conjuntos de simulações reproduzem a tendência observada nas RG2 e RG3, mas subestimam a tendência na RG1. É importante destacar que para o período 1979-2005 (27 anos) todas tendências não apresentam significância estatística ao nível de 95\% (p-value > 0.05) de acordo com o teste estatístico Mann-Kendall (Kendall, 1975; Mann, 2008).

Para as três regiões ciclogenéticas, no clima presente a reanálise indica a presença de forte variabilidade interanual na frequência de ciclones, uma característica que é melhor capturada pelos RegCM4s do que GCMs (Figura 4.3.1). Este resultado indica uma adição de valor muito importante da regionalização climática dinâmica, e fornecendo confiança para as projeções regionais que continuam indicando grande variabilidade interanual no cenário futuro. Outro aspecto muito importante é a presença de variabilidade de baixa frequência (decadal para multidecadal) sobreposta à tendência negativa diminuição geral do número anual de ciclones, isto é, mesmo com tendência negativa geral, as projeções indicam que os ciclones mais/menos frequentes em algumas décadas do que em outras (Reboita et al. 2018). 


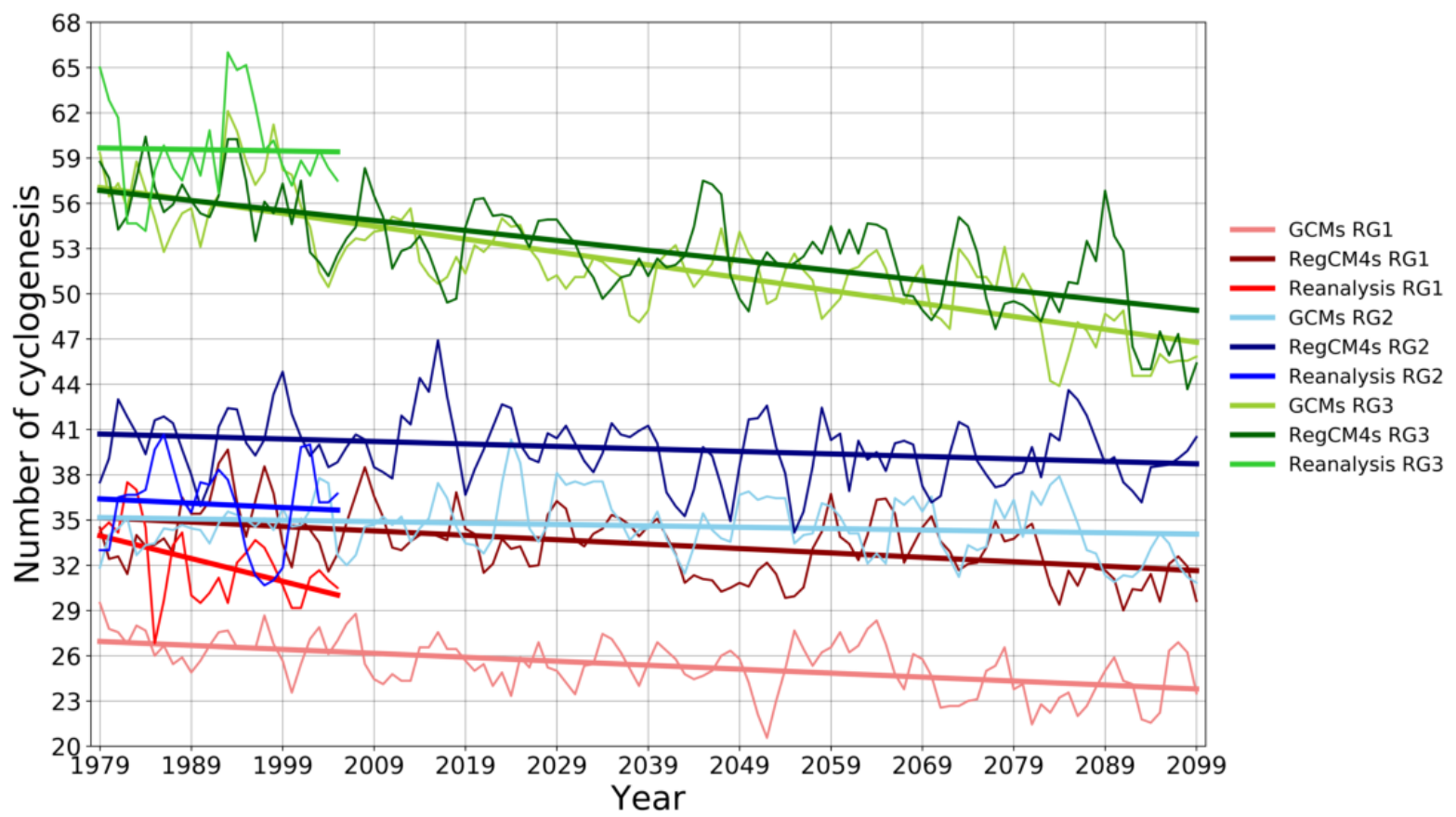

Figura 4.3.1 - Frequência absoluta anual e tendência (retas) de ciclogêneses da reanálise (1979-2005) e simuladas (1979-2099) na RG1 (cores avermelhadas), RG2 (cores azuladas) e RG3 (cores esverdeadas). As linhas retas indicam a tendência.

As projeções de diminuição na frequência dos ciclones em cada região ciclogenética reflete uma tendência negativa geral para todos os ciclones sobre o Atlântico Sul (Figura 4.3.2). Particularmente quando se considera todo o domínio, nota-se uma clara melhoria do regionalização dinâmica que no clima presente simula em maior concordância com a reanálise tanto a frequência anual como a tendência. 


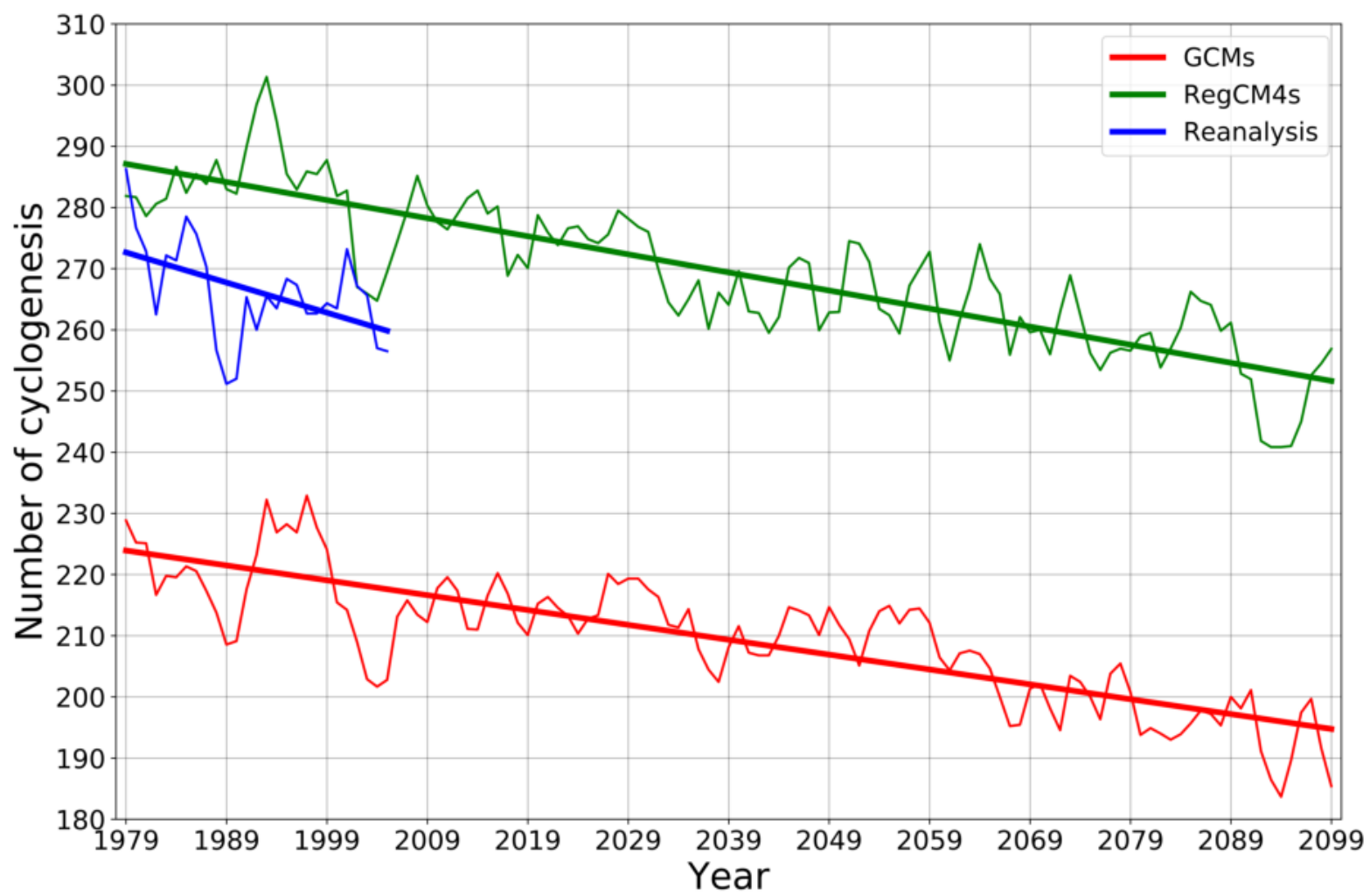

Figura 4.3.2 - Frequência absoluta anual e tendência de ciclogêneses observadas (1979-2005) e simuladas (1979-2099) em todo o domínio do Atlântico Sul (área delimitada na Figura 3.3.1). As linhas em negrito indicam a tendência.

Buscando sintetizar as tendências de vento em 1000 hPa associadas com ciclogêneses intensas, a Figura 4.3.3 apresenta a média anual de velocidade para cada região de ventos fortes no clima presente (caixas delimitadas destacadas nas Figuras 4.1.5 e 4.2.2). Em geral, para o clima presente na RG3, os GCMs e RegCM4s superestimam (em $2 \mathrm{~m} \mathrm{~s}^{-1}$ ) a velocidade dos ventos em baixos níveis associados aos ciclones intensos. Entretanto, para a RG1 e RG2 os vieses (de 1 m $\mathrm{s}^{-1}$ ) são muito menores e da mesma ordem de grandeza da subestimativa pelas reanálises das observações locais dos ventos próximo à superfície (Cardoso, 2019).

A reanálise indica tendência positiva na velocidade do vento em 1000 hPa associado com os ciclones intensos iniciados na RG1, que não é capturado pelos conjuntos de simulações (Figura 4.3.3). Já que na reanálise (e RegCM4s) a frequência de ciclones está diminuindo (ambos total Figura 4.3.1 - e ciclones intensos - Figura A.1 - Apêndice), cada evento estaria associado com ventos mais fortes, tal que, a velocidade média apresenta tendência positiva. Para o clima futuro, projeta-se intensidade dos ventos similares ao clima presente de acordo com os conjuntos de 
simulações (Figura 4.3.3). Contudo, uma vez que a frequência está diminuindo nos RegCM4s, isso indicaria que cada ciclone produzirá ventos mais fortes.

Há também tendência positiva na velocidade do vento para ciclones mais fortes iniciados na RG2 na reanálise, que é muito bem capturada pelos conjuntos de simulações (Figura 4.3.3). Nesta região, ambos os conjuntos projetam tendência similar no futuro, assim como as tendências negativas dos eventos intensos.

Para ciclogêneses intensas a RG3, o RegCM4s captura a fraca tendência positiva da velocidade do vento e a tendência negativa destes eventos (Figura A.1 - Apêndice) presente na reanálise (Figura 4.3.3). Os GCMs não apresentam tendência na velocidade dos ventos para a RG3. Para o clima futuro, os RegCM4s continuam mostrando tendência positiva da velocidade do vento. Como na frequência de ciclones, somente para o período mais longo (1979-2099) as tendências de velocidade do vento em 1000 hPa (Figura 4.3.3) são estatisticamente significativas ao nível de 95\% (p-value < 0.05) de acordo com o teste Mann-Kendall.

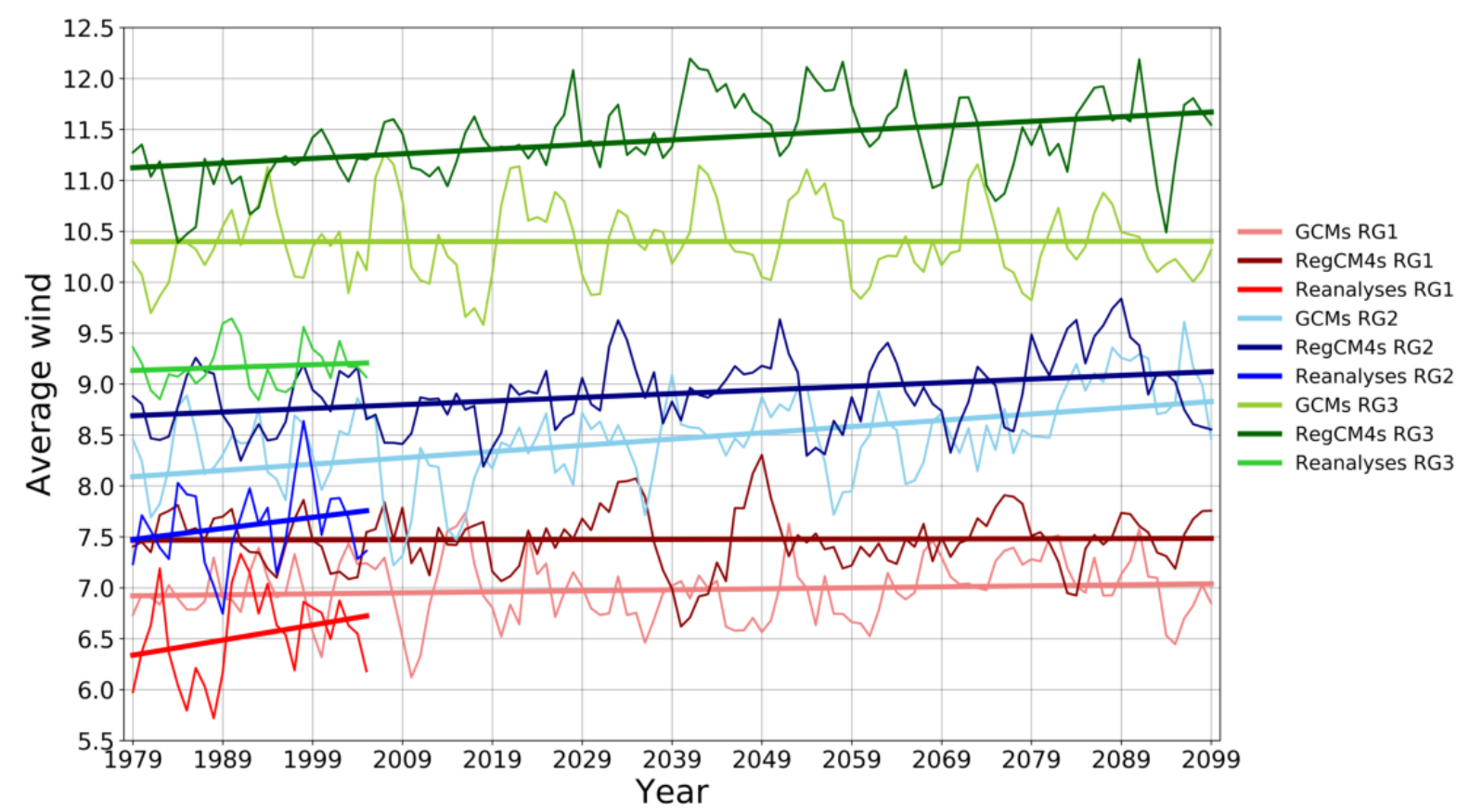

Figura 4.3.3 - Vento médio em 1000 hPa associado às ciclogêneses intensas e tendência para a reanálise (1979-2005) e simulações (1979-2099) considerando ciclones iniciados na RG1 (cores avermelhadas), RG2 (cores azuladas) e RG3 (cores esverdeadas). Estas médias foram calculadas na área de velocidade do vento máximo associado com os ciclones intensos no clima presente (caixas nas Figuras 4.1.5 e 4.2.2). 


\section{Ciclones Subtropicais no Atlântico Sul: validação, clima presente e tendências climáticas}

Este capítulo apresenta uma discussão sobre a classificação dos ciclones subtropicais, bem como uma validação do método automático de classificação. Além disso, serão apresentadas características destes ciclones no clima presente e projeções para o clima futuro.

\subsection{Validação do método automático de classificação dos ciclones subtropicais}

Primeiramente, para discutir a climatologia dos ciclones subtropicais é necessário validar o software desenvolvido para classificação automática dos ciclones. A climatologia obtida em Gozzo et al. (2014) envolve extrair os parâmetros $\left(\mathrm{V}_{\mathrm{T}}^{\mathrm{U}}, \mathrm{V}_{\mathrm{T}}^{\mathrm{L}}\right.$ e B) do CPS e, após uma primeira identificação, a classificação definitiva utilizou uma verificação visual de vários eventos de forma individual. Em seu trabalho, o autor aplicou o método de verificação visual de identificação dos ciclones subtropicais utilizando os critérios: 1) ciclogênese entre $40^{\circ} \mathrm{S}$ e $20^{\circ} \mathrm{S}$, o qual evita a inclusão de baixas polares e vórtices de mesoescala formados em altas latitudes; 2) possuir núcleo quente em baixos e núcleo frio em altos níveis por um tempo maior ou igual a 36 horas - com limiares de $-\left|V_{T}^{L}\right| \geq-50$ e $-\left|V_{T}^{U}\right| \leq-10$; 3) valores de simetria térmica (B) menores que $25 \mathrm{~m}$ por um período de 36 horas ou superior. Adicionalmente, os critérios para os parâmetros devem ser simultâneos por no mínimo 24 horas para evitar inclusão de ciclones subtropicais não puros. Gozzo et al. (2014) utilizou a área de rastreamento compreendida entre $70^{\circ} \mathrm{W}-5^{\circ} \mathrm{W}$ e $10^{\circ} \mathrm{S}-50^{\circ} \mathrm{S}$, essa área foi aplicada para melhor avaliação do desempenho do SCS. Esta área é um pouco diferente em comparação ao rastreamento aplicado aqui, com área de rastreamento compreendida entre $81^{\circ} \mathrm{W}-21^{\circ} \mathrm{W}$ e $15^{\circ} \mathrm{S}-57^{\circ} \mathrm{S}$ (Figura 3.3.1). 
Apesar da inspeção visual qualitativa, o procedimento de classificação visual descrito acima é inviável de ser aplicado a um grande número de simulações e por longo período de tempo. Portanto, para este trabalho foi desenvolvido e aplicado o SCS, software (escrito em Fortran) que parte dos parâmetros do CPS e utiliza os limiares propostos por Gozzo et al., (2014) para encontrar ciclones subtropicais, isso permite a classificação automática e rápida aplicável a um grande volume de dados.

Antes de aplicar ao conjunto de simulações será apresentada a validação do SCS, ou seja, uma comparação da climatologia de ciclones subtropicais de Gozzo et al., (2014) com aquela obtida com o SCS. Como as informações (data e localização) de ciclones subtropicais de Gozzo et al., (2014) utilizaram a reanálise da ERA-Interim, todas as análises desses sistemas, inclusive a validação do SCS, utilizam essa base de dados.

\section{a) Densidade, trajetória e variabilidade}

A Figura 5.1.1 mostra as climatologias para o período 1979-2005 da densidade total de ciclones subtropicais a partir da base de dados de Gozzo (2014) e do SCS. Em termos de posição de formação destes sistemas, nota-se grande similaridade entre os dois métodos, sendo que o principal núcleo de ciclones subtropicais próximo à costa sudeste do Brasil é captado pelo SCS com posição e intensidade similares à de Gozzo (2014). A maior frequência de formação de ciclones subtropicais está localizada na costa dos estados do Rio de Janeiro e São Paulo, que então torna-se mais fraca ao sul (chegando até a costa do estado Rio Grande do Sul) e ao norte (atingindo o estado da Bahia). No leste do Uruguai e em $50^{\circ} \mathrm{W}-40^{\circ} \mathrm{S}$ o SCS mostra um centro de fraca densidade de ciclones subtropicais que não é observado na climatologia de Gozzo (2014), mas que, no entanto, esta diferença pode ser considerada pequena e dentro da margem de erro de métodos automáticos de classificação de sistemas meteorológicos (Reboita et al., 2010). 

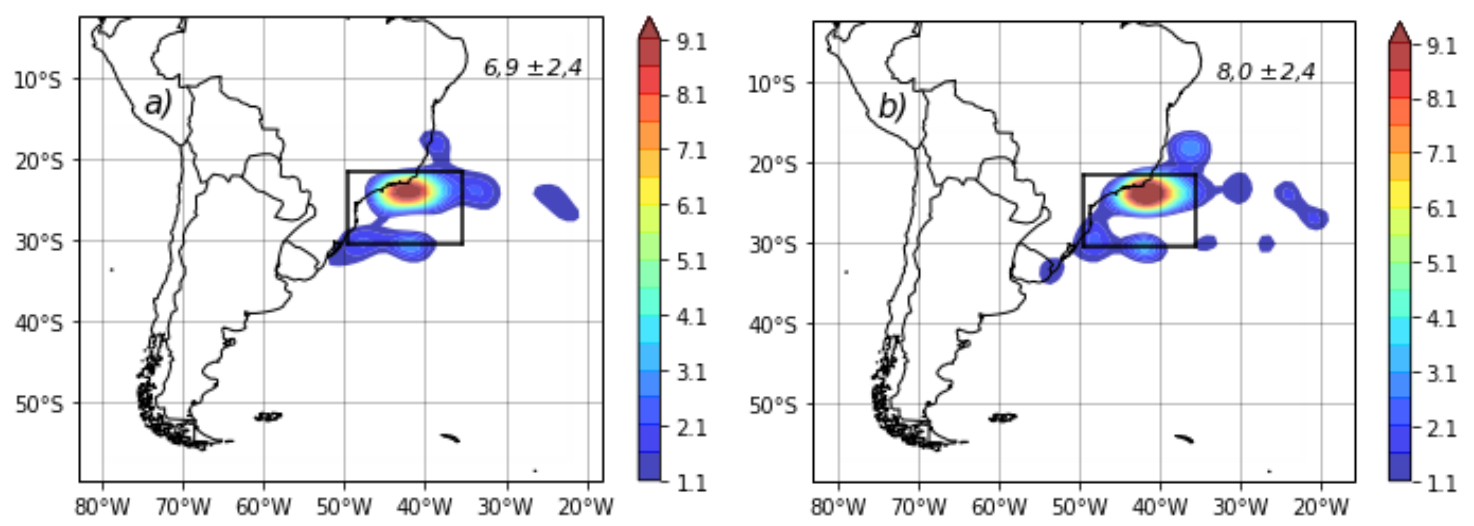

Figura 5.1.1 - Densidade média anual de ciclogêneses subtropicais para o período 1979-2005 em a) Gozzo (2014) e b) SCS. A unidade é ciclone por área $\left(\mathrm{km}^{2}\right) \times 10^{6}$ por ano.

Integrando na RG1, a média anual é bastante similar, de 6,9 \pm 2,4 e 8,0 \pm 2,4 ciclones por ano, respectivamente, em Gozzo (2014) e SCS. Nota-se que o SCS apresenta uma média ligeiramente superior, mas captura adequadamente a variabilidade interanual (desvio padrão similar) da climatologia de Gozzo (2014). Em termos sazonais, ambos os métodos mostram densidades similares sobre o Atlântico Sul (Figura A.3 - Apêndice).

As densidades de trajetória mostram que o SCS consegue capturar os principais padrões anual (Figura 5.1.2) e sazonal (Figura A.4 - Apêndice) dos deslocamentos dos dos ciclones subtropicais sobre o Atlântico Sul. Também o ciclo ano, com as variações mensais de ciclones encontradas em Gozzo (2014) são reproduzidas pelo SCS (Figura 5.1.3a), sendo em média o verão (inverno) a estação com maior (menor) número de ciclogêneses subtropicais na Era-Interim. Já na frequência de tempo de vida (Figura 5.1.3b), o SCS também se mostra hábil em reproduzir os padrões obtidos por Gozzo (2014), em que mais de 60\% destes sistemas tem duração de até 4 dias e sistemas com maior tempo de vida (acima de 7 dias) são menos frequentes. As Figura 5.1.3a-b mostram que o SCS consegue capturar variações sazonais, mensais e diárias em grande concordância com os resultados obtidos por Gozzo et al. (2014). 

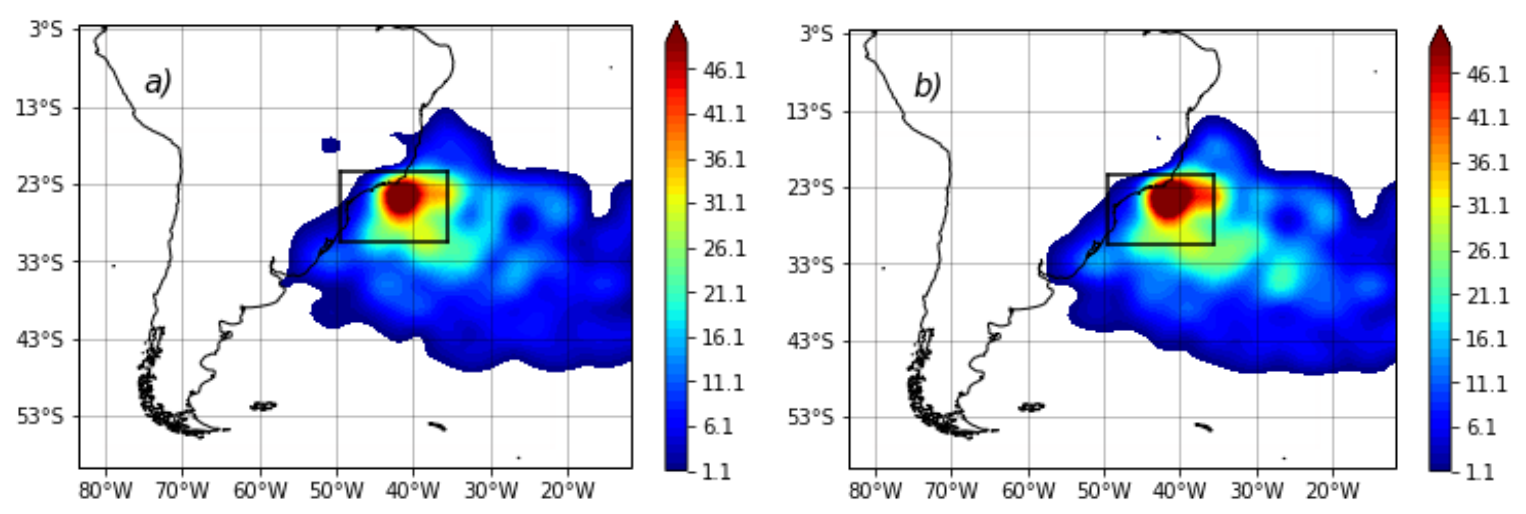

Figura 5.1.2 - Densidade média anual de trajetórias de ciclones subtropicais para o período 1979-2005 em a) Gozzo (2014) e b) SCS. A unidade é ciclone por área $\left(\mathrm{km}^{2}\right)$ x10 $10^{6}$ por ano.
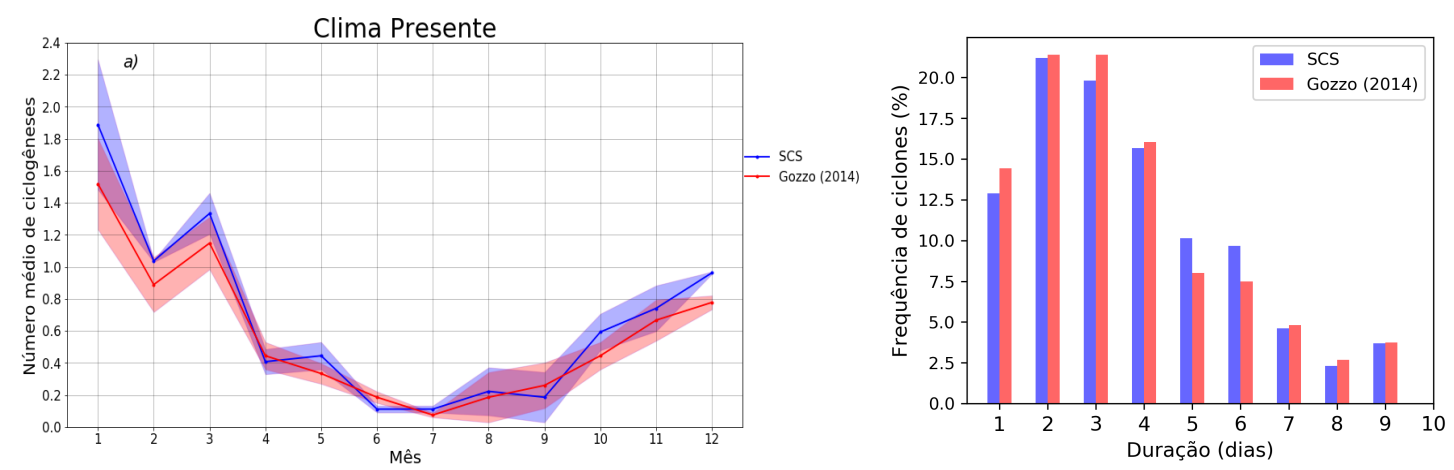

Figura 5.1.3 - a) Média mensal (linhas) e desvio padrão (sombreado) climatológico e b) duração (dias) dos ciclones subtropicais obtidos por Gozzo (2014; vermelho) e SCS (azul) para o período de 1979-2005.

O padrão de variabilidade interanual de ciclogênese subtropical encontrado por Gozzo (2014) também é reproduzido pelo SCS (Figura 5.1.4). Nota-se, em média, uma superestimativa de um sistema por ano pelo SCS, no entanto existe alta correlação entre ambos conjuntos de dados $(+0,82)$ e relativamente baixo raiz do erro médio quadrático $(1,82)$. Anos extremos como os de maior ocorrência, em 2001 (14 eventos) e 1983 (12 eventos), e menor, em 2003 (4 em Gozzo (2014) e 3 no SCS), de ciclones subtropicais são também adequadamente representados pelo SCS. 


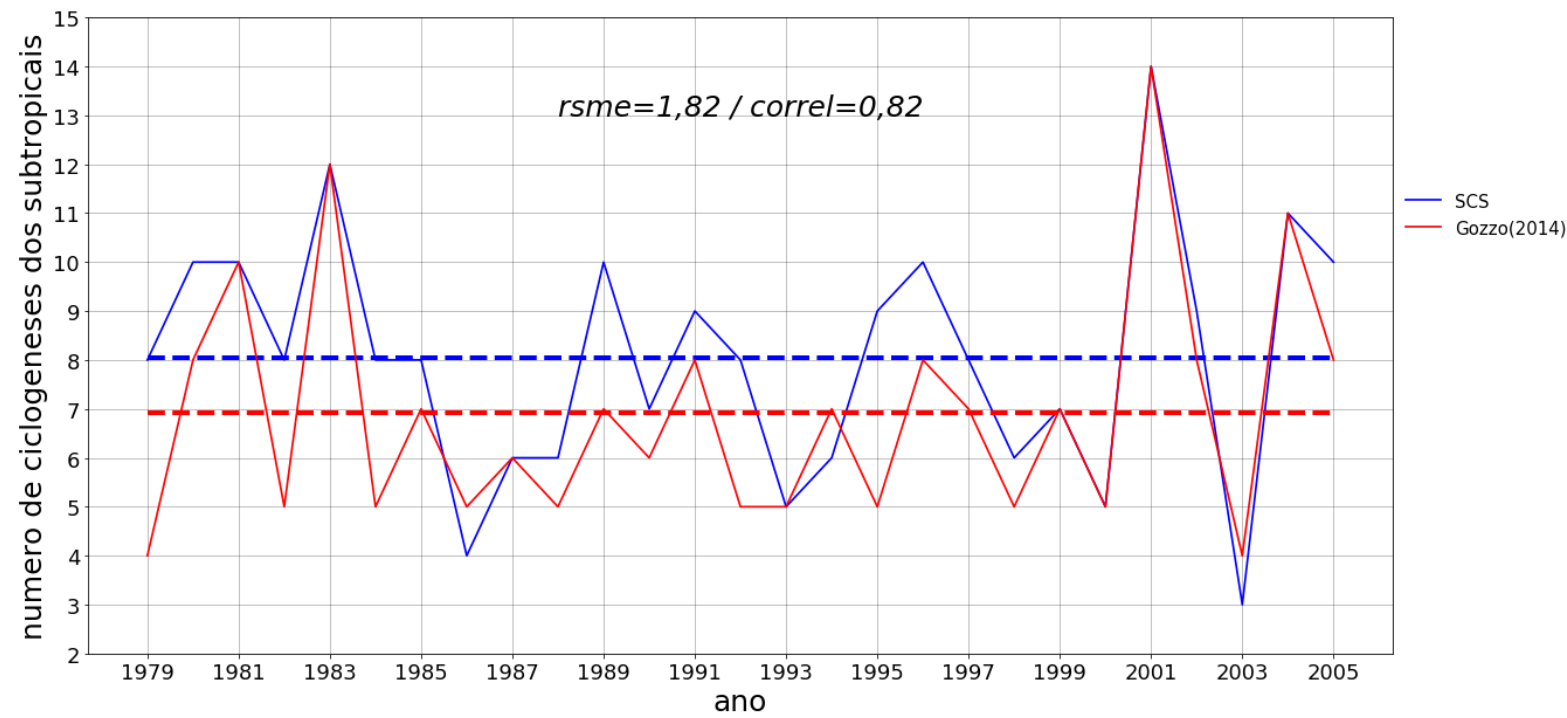

Figura 5.1.4 - Série temporal do número anual (linhas cheias) e valor médio anual (linhas tracejadas) de ciclones subtropicais obtidos por Gozzo (2014; vermelho) e SCS (azul) no período 1979-2005 obtida da reanálise ERA-Interim.

A partir destes resultados, conclui-se que a aplicação do SCS, utilizando-se dos parâmetros do CPS, é um método robusto para encontrar automaticamente os ciclones subtropicais nos modelos globais e regionais.

\section{b) Parâmetros do CPS: $\mathrm{V}_{\mathrm{T}}^{\mathrm{U}}, \mathrm{V}_{\mathrm{T}}^{\mathrm{L}}$ e B}

Os ciclones subtropicais são obtidos através do conjunto de critérios descritos na metodologia, em que os limiares dos parâmetros do CPS seguem os de Gozzo (2014). Para fins de validação, são apresentados os campos espaciais dos parâmetros $\mathrm{B}, \mathrm{V}_{\mathrm{T}}^{\mathrm{U}}$ e $\mathrm{V}_{\mathrm{T}}{ }^{\mathrm{L}}$ para todas as posições ao longo do ciclo de vida dos ciclones subtropicais obtidos por Gozzo (2014) e pelo SCS.

Próximo à faixa costeira, desde o estado do Espírito Santo até o Uruguai, os valores do parâmetro B não ultrapassam 5 m, indicando simetria térmica (Figuras 5.1.5a-b; Hart, 2003), e à medida que o ciclone subtropical se movimenta para sudeste (centro do Oceano Atlântico Sul) este parâmetro vai aumentando de valor. Em latitudes a sul de $40^{\circ} \mathrm{S}$, observam-se valores acima de 25 m, o que indica probabilidade de transição de subtropical para extratropical nestas regiões. Valores mais altos do parâmetro B indicam assimetria térmica ou ciclone com atividade frontal associada (Hart, 2003), com advecção quente à leste do sistema no Hemisfério Sul. De forma geral, os 
ciclones subtropicais detectados pelo SCS representam o padrão da distribuição espacial do parâmetro B seguindo Gozzo (2014), posicionando valores menores que 5 m próximo à região costeira e acima de $25 \mathrm{~m}$ em latitudes mais altas (acima de $40^{\circ} \mathrm{S}$ ).

$\mathrm{O}$ parâmetro $\mathrm{V}_{\mathrm{T}}^{\mathrm{L}}$ mostra valores acima de $10 \mathrm{~m}^{3} / \mathrm{kg}$ próximo à costa e uma diminuição (ou aumento em módulo) à medida que se afasta da região costeira do Brasil, chegando a valores negativos abaixo de $-100 \mathrm{~m}^{3} / \mathrm{kg}$ (Figuras $5.1 .5 \mathrm{c}-\mathrm{d}$ ). O limiar utilizado neste trabalho $\left(\mathrm{V}_{\mathrm{T}}^{\mathrm{L}} \geq-50\right)$ é observado em uma extensa área sobre o oceano Atlântico Sul, isto é, onde os ciclones subtropicais se mantêm com núcleo quente em baixos níveis. A faixa a sul de $35^{\circ} \mathrm{S}$ indica que esta é uma provável região de transição de ciclones subtropicais para extratropicais. Em geral, os padrões espaciais de $\mathrm{V}_{\mathrm{T}}^{\mathrm{L}}$ são capturados pelo SCS quando comparado com Gozzo (2014). A formação dos ciclones subtropicais sobre o Oceano Atlântico Sul está muitas vezes associada a uma situação de bloqueio localizado ao sul da ciclogênese (Gozzo et al., 2014; Evans e Braun, 2012; Dias Pinto et al., 2011; da Rocha et al., 2018). A permanência desta configuração promove uma modificação na estrutura vertical do sistema de baixa pressão, onde a advecção de umidade desde a região tropical do Oceano Atlântico Sul até a costa sudeste do Brasil, somando-se à umidade presente na região, promove o aumento positivo no $\mathrm{V}_{\mathrm{T}}^{\mathrm{L}}$ associado ao ciclone (Gozzo et al., 2017).

$\mathrm{O} \mathrm{V}_{\mathrm{T}}{ }_{\mathrm{U}}^{\mathrm{U}}$ apresenta valores menores que $-20 \mathrm{~m}^{3} / \mathrm{kg}$ em praticamente todo o Oceano Atlântico Sul (Figuras 5.1.5e-f; limiar $\mathrm{V}_{\mathrm{T}}^{\mathrm{U}}<-10$ para ciclones subtropicais); valores no intervalo -20 até -80 $\mathrm{m} / \mathrm{s}$ se concentram em sua maioria próximo ao núcleo de ciclogênese dos subtropicais (Figura 5.1.1) e abaixo de $-155 \mathrm{~m}^{3} / \mathrm{kg}$ em latitudes mais altas $\left(\sim 40^{\circ} \mathrm{S}\right)$. Em praticamente todo o Atlântico Sul os valores de $\mathrm{V}_{\mathrm{T}}^{\mathrm{U}}$ estão dentro do limiar para classificação como ciclones subtropicais, desta forma, apontando a manutenção do núcleo frio em altos níveis ao longo do ciclo de vida.

Em resumo, o SCS consegue capturar as principais características de distribuição dos parâmetros do CPS obtidos por Gozzo (2014). A distribuição dos parâmetros do CPS mostram que as ciclogêneses subtropicais puras ocorrem próximo à costa sudeste do Brasil e, à medida que se deslocam para sudeste, vão perdendo as características subtropicais iniciais, fazendo transição para ciclones com características frontais, onde valores de B são maiores que 25 m. 

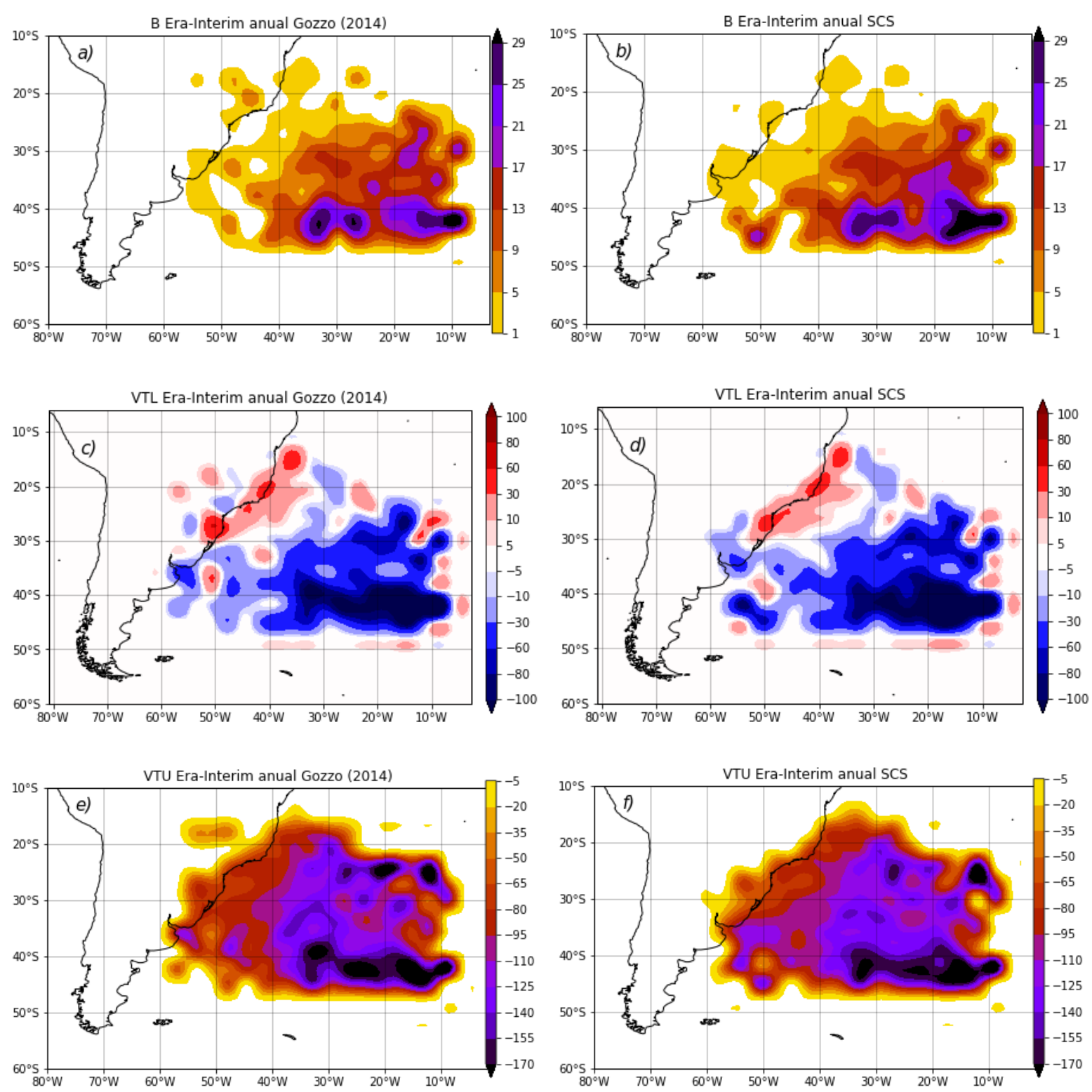

Figura 5.1.5 - Campos espaciais médios anuais no período 1979-2005, obtidos da reanálise ERA-Interim, dos parâmetros a,b) $\mathrm{B}(\mathrm{m}), \mathrm{c}, \mathrm{d}) \mathrm{V}_{\mathrm{T}}^{\mathrm{L}}\left(\mathrm{m}^{3} / \mathrm{kg}\right)$ e e,f) $\mathrm{V}_{\mathrm{T}}{ }_{\mathrm{U}}\left(\mathrm{m}^{3} / \mathrm{kg}\right)$ associados às trajetórias dos ciclones subtropicais obtidas por a,c,e) Gozzo (2014) e b,d,f) SCS (azul).

\subsection{Simulação de ciclones subtropicais no clima presente (1979-2005)}

Nesta seção, serão discutidas as características dos ciclones subtropicais em termos de reanálise e conjuntos das simulações dos modelos globais (GCMs) e regionais (RegCM4s) para o período histórico (1979-2005). Destaca-se que o conjunto dos RegCM4s possui um membro a 
menos (RegCM4-bats) do que o utilizado para validar todos os ciclones. Na Figura 5.2.1 pode-se observar que tanto os GCMs como o RegCM4s reproduzem as principais aspectos da densidade de ciclones subtropicais mostrados na reanálise , ou seja, o máximo de densidade muito próximo da costa entre São Paulo e Rio de Janeiro, além de dois máximos secundários no leste da região sul e da Bahia. No entanto, o principal máximo ciclogenético simulado pelo RegCM4s (Figura 5.2.1c) possui intensidade e localização mais próximas da reanálise (Figura 5.2.1a) do que no GCMs (Figura 5.2.1b). Essa melhoria no padrão de densidade ciclogenética no RegCM4s é também encontrada para cada membro individual (Figura A.2 - Apêndice).

O pequeno prolongamento para nordeste da atividade ciclogenética, encontrada tanto nos GCMs e ligeiramente mais intensa no RegCM4 (Figuras 5.2.1b,c), resulta principalmente do modelo MPI-ES (Figura A.2b,c - Apêndice). Isto está associado ao erro sistemático da família de GCMs-MPI, que simulam a TSM mais quente no Atlântico tropical sul, com consequente deslocamento para norte da atividade convectiva e excessiva precipitação no setor centro-leste da América do Sul e Atlântico adjacente (Reboita et al., 2014). Este erro sistemático na TSM provavelmente favorece a maior ocorrência de ciclones subtropicais deslocados para norte da região esperada no par de simulações GCM-RegCM4-MPI-ES (Figuras A.2b,c - Apêndice).

Ao considerar todos os eventos, as médias anuais (topo direito da Figura 5.2.1) de ciclogêneses subtropicais nos RegCM4s e GCMs são muito próximas e ligeiramente menores do que na reanálise ( -10\%). Por outro lado, a variabilidade interanual, medida pelo desvio padrão, é ligeiramente maior $(\sim 3,0)$ nas simulações do que na reanálise $(2,4)$.
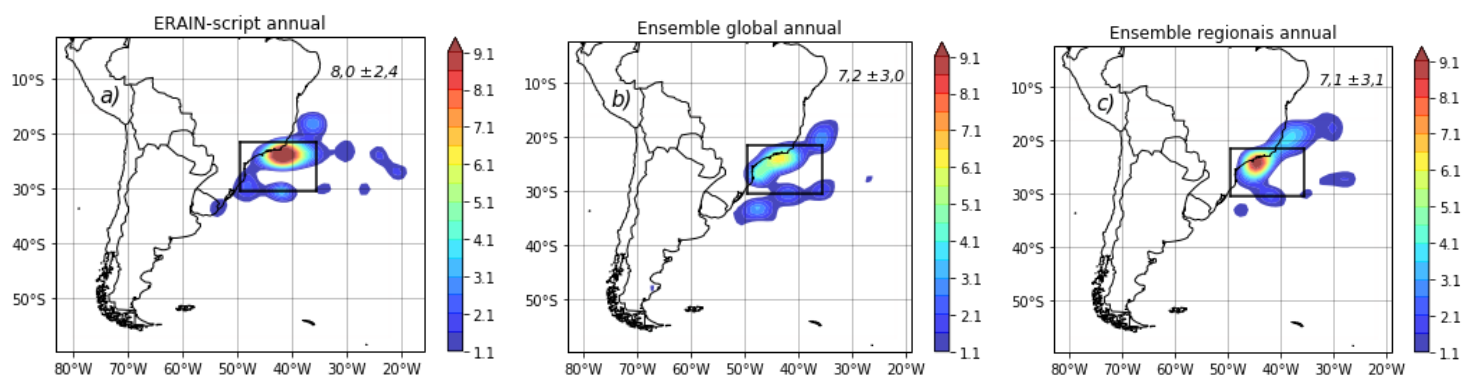

Figura 5.2.1 - Densidade média anual de ciclogêneses subtropicais no período 1979-2005 obtidas em a) reanálise ERA-Interim, b) GCMs e c) RegCM4s. Os valores no canto superior direito indicam a média anual e o respectivo desvio padrão de ciclogêneses subtropicais. A unidade é ciclone por área $\left(\mathrm{km}^{2}\right) \times 10^{6}$ por ano. 
Nas densidades de trajetória (Figura 5.2.2a-c) os GCMs e RegCM4s simulam as características de movimentação dos ciclones subtropicais, com maior permanência próximo à costa dos estados do Rio de Janeiro e São Paulo, em comparação com a reanálise da Era-Interim. Na reanálise, observa-se a posição preferencial próximo à costa sudeste do Brasil, com densidade de trajetória ultrapassando o limiar de 46,1 ciclones por área/ano (Figura 5.2.2a). Comparando com a reanálise, os GCMs (Figura 5.2.2b) subestimam este núcleo de densidade de trajetória e os RegCM4s (Figura 5.2.2c) mostram uma melhora na simulação deste núcleo. É importante notar que a leste de $20^{\circ} \mathrm{W}$ não são observadas densidades de trajetória de ciclones nos GCMs e RegCM4s (Figuras 5.2.2b,c). De forma geral, as características de distribuição de trajetória simuladas são muito similares às observadas, exceto para a região próximo à costa do Espírito Santo e sul da Bahia. Nessa área, a densidade de trajetória supera o limiar de 26,1 ciclones por área/ano nos GCMs e RegCM4s (Figuras 5.2.2b,c), o que estaria associado à superestimação da TSM no Atlântico tropical Sul no MPI-ES, como descrito anteriormente.
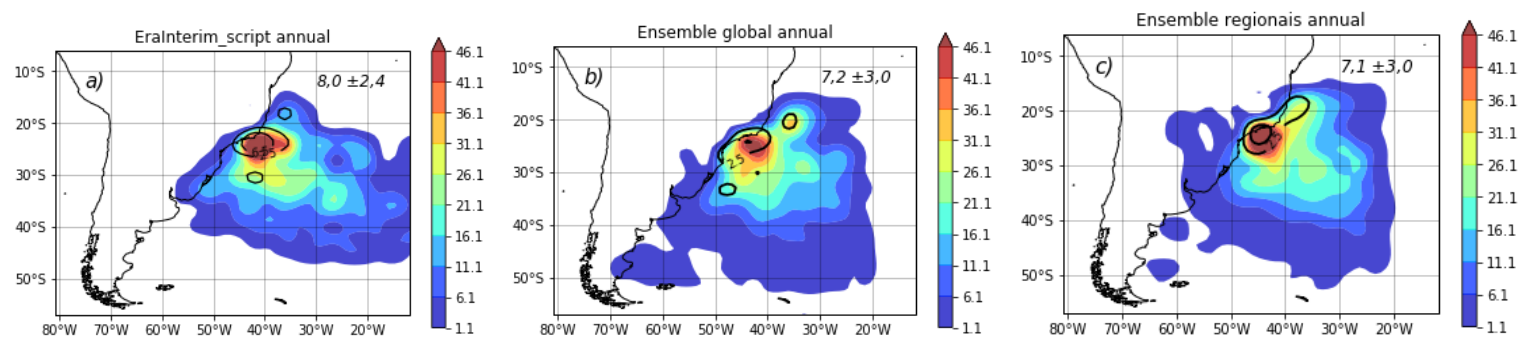

Figura 5.2.2 - Densidade média anual de trajetória (sombreado) e gênese (linhas pretas, valores de 2,5 e 6,5) dos ciclones subtropicais para o período de 1979-2005. (a) ERA-Interim (b) GCMs e c) RegCM4s. A unidade é ciclone por área $\left(\mathrm{km}^{2}\right)$ x $10^{6}$ por ano.

A Figura 5.2.3 apresenta os ventos médios próximos à superfície (1000 hPa) associados às ciclogêneses subtropicais da RG1 (indicada pelo retângulo na Figura 5.2.3). Observa-se uma faixa de ventos intensos, atingindo valores de até $6 \mathrm{~m} / \mathrm{s}$, desde regiões tropicais até a costa sul/sudeste do Brasil. Ou seja, no horário de formação dos ciclones subtropicais na RG1 os ventos de nordeste no leste do nordeste-sudeste do Brasil se intensificam. Gozzo et al., (2014) mostrou que existe uma fonte de umidade na região tropical do Oceano Atlântico Sul para a RG1, com escoamento de nordeste, entre $30-10^{\circ} \mathrm{S}$, semelhante ao mostrado na Figura 5.2.3. De acordo com Gozzo et al., 
(2014), a umidade proveniente de faixas tropicais sobre o Atlântico Sul é um componente importante para a formação destes sistemas.

Nos GCMs (Figura 5.2.3b) o vento médio associado às ciclogêneses subtropicais possui o mesmo padrão da reanálise, no entanto, a intensidade é subestimada em toda a faixa costeira entre o sudeste e o nordeste do Brasil. Por outro lado, a magnitude dos ventos no RegCM4s (Figura 5.2.3c) é mais próxima da reanálise (Figura 5.2.3a) agregando assim valor quando comparado aos GCMs. Esta melhora na representação do padrão e intensidade dos ventos associados aos ciclones subtropicais é notada individualmente em cada membro do RegCMs (Figura A.6 - Apêndice). Mais ao sul do domínio, os ventos de oeste e noroeste sobre e a leste do sul da Argentina são mais intensos o RegCM4s do que no GCMs e reanálise (Figura 5.2.3).
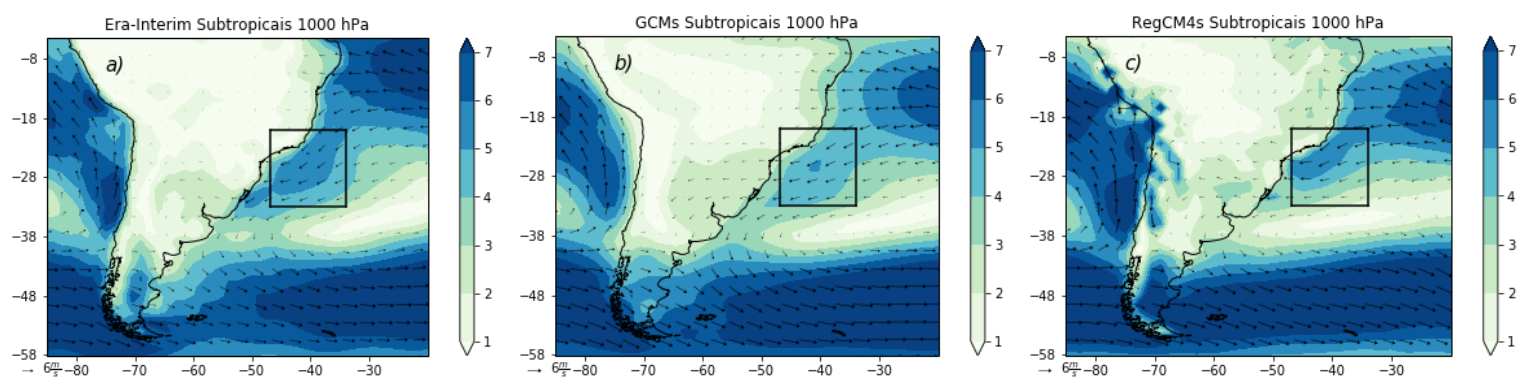

Figura 5.2.3 - Vento médio (vetores e magnitude em sombreado; m/s) em $1000 \mathrm{hPa}$ associado às ciclogêneses subtropicais para o período 1979-2005: a) reanálise ERA-Interim, b) GCMs e c) RegCM4s. O retângulo preto indica a região de gênese dos ciclones subtropicais.

Quanto aos ventos em altos níveis (300 hPa) associados à ciclogênese subtropical, próximo à área de formação não é notada a presença de corrente de jato nem na reanálise e nem nos GCMs e RegCM4s (Figura 5.2.4). Corrente acima da região de ciclogênese subtropical ( 50W), no entanto, observa-se a presença de um cavado no campo da reanálise (Figura 5.2.4a), menos evidente nos GCMs e RegCM4s (Figuras 5.2.4b,c). De forma geral, o jato em altos níveis posiciona-se ao sul e distante da região de formação dos ciclones subtropicais (Figura 5.2.4), concordando com a climatologia de Gozzo (2014), que indica fraca atuação dos jatos de altos níveis na formação sistemas subtropicais. As simulações, superestimam a magnitude desse jato em comparação com a reanálise da Era-Interim (Figura 5.2.4a), simulando um núcleo mais intenso e 
com velocidades maiores nas bordas do domínio entre a banda latitudinal $40^{\circ} \mathrm{S}-56^{\circ} \mathrm{S}$ (Figuras 5.2.4b,c). Para esse jato em particular, a superestimativa é maior nos RegCMs do que nos GCMs.
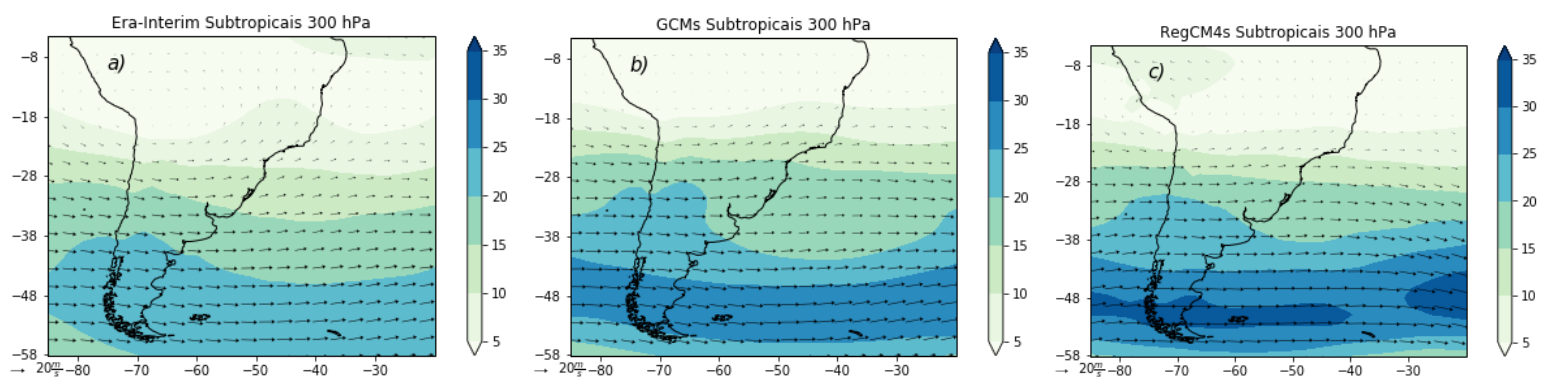

Figura 5.2.4 - Vento médio (vetores e magnitude em sombreado; m/s) em $300 \mathrm{hPa}$ associado às ciclogêneses subtropicais para o período 1979-2005: a) reanálise ERA-Interim, b) GCMs e c) RegCM4s.

\subsection{Tendências futuras dos ciclones subtropicais}

As mudanças na distribuição espacial dos ciclones subtropicais foram avaliadas considerando a diferença entre dois períodos no futuro (futuro próximo entre 2020-2050 e distante entre 2020-2099) e presente (1979-2005) nos conjuntos de projeções para o RCP8.5.

A Figura 5.3.1 apresenta a diferença entre o futuro próximo e o presente para a densidade de trajetória dos ciclones subtropicais. Para o futuro próximo, as projeções indicam um decréscimo de trajetórias de ciclones nos GCMs e RegCM4s próximo à costa dos estados de São Paulo, Rio de Janeiro e oceano adjacente (Figura 5.3.1a,b), e um aumento nas imediações da costa do estado do Espírito Santo nos GCMs (Figura 5.3.1a). Nas vizinhanças da costa sudeste do Brasil a tendência de redução na densidade de trajetórias é maior no RegCMs do que no GCMs.

Tanto nos RegCM4s e GCMs, no futuro distante (Figura 5.3.1c,d), o cenário é principalmente de intensa diminuição de atividade de trajetórias de ciclones subtropicais próximo à costa dos estados de São Paulo e Rio de Janeiro, exceto próximo das costas dos estados do Espírito Santo e Bahia, onde os GCMs (Figura 5.3.1c) continuam apresentando um aumento na atividade dos subtropicais. Nessa mesma área, os RegCM4s projetam um forte decréscimo na densidade de trajetória de ciclones subtropicais, enquanto mais ao sul, entre o Rio Grande do Sul e o Uruguai, 
existe tendência mais acentuada de aumento da atividade de trajetórias de ciclones subtropicais (Figura 5.3.1d). Para o futuro distante, próximo da costa sudeste, onde existe tendência mais acentuada de decréscimo futuro de trajetória ciclones subtropicais, o padrão espacial assemelha-se ao de todos os ciclones da RG1 (Figuras 4.2.1c-d). Essa característica é notada tanto nos GCMs como nos RegCM4s e indica que esse decréscimo no futuro distante no total de trajetórias de ciclones impacta as de subtropicais. Uma observação importante é que as escala de tendência na Figura 4.2.1 ( \pm 24 ciclones por $\mathrm{km}^{2} \times 10^{6}$ por ano) é diferente da Figura 5.3 .1 ( \pm 12 ciclones por $\mathrm{km}^{2} \times 10^{6}$ por ano). No futuro próximo, as semelhanças entre os padrões espaciais de tendência de trajetória de todos os ciclones e dos subtropicais são maiores para os RegCM4s do que GCMs (Figuras 4.2.1a-b e 5.3.1 a-b).
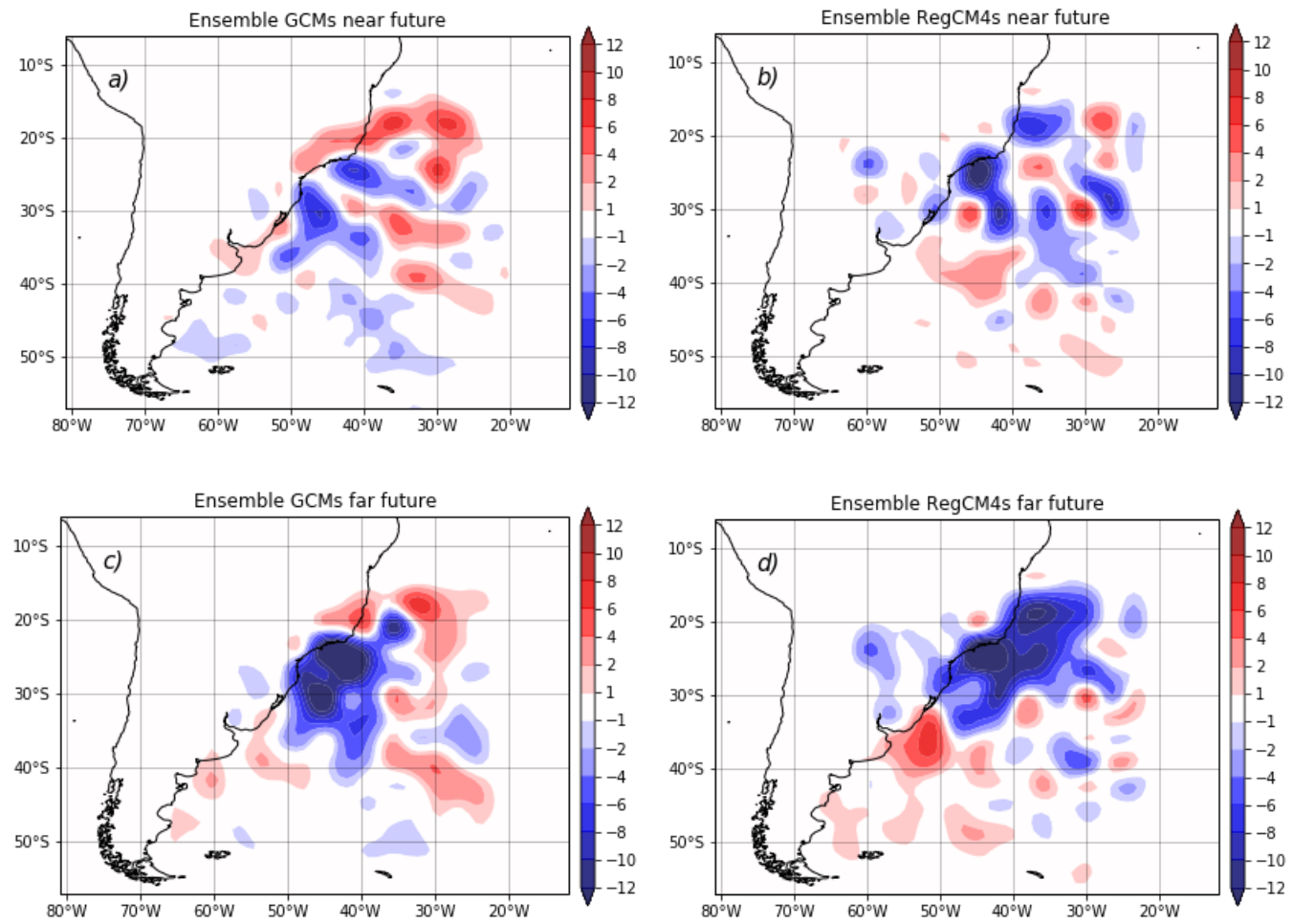

Figura 5.3.1 - Tendência da densidade de trajetória dos ciclones subtropicais para o RCP8.5 no a,b) futuro próximo (2020-2050) e c,d) futuro distante (2070-2099) nos GCMs e RegCM4s, respectivamente. A unidade é ciclone por área $\left(\mathrm{km}^{2}\right) \times 10^{6}$ por ano.

As projeções climáticas dos ventos em baixos (1000 hPa) e altos (300 hPa) níveis associados aos ciclones subtropicais na RG1 são apresentadas na Figuras 5.3.2. No futuro próximo, os ventos em 1000 hPa nas projeções dos GCMs não apresentam grandes mudanças com relação 
ao clima presente, com magnitudes de aproximadamente $\pm 1 \mathrm{~m} / \mathrm{s}$ (Figura 5.3.2a). Já os RegCM4s projetam um pequeno aumento os ventos de leste/nordeste próximo à costa das regiões sudeste e sul do Brasil e no oceano adjacente (Figura 5.3.2b). Um pequeno aumento na velocidade também é projetado para os ventos de noroeste/oeste ao sul, caracterizando assim uma anomalia anticiclônica centrada em aproximadamente $30^{\circ} \mathrm{W}-48^{\circ} \mathrm{S}$ como também encontrada para todos os ciclones da RG1 (Figura 4.2.2 a-b). No entanto, quando se considera todos os ciclones, os ventos praticamente não mudam de intensidade no futuro próximo (Figura 4.2.2 a-b), enquanto nos RegCMs mostra um pequeno aumento da velocidade do vento em $1000 \mathrm{hPa}$ no futuro próximo associado aos ciclones subtropicais (Figura 5.3.2b).

No futuro distante as projeções indicam uma significativa diminuição da velocidade do vento de nordeste em 1000 hPa desde o Atlântico Sul tropical até à costa sudeste do Brasil (Figura 5.3.2c-d), esta diminuição ocorre principalmente principalmente no conjunto RegCM4s, isto indica uma diminuição de temperatura e umidade no futuro associada ciclogênese subtropical. Esse sinal de tendência difere daquele para todos os ciclones, onde os ventos mais fortes próximo da costa sudeste se organizam e ocupam uma área maior no futuro distante comparado ao futuro próximo (Figura 4.2.2a-d). Para os ciclones subtropicais, as maiores mudanças ocorrem ao sul, na faixa latitudinal entre $48^{\circ} \mathrm{S}$ e $38^{\circ} \mathrm{S}$, onde são projetadas intensa diminuição dos ventos de oeste, em região similar das projeções para todos os ciclones da RG1 (Figura 4.2.2c-d). No entanto, essas anomalias de magnitude do vento são maiores para as trajetórias subtropicais do que para todos os ciclones da RG1. 

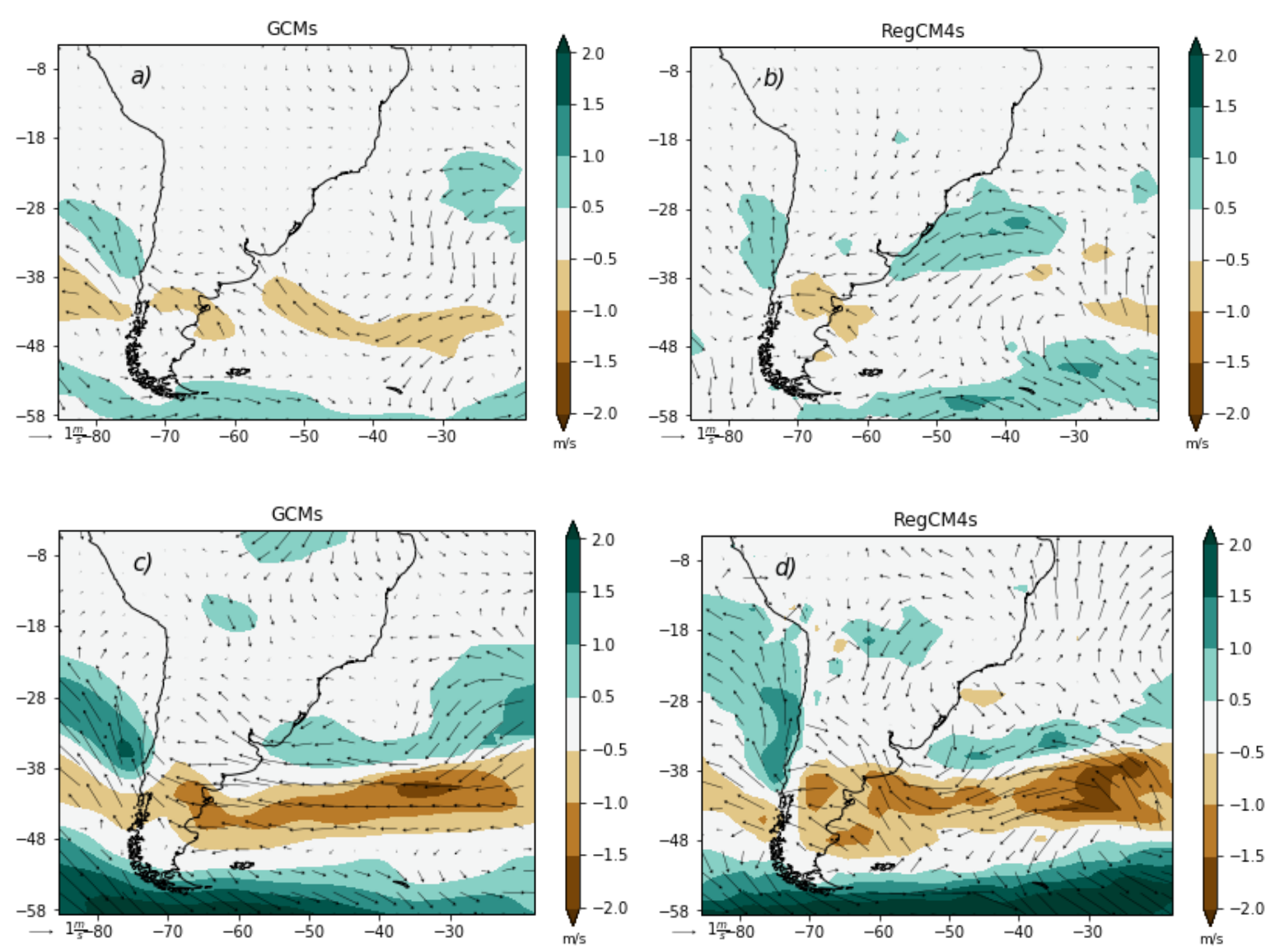

Figura 5.3.2 - Composições da tendência dos ventos (vetores e magnitude em sombreado; m/s) em $1000 \mathrm{hPa}$ associados às ciclogêneses subtropicais para o RCP8.5 no a,b) futuro próximo (2020-2050) e c,d) futuro distante (2070-2099) nos GCMs e RegCM4s, respectivamente.

Em altos níveis (300 hPa), os ventos nos GCMs mostram uma tendência de aumento sobre e ao sul da região de formação dos ciclones subtropicais no futuro próximo (Figura 5.3.3a), enquanto que nos RegCM4s o aumento situa-se mais ao norte (Figura 5.3.3b). Esse aumento de velocidade pode aumentar o cisalhamento vertical do vento na camada superior contribuindo para diminuir ciclogêneses subtropicais. Além disso, a tendência de aumento de velocidade mais ao norte explicaria a tendência negativa de trajetórias próximo à costa da Bahia nos RegCM4s (Figura 5.3.1b). Por outro lado, nos GCMs o núcleo de tendência negativa de trajetórias subtropicais centrado em $30^{\circ} \mathrm{S}$ (Figura 5.3.1a) estaria associado ao aumento de velocidade mais ao sul (Figura 5.3.3a)

No futuro distante, os GCMs e RegCM4s projetam um aumento nos ventos de oeste em 300 hPa sobre a principal região de formação dos ciclones subtropicais, indicando aumento do 
cisalhamento vertical do vento associado às ciclogêneses subtropicais (Figura 5.3.3c,d). O padrão espacial é similar ao obtido para tendências nos ventos em 300 hPa para as ciclogêneses na RG1 (Figura 4.2.3c,d), em que as anomalias positivas variam em torno de $+3,0 \mathrm{~m} / \mathrm{s}$, similares às do futuro distante na ciclogênese subtropical (Figuras 5.3.3b,c). Assim como ocorreu para 1000 hPa, projeta-se maior enfraquecimento dos ventos de oeste em $300 \mathrm{hPa}$ no cinturão $38-48^{\circ} \mathrm{S}$ associados às ciclogêneses subtropicais (Figura 5.3.3c,d) do que para todos os ciclones da RG1 (Figuras 4.2.3c,d).
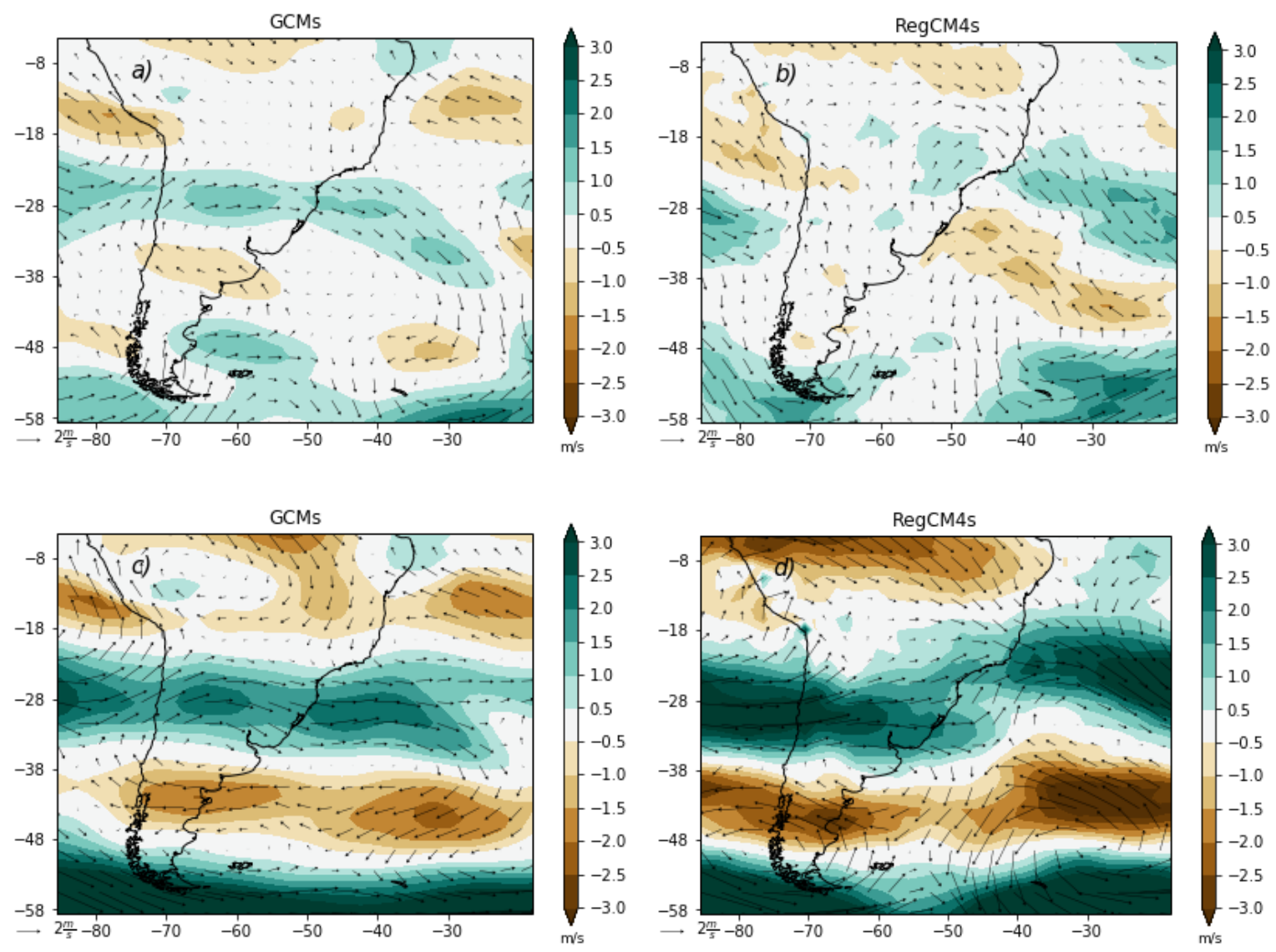

Figura 5.3.3 - Composições da tendência dos ventos (vetores e magnitude em sombreado; m/s) em $300 \mathrm{hPa}$ associados às ciclogêneses subtropicais para os climas a,b) futuro próximo (2020-2050) e c,d) futuro distante (2070-2099) nos GCMs e RegCM4s, respectivamente.

As distribuições espaciais indicam forte diminuição nas trajetórias dos ciclones subtropicais para o final do século (Figura 5.3.1). A Figura 5.3.4 apresenta as séries temporais do número anual de ciclogêneses subtropicais. Conforme já discutido, os GCMs e RegCM4s subestimam o número 
de ciclones subtropicais, mas os RegCM4s são um pouco mais próximos da reanálise Era-Interim. A tendência negativa na frequência de ciclones subtropicais na ERA-Interim é capturada pelas projeções dos GCMs e RegCM4s. Segundo essas projeções a tendência negativa se manterá ao longo do século (Figura 5.3.4). Na região de máxima velocidade do vento (indicado na Figura 5.2.3), os RegCM4s e GCMs superestimam a velocidade média dos ventos em 1000 hPa em relação à reanálise, o que fica evidente na Figura 5.3.5. A reanálise ERA-Interim indica tendência de aumento na magnitude do vento, o que é capturado no clima presente apenas pelos GCMs. Esses projetam tendência de aumento da velocidade do vento nessa área até fim do século, enquanto que nos RegCM4s os ventos praticamente não mudam de intensidade (Figura 5.3.5). Assim, como ocorreu para todos os ciclones, para os subtropicais a diminuição na frequência anual de sistemas com a tendência de aumento da velocidade em 1000 hPa nos GCMs (ou manutenção nos RegCM4s) indicaria sistemas mais intensos no futuro.

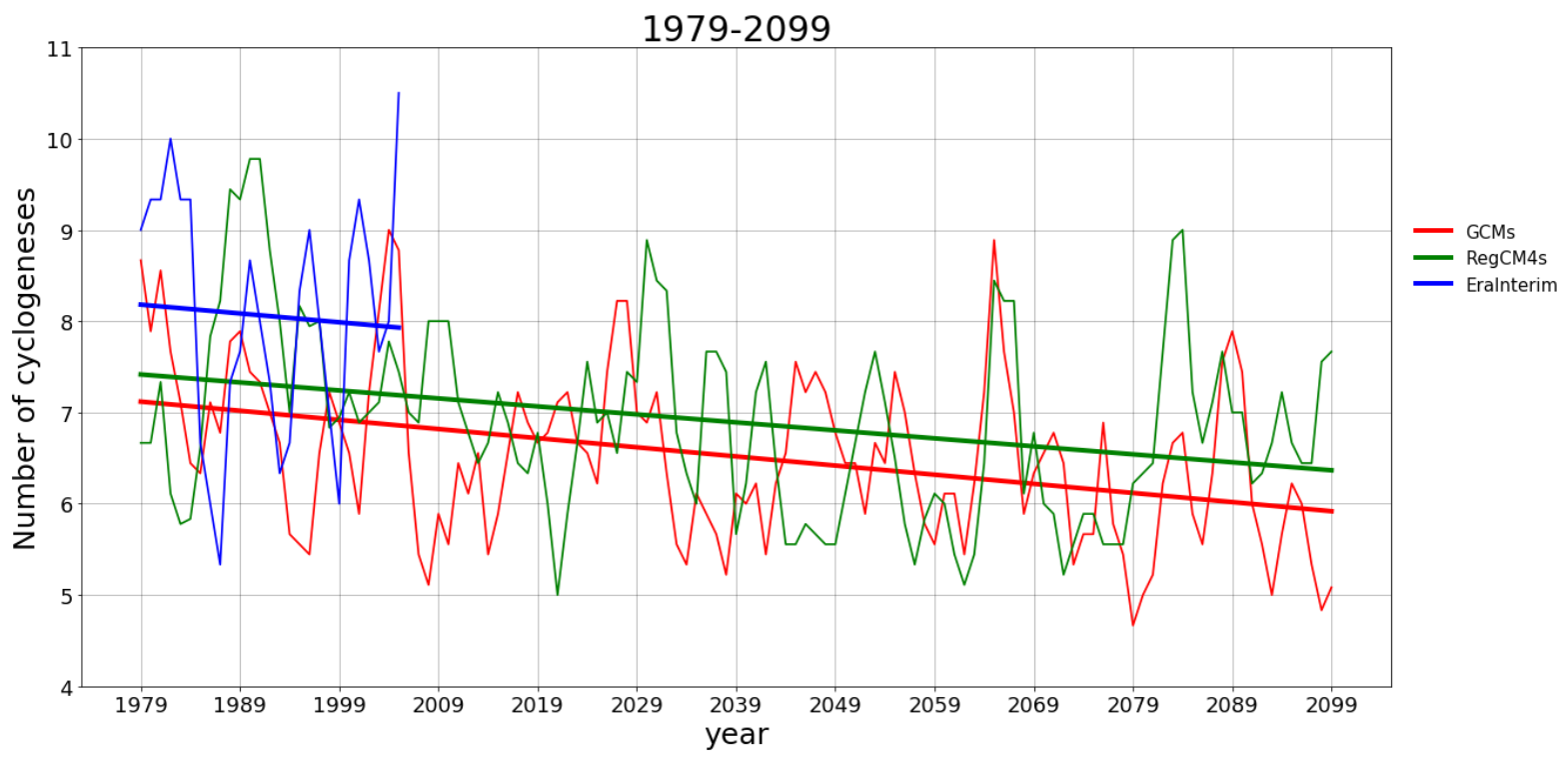

Figura 5.3.4 - Série temporal da frequência absoluta anual, juntamente com a reta de tendência, de ciclogêneses subtropicais nos GCMs (linha vermelha), RegCM4s (linha verde) para o período 1979-2099 e reanálise ERA-Interim (linha azul) entre 1979-2005. 


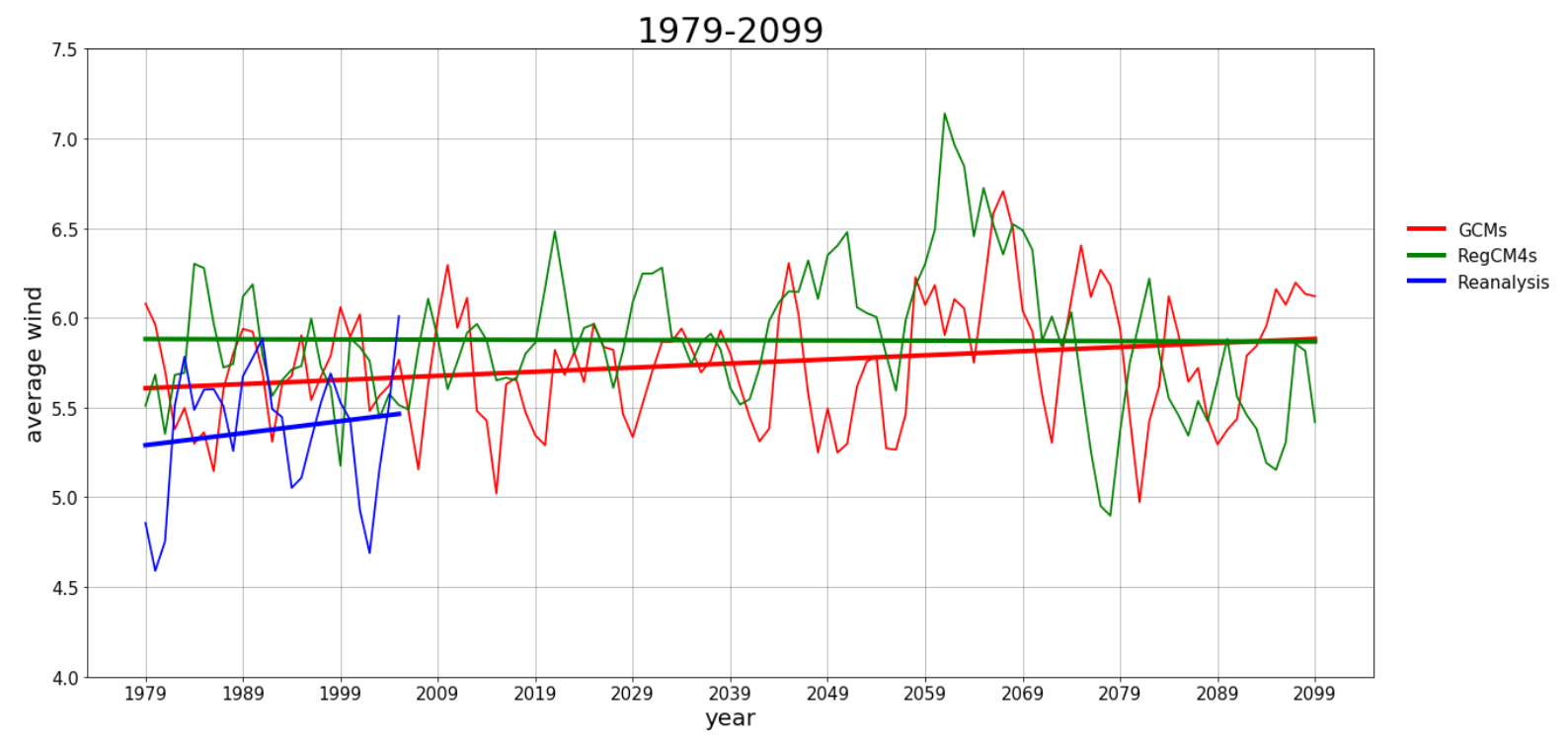

Figura 5.3.5 - Série temporal da velocidade média anual (m/s) em $1000 \mathrm{hPa}$ associada às ciclogêneses subtropicais nos GCMs (linha vermelha), RegCM4s (linha verde) para o período 1979-2099 e reanálise ERA-Interim (linha azul) entre 1979-2005. As médias foram calculadas na região indicada na Figura 5.2.3 (retângulo preto).

A Tabela 5.3.1 sintetiza e permite comparar tendência de ciclones na RG1 e ciclones subtropicais nos períodos futuros próximo e distante. Em termos percentuais no futuro próximo: (a) a tendência de decréscimo na frequência anual de todos os ciclones na RG1 ( -4,0\%) e de subtropicais ( -8.5\%) é similar entre os GCMs e RCMs; (b) a tendência negativa nas projeções é sempre maior para os subtropicais do que para todos os ciclones na RG1; (c) o teste t não indica significância estatística ao nível de 90\% para essas tendências. Para o futuro distante, projeta-se maior decréscimo na frequência anual, tanto de todos os ciclones na RG1 como de subtropicais, nos GCMs do que nos RegCM4s, sendo mais intenso e estatisticamente significativas ao nível de 90\% apenas nos GCMs. 
Tabela 5.3.1 - Número médio anual, com respectivo desvio padrão, e tendência relativa (\%) de ciclones totais e de subtropicais no período histórico (1979-2005), futuro próximo (2020-2050) e futuro distante (2070-2099) na RG1. As tendências estatisticamente significativas ao nível de 90\% confiança estão em negrito.

\begin{tabular}{c|c|c|c|c|}
\hline \multirow{2}{*}{} & \multicolumn{2}{|c|}{ Ciclones totais } & \multicolumn{2}{c|}{ Subtropicais } \\
\cline { 2 - 5 } & GCMs & RegCM4s & GCMs & RegCM4s \\
\hline Histórico & $26,6 \pm 4.6$ & $34,4 \pm 6,6$ & $7,2 \pm 3,0$ & $7,1 \pm 3,0$ \\
$1979-2005$ & & & & \\
\hline Futuro próximo & $25,4 \pm 4,4$ & $33,0 \pm 5,3$ & $6,6 \pm 2,4$ & $6,6 \pm 2,6$ \\
2020-2050 & $-4,5 \%$ & $-4,0 \%$ & $-8,3 \%$ & $-8.5 \%$ \\
\hline Futuro distante & $\mathbf{2 3 , 5 \pm \mathbf { 5 , 0 }}$ & $32,2 \pm 5,3$ & $\mathbf{6 , 0} \pm \mathbf{2 , 4}$ & $6,6 \pm 2,5$ \\
2070-2099 & $-\mathbf{1 1 , 7 \%}$ & $-6,4 \%$ & $\mathbf{- 1 6 , 6 \%}$ & $-8,5 \%$ \\
& & & & \\
\hline
\end{tabular}

\subsection{Estrutura dos ciclones subtropicais baseada nos parâmetros CPS}

Os valores dos parâmetros $\mathrm{B}, \mathrm{V}_{\mathrm{T}}^{\mathrm{U}}$ e $\mathrm{V}_{\mathrm{T}}^{\mathrm{L}}$ do CPS apresentados neste subcapítulo são obtidos após a classificação dos ciclones subtropicais utilizando o SCS e serão analisados nos conjuntos dos GCMs e RegCM4s e comparados com a reanálise da ERA-Interim. Existe um esforço para entender os diversos tipos de ciclones atuando em várias bacias do globo. A separação dos tipos de ciclones simulados por modelos globais e regionais permite avaliar a habilidade dos mesmos em simular os diferentes tipos para permitir entender suas atuações em cenários futuros (Cavicchia et al., 2020; Cavicchia, 2019). Neste sentido, as análises a seguir buscam entender como os RegCM4s e GCMs simulam parâmetros do CPS associados aos ciclones subtropicais desde sua gênese.

\section{a) $\mathrm{V}_{\mathrm{T}}^{\mathrm{U}}, \mathrm{V}_{\mathrm{T}}^{\mathrm{L}}$ e B - clima presente}

As ciclogêneses subtropicais foram obtidas através dos parâmetros do CPS (Tabela 3.4.1) na reanálise e aos conjuntos GCMs e RegCM4s aplicando o SCS. Para o clima presente esses 
parâmetro estão apresentados na Figura 5.3.6. As análises concentram-se na distribuição espacial dos mesmos desde a gênese até o fim da vida dos ciclones subtropicais.

No parâmetro B os valores simulados e da reanálise não ultrapassam 5 m próximo à costa sudeste do Brasil (Figura 5.3.6a-c). Esses baixos valores do parâmetro B estão diretamente ligados às ciclogêneses dos subtropicais, por estes sistemas apresentarem simetria térmica. Em regiões adjacentes à costa sudeste do Brasil, os GCMs simulam valores acima de 5 m, B 9 m (Figura 5.3.6b), por outro lado, os RegCM4s simulam valores abaixo de $1 \mathrm{~m}$ (Figura 5.3.6c). Estes resultados indicam que os RegCM4s simulam ciclones subtropicais mais termicamente simétricos próximo à principal região de ciclogênese subtropical. À medida que os ciclones subtropicais vão se afastando da costa em direção ao sudeste do Atlântico Sul, a reanálise apresenta um aumento gradativo de $\mathrm{B}$, chegando a valores superiores a 25 m, padrão de distribuição também simulado pelos GCMs e RegCM4s. No entanto, os RegCM4s simulam sistematicamente valores menores em toda a região de movimentação dos ciclones subtropicais em comparação com a reanálise e GCMs. Isso indica que o B se mantém em média dentro do intervalo que caracteriza ciclones subtropicais nos RegCM4s em todo domínio de estudo, ou seja, não apresenta mudança do limiar para classificação como subtropical. Em geral, os conjuntos GCMs e RegCM4s simulam os padrões espaciais do parâmetro B similar ao da reanálise da ERA-Interim, com os RegCM4s subestimando os valores da reanálise.

No parâmetro $\mathrm{V}_{\mathrm{T}}{ }^{\mathrm{L}}$ observa-se valores médios, acima de $10 \mathrm{~m}^{3} / \mathrm{kg}$, nos três conjuntos de dados próximo à costa sul e sudeste do Brasil (Figura 5.3.6d-f). Em média, a ciclogênese subtropical na região costeira do Brasil ocorre com valores de $\mathrm{V}_{\mathrm{T}}{ }_{\mathrm{L}}^{\mathrm{L}}$ superiores a $10 \mathrm{~m}^{3} / \mathrm{kg}$, e este padrão é capturado pelos GCMs e RegCM4s. À medida que os ciclones subtropicais se afastam da costa, os valores de $\mathrm{V}_{\mathrm{T}}^{\mathrm{L}}$ diminuem rapidamente, chegando a ultrapassar o limiar de $-50 \mathrm{~m}^{3} / \mathrm{kg}$ na reanálise e nas simulações. Nota-se então, a extrapolação do limiar de $\mathrm{V}_{\mathrm{T}}^{\mathrm{L}}$ subtropical, principalmente em latitudes mais altas a sul de 40S nos GCMs e RegCM4s (Figura 5.3.6d-f).

As simulações apresentam padrão espacial de $\mathrm{V}_{\mathrm{T}}^{\mathrm{U}}$ similar ao da reanálise, em que valores de $\mathrm{V}_{\mathrm{T}}^{\mathrm{U}}$ abaixo de $-10 \mathrm{~m}^{3} / \mathrm{kg}$ ocorrem em praticamente em todo o domínio de análise (Figura 5.3.6g-i). Os GCMs superestimam em módulo o parâmetro $\mathrm{V}_{\mathrm{T}}^{\mathrm{U}}$ em comparação com a ERA-Interim, por outro lado, os RegCM4s o subestimam em praticamente todo o Atlântico Sul. 
Em geral, as simulações reproduzem os padrões espaciais de intensidade dos parâmetros do CPS associados aos ciclones subtropicais, apesar da subestimativa do parâmetro B e da forte superestimativa em módulo do parâmetro $\mathrm{V}_{\mathrm{T}}{ }^{\mathrm{U}}$ nos RegCM4s. Portanto, os conjuntos de simulações apresentam-se como um método robusto de avaliação de como poderá se modificar a estrutura dinâmica destes sistemas.
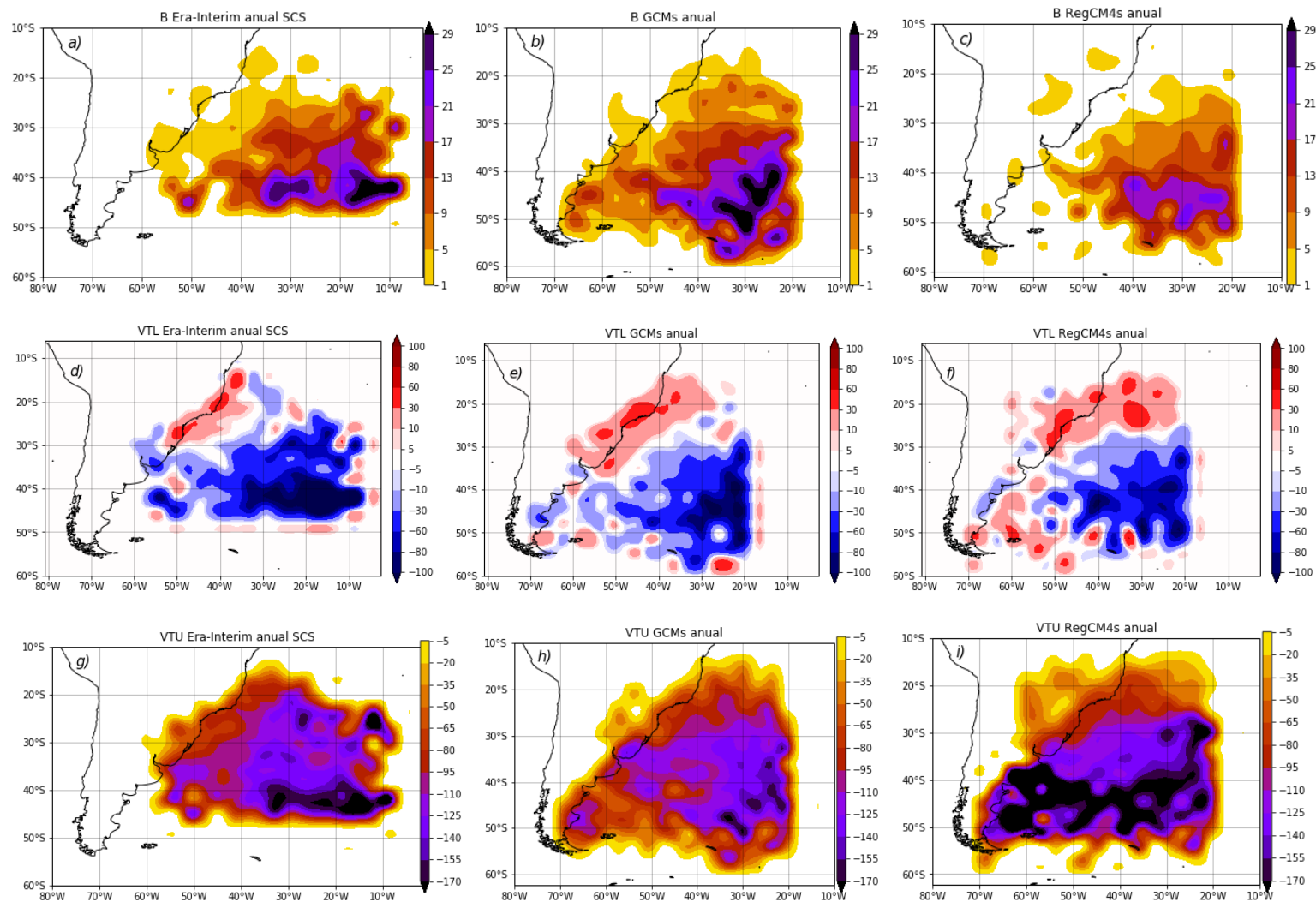

Figura 5.3.6 - Campo espacial médio anual dos parâmetros a,b,c) $B(m), d, e, f) V_{T}{ }^{L}\left(m^{3} / k g\right)$ e g,h,i) $\mathrm{V}_{\mathrm{T}}^{\mathrm{U}}\left(\mathrm{m}^{3} / \mathrm{kg}\right)$ associados às trajetórias dos ciclones subtropicais no período 1979-2005 para SCS, GCMs e RegCM4s, respectivamente.

\section{b) $\mathrm{V}_{\mathrm{T}}^{\mathrm{U}}, \mathrm{V}_{\mathrm{T}}^{\mathrm{L}} \mathrm{e} \mathrm{B}$ - tendência}

A comparação dos parâmetros do CPS simulados com os da reanálise da ERA-Interim mostra que as simulações reproduzem a distribuição espacial destes parâmetros. Neste item são apresentadas as tendências futuras destes parâmetros com o objetivo de avaliar os impactos de suas mudanças futuras na ciclogênese subtropical e quais as características destes sistemas no futuro. 
Dessa forma, nas análises de tendência do parâmetro B as anomalias negativas (positivas) significam aumento (diminuição) da simetria térmica. No parâmetro $\mathrm{V}_{\mathrm{T}}{ }^{\mathrm{L}}$ as anomalias negativas indicam redução que indicam que os ciclones subtropicais devem adquirir características frontais no futuro, já anomalias positivas indicam que estes sistemas devem ganhar características de ciclones tropicais. Em especial Hart (2003) mostra que ciclones tropicais intensos apresentam $\mathrm{V}_{\mathrm{T}}{ }_{\mathrm{L}}^{\mathrm{L}}$ em torno de $250 \mathrm{~m}^{3} / \mathrm{kg}$. No parâmetro $\mathrm{V}_{\mathrm{T}}^{\mathrm{U}}$ anomalias negativas indicam que os ciclones subtropicais tendem a adquirir características extratropicais no futuro, enquanto as anomalias positivas mostram tendência de apresentar características mais tropicais no futuro. Esta análise da tendência permite avaliar como as estruturas horizontal e vertical dos ciclones subtropicais podem ser modificadas e como estas mudanças podem impactar estes sistemas no futuro.

No futuro próximo a tendência de ciclogênese subtropicais mostra uma diminuição na formação destes sistemas (Figura 5.3.7a-b) na mesma região de maior densidade de eventos no clima presente nos GCMs e RegCM4s (Figura 5.2.1b-c). Sobre essa região (costa dos estados de São Paulo e Rio de Janeiro), as tendências futuras do parâmetro B são pequenas (menores que \pm 5 m) tanto nos GCMs como RegCM4s, indicando fraca influência na tendência de formação desses sistemas desde que B manteria-se abaixo do limiar de $25 \mathrm{~m}$. No entanto, à medida que os sistemas se afastam da região costeira, as diferenças no parâmetro B mostram tendência de aumento/diminuição ligeiramente maior (menores que $\pm 15 \mathrm{~m}$ ). Nos GCMs, em latitudes ao sul de $30^{\circ} \mathrm{S}$, projetam-se anomalias positivas, mostrando que nestas regiões os ciclones subtropicais terão maior tendência de adquirir características frontais (Figura 5.3.7a). Por outro lado, os RegCM4s indicam um comportamento oposto nessa mesma área, ou seja, de diminuição nas características frontais (Figura 5.3.7b).

Em relação ao futuro distante, projeta-se uma diminuição ainda maior na formação de sistemas subtropicais com relação ao presente e futuro próximo, tanto para os GCMs quanto para os RegCM4s, com tendência negativa se estendendo para o norte e sul da principal região ciclogenética dos subtropicais (Figura 5.3.7c-d). Nos GCMs, para o futuro distante projetam-se anomalias fracas do parâmetro B em toda a região de forte subestimativa ciclogenética. Nos RegCM4s na região de maior diminuição ciclogenética também não são se projetam fortes tendências do parâmetro B. No entanto, próximo à costa do Uruguai, o aumento de incidência de 
ciclogêneses subtropicais ocorre em conjunto com pequeno aumento no parâmetro B (inferior a 10 m) (Figura 5.3.7d). À medida que os ciclones subtropicais vão se afastando da região costeira, as tendências positivas do parâmetro B aumentam, portanto os RegCM4s indicam sistemas com características mais frontais nessa região no futuro distante.
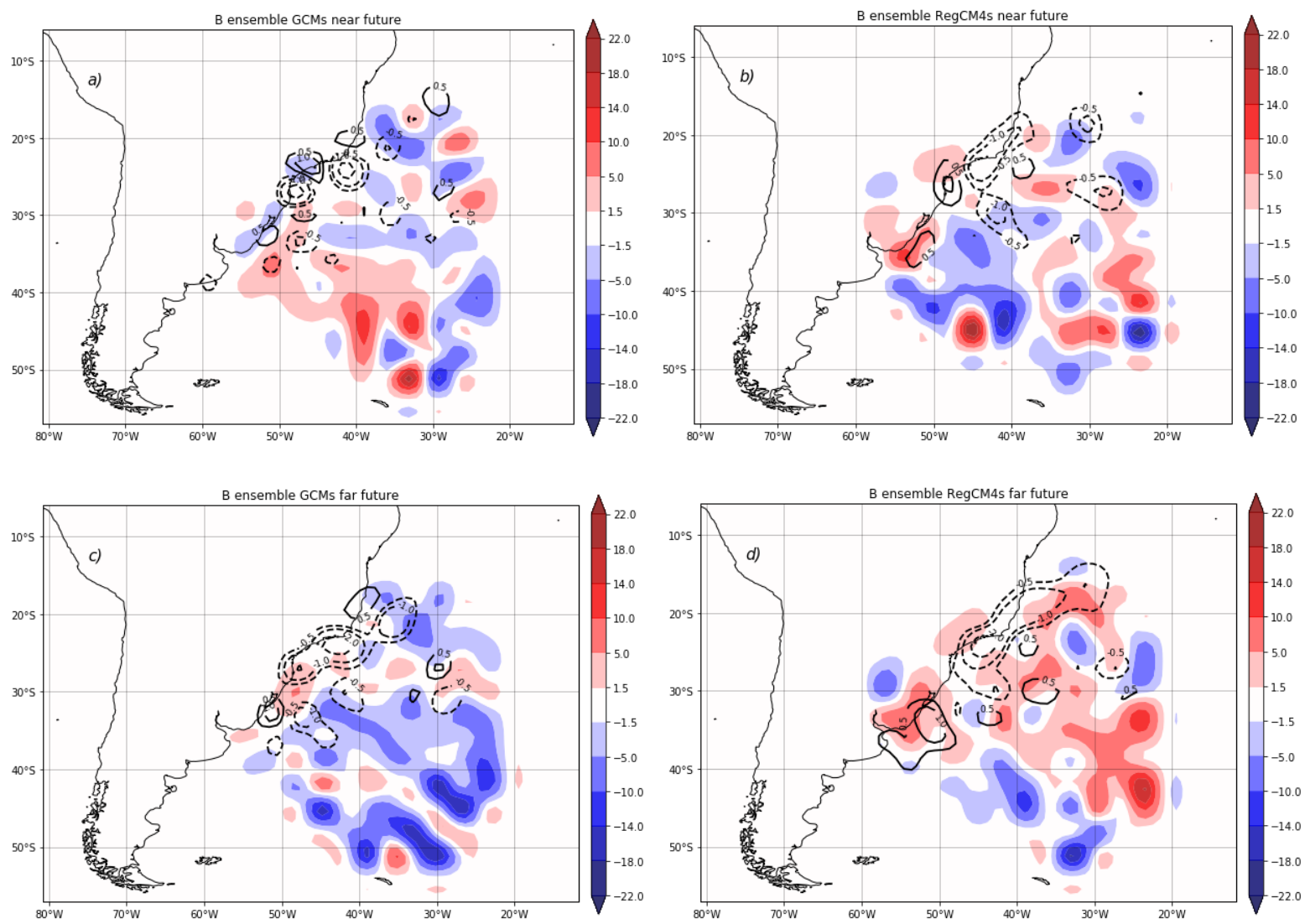

Figura 5.3.7 - Composições da tendência do parâmetro B (m; sombreado) considerando toda trajetória e da densidade ciclogenética (ciclone por área $\left(\mathrm{km}^{2}\right) \times 10^{6}$ por ano; linhas pretas cheias valores positivos e tracejadas valores negativos) dos ciclones subtropicais para o a,b) futuro próximo (2020-2050) e c,d) futuro distante (2070-2099) nos GCMs e RegCM4s. Apresentados somente valores de $\mathrm{B}$ associados à densidade de trajetórias maiores que 2 ciclone por área $\left(\mathrm{km}^{2}\right)$ $\mathrm{x} 10^{6}$ por ano..

Próximo à costa do sudeste do Brasil as tendências de $\mathrm{V}_{\mathrm{T}}{ }^{\mathrm{L}}$ são menos intensas no futuro próximo nos GCMs e RegCM4s (Figura 5.3.8a-b) e, à medida que os ciclones subtropicais se afastam, as anomalias se intensificam. No futuro distante, as anomalias de $\mathrm{V}_{\mathrm{T}}{ }^{\mathrm{L}}$ nos GCMs (Figura 5.3.8c) se intensificam em praticamente toda a trajetória dos ciclones subtropicais. Ao norte da 
região do principal núcleo ciclogenético projeta-se uma diminuição do $\mathrm{V}_{\mathrm{T}}^{\mathrm{L}}$ no futuro distante, enquanto que no centro do Atlântico Sul a tendência é positiva (Figura 5.3.8c-d). No futuro distante, os RegCM4s (Figura 5.3.8d) indicam um gradiente de anomalias de $\mathrm{V}_{\mathrm{T}}{ }_{\mathrm{L}}^{\mathrm{L}}$ mais intensas em todo o campo, com as negativas predominando em torno do núcleo ciclogenético no clima presente (Figura 5.2.1c), região que, por sua vez, apresenta uma diminuição de gênese no futuro distante (Figura 5.3.8d). Os resultados das anomalias de $\mathrm{V}_{\mathrm{T}}{ }^{\mathrm{L}}$ indicam que no futuro distante a ciclogênese subtropical poderá obter características frontais, pelo predomínio de anomalias negativas próximo à costa sudeste do Brasil. Por outro lado, a medida que os ciclones subtropicais se deslocam para sudeste tendem a adquirir um núcleo quente mais intenso.
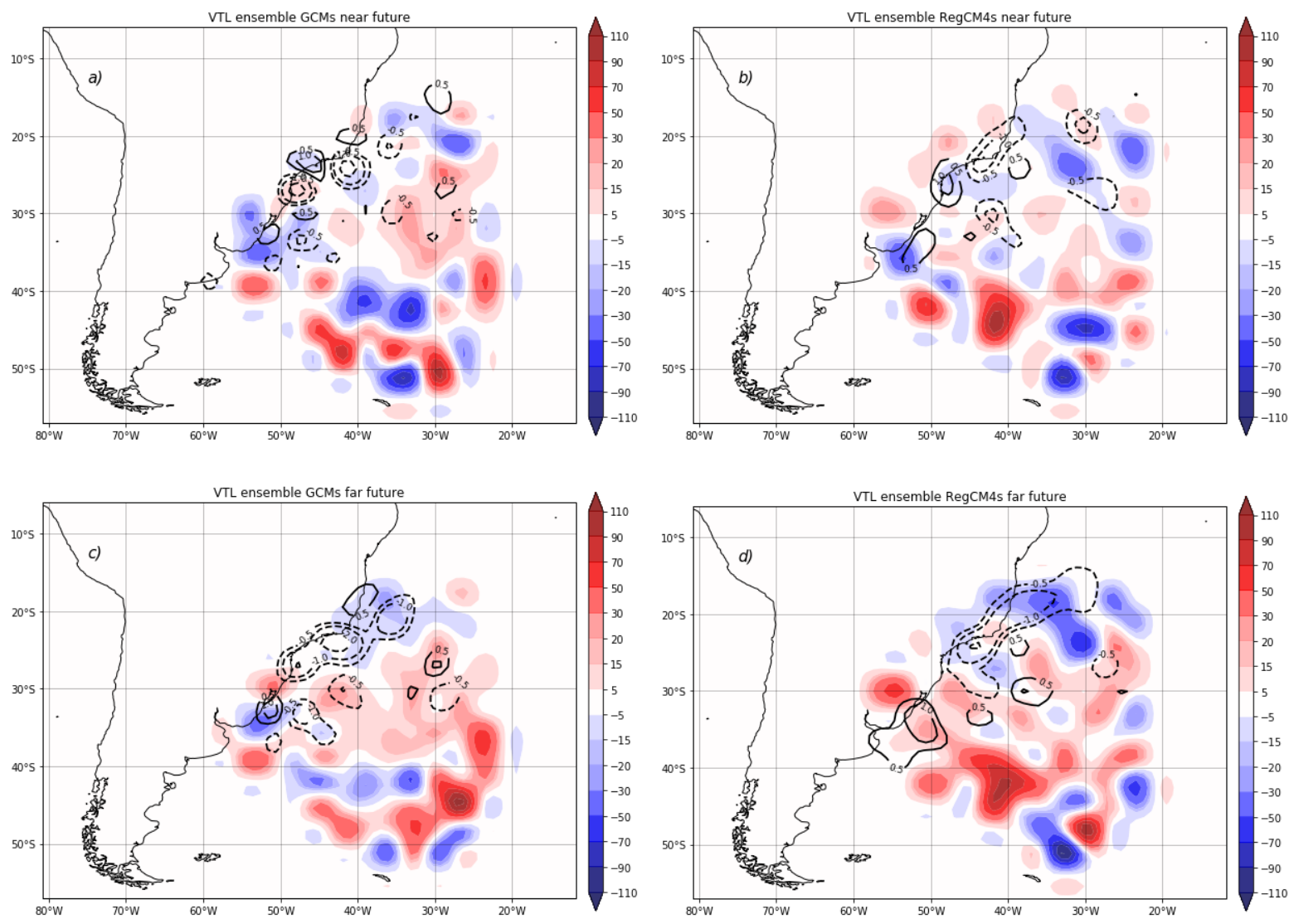

Figura 5.3.8 - Composições da tendência do parâmetro $V_{T}{ }_{T}$ (sombreado) em toda a trajetória e da densidade ciclogenética (linhas pretas cheias valores positivos e tracejadas valores negativos) associados aos ciclones subtropicais para os climas a,b) futuro próximo (2020-2050) e c,d) futuro distante (2070-2099) nos GCMs e RegCM4s, respectivamente. Apresentados somente valores de $\mathrm{V}_{\mathrm{T}}^{\mathrm{L}}$ associados à densidade de trajetórias maiores que 2 ciclone por área $\left(\mathrm{km}^{2}\right) \times 10^{6}$ por ano.. 
No futuro próximo, o $\mathrm{V}_{\mathrm{T}}^{\mathrm{U}}$ nos GCMs e RegCM4s projetam também anomalias menos intensas sobre a região do principal núcleo ciclogenético dos subtropicais (Figura 5.3.9a-b), nesta região existe um predomínio de anomalias negativas em ambos os conjuntos, indicando que próximo à costa sudeste do Brasil a ciclogênese subtropical poderá apresentar maiores características extratropicais. Esta característica mais extratropical se mantém à medida que o sistema se desloca para sudeste. No futuro distante, as projeções indicam $\mathrm{V}_{\mathrm{T}}^{\mathrm{U}}$ em ambos, GCMs e RegCMs, com padrão muito similar, mostrando um aumento das anomalias sobre a região de ciclogênese dos subtropicais (Figura 5.3.9c-d). Essa tendência indica que o decréscimo de formação dos subtropicais tem relação com a intensificação do vento em altos níveis, com consequente aumento do cisalhamento vertical do vento, no futuro distante (Figura 5.3.3c-d). Esta característica de aumento na velocidade do jato subtropical está associada às anomalias negativas de $\mathrm{V}_{\mathrm{T}}^{\mathrm{U}}$, que predominam sobre a costa sudeste do Brasil nos dois conjuntos. Os ciclones subtropicais apresentaram características mais próximas dos ciclones extratropicais em latitudes subtropicais, onde o jato subtropicais deve se intensificar no futuro (Figura 5.3.3c,d). Nos GCMs as anomalias positivas se posicionam em torno de $20^{\circ} \mathrm{S}$ e predominam em latitudes mais altas de $30^{\circ} \mathrm{S}$, indicando que nestas regiões os ciclones subtropicais devem apresentar características mais próximas das de ciclones tropicais no futuro distante. Nos RegCM4s é simulado um padrão semelhante, no entanto, características mais próximas das tropicais foram simuladas na faixa costeira que vai do Paraná até a Bahia e oceano adjacente. Isto indica que nestas regiões os ciclones subtropicais podem ter características mais próximas dos tropicais de acordo com o RegCM4s. 

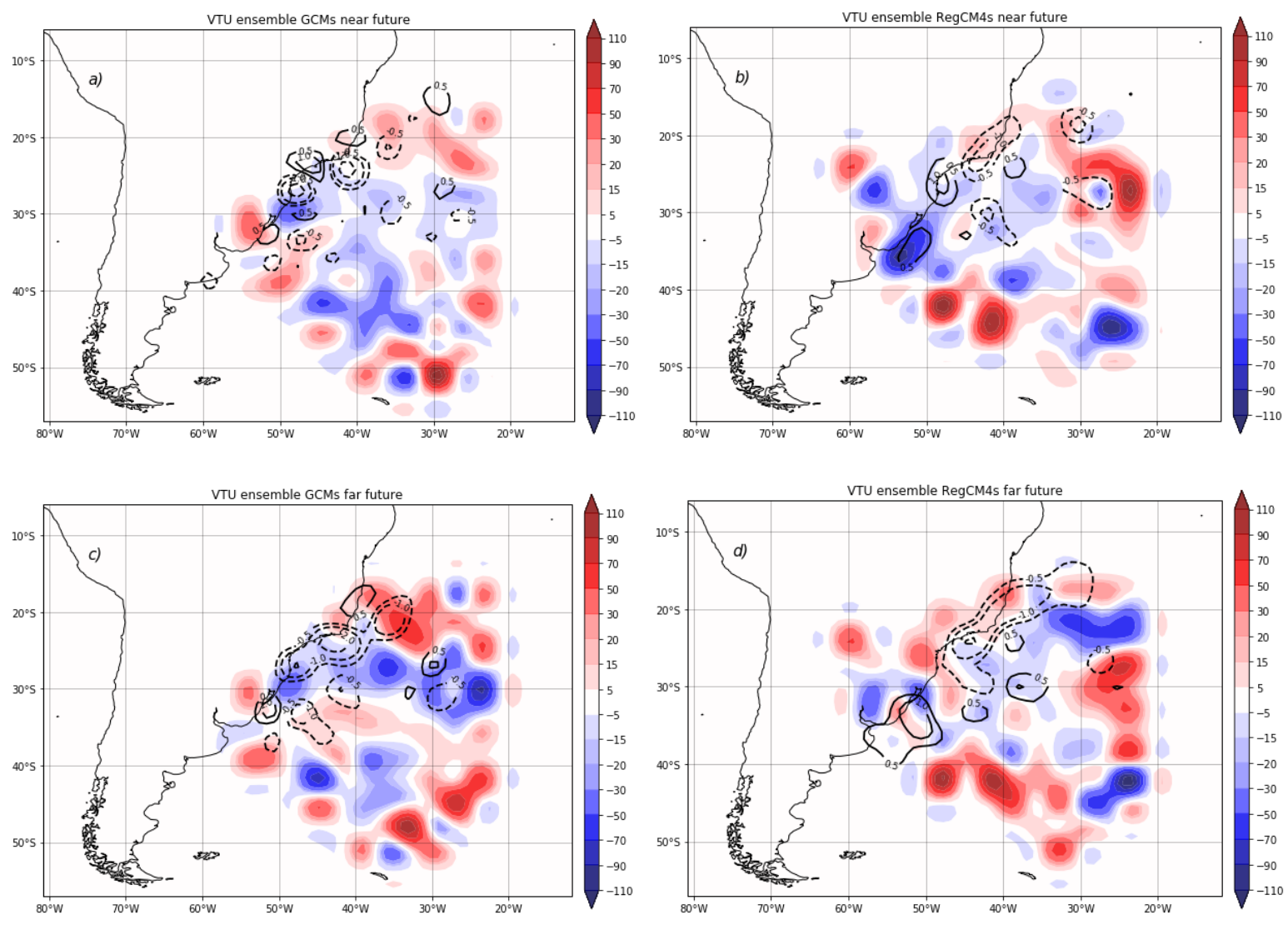

Figura 5.3.9 - Composições da tendência do parâmetro $\mathrm{V}_{\mathrm{T}}^{\mathrm{U}}$ (sombreado) em toda a trajetória e da densidade ciclogenética (linhas pretas cheias valores positivos e tracejadas valores negativos) associados aos ciclones subtropicais para os climas a,b) futuro próximo (2020-2050) e c,d) futuro distante (2070-2099) nos GCMs e RegCM4s, respectivamente. Apresentados somente valores de $\mathrm{V}_{\mathrm{T}}^{\mathrm{U}}$ associados à densidade de trajetórias maiores que 2 ciclone por área $\left(\mathrm{km}^{2}\right) \times 10^{6}$ por ano.

Guishard et al. (2008) avaliou a evolução dos parâmetros $\mathrm{V}_{\mathrm{T}}^{\mathrm{L}}, \mathrm{V}_{\mathrm{T}}^{\mathrm{U}}$ e cisalhamento do vento do ciclone Karen que passou pela sequência de fases de subtropical, tropical e extratropical. Neste estudo, os maiores valores de cisalhamento vertical do vento associado aos ciclones subtropicais foram observados quando os valores de $\mathrm{V}_{\mathrm{T}}^{\mathrm{U}}$ eram menores que $-70 \mathrm{~m}^{3} / \mathrm{kg}$. $\mathrm{O}$ parâmetro $\mathrm{V}_{\mathrm{T}}^{\mathrm{L}}$ permaneceu praticamente constante em todo o ciclo de vida como ciclone subtropical, com valores em torno de $50 \mathrm{~m}^{3} / \mathrm{kg}$. Portanto, a partir da análise de Guishard et al. (2008) a avaliação do cisalhamento do vento será feita dando maior importância ao parâmetro $\mathrm{V}_{\mathrm{T}}^{\mathrm{U}}$, que se mostrou mais decisivo na avaliação do cisalhamento. Dessa forma, para o parâmetro $\mathrm{V}_{\mathrm{T}}^{\mathrm{L}}$ (Figura 5.3.8) não apresenta grandes mudanças na região de forte subestimativa na densidade ciclogenética dos subtropicais, mostrando fraca relação deste parâmetro na diminuição dessas ciclogêneses. Por outro 
lado, no futuro próximo o parâmetro $\mathrm{V}_{\mathrm{T}}^{\mathrm{U}}$ (Figura 5.3.9a,b) apresenta uma ligeira diminuição na costa sudeste do Brasil, sobre a mesma região com tendência de pequena diminuição ciclogenética dos subtropicais.

No futuro distante (Figura 5.3.9c,d) a diminuição das ciclogêneses subtropicais se intensifica e o parâmetro $\mathrm{V}_{\mathrm{T}}^{\mathrm{U}}$ também se aprofunda, principalmente nos GCMs sobre a costa sudeste do Brasil. Isso mostra uma forte relação entre a diminuição de ciclogêneses subtropicais e a redução do $\mathrm{V}_{\mathrm{T}} \mathrm{U}$, ou seja, aumento do cisalhamento vertical do vento sobre a região no clima futuro distante. Os RegCM4s projetam uma diminuição menor no $\mathrm{V}_{\mathrm{T}}^{\mathrm{U}}$ e nas ciclogêneses subtropicais em comparação com os GCMs na região. Estes resultados mostram o importante papel do cisalhamento do vento em níveis superiores na formação dos ciclones subtropicais próximo às costas de São Paulo e Rio de Janeiro (principal núcleo ciclogenético dos subtropicais). Esse mecanismo também contribui para entender a tendência negativa mais intensa dos ciclones subtropicais do que de todos os ciclones na RG1 sintetizada na Tabela 5.3.1.

Os ciclones subtropicais, que têm características híbridas, podem no futuro apresentar características mais próximas das de ciclones tropicais e extratropicais dependendo das anomalias nos campos bidimensionais dos parâmetros do CPS. No parâmetro de simetria térmica (B; Figura 5.3.7) os conjuntos mostram que no futuro próximo ocorrerá um predomínio de anomalias negativas sobre o Atlântico Sul, ou seja, os ciclones subtropicais serão mais simétricos termicamente. No futuro distante, os RegCM4s simulam uma alteração no padrão de distribuição do parâmetro B, em que anomalias positivas predominam sobre o Atlântico Sul, indicando que no futuro os ciclones subtropicais serão mais assimétricos termicamente. Por outro lado, os GCMs simulam um aprofundamento das anomalias negativas ou os subtropicais se tornando mais simétricos termicamente.

No parâmetro $\mathrm{V}_{\mathrm{T}}^{\mathrm{L}}$ (Figura 5.3.8) os conjuntos simulam no futuro anomalias negativas na região próximo à costa sudeste do Brasil, mostrando que os ciclones subtropicais nesta região do Atlântico Sul tendem a ter características mais próximas dos ciclones extratropicais. No entanto, à medida que os ciclones subtropicais se deslocam para sudeste os conjuntos simulam anomalias positivas, mostrando que tendem a adquirir características de núcleo mais quente em baixos níveis de acordo com o $\mathrm{V}_{\mathrm{T}}^{\mathrm{L}}$. 
No futuro os conjuntos simulam predomínio de anomalias negativas do parâmetro $\mathrm{V}_{\mathrm{T}}^{\mathrm{U}}$ (Figura 5.3.9), estas anomalias se posicionam principalmente em latitudes próximas a região de fortalecimento do jato subtropical no futuro (Figura 5.3.3). Este padrão mostra que os ciclones subtropicais localizados abaixo do jato subtropical tendem a apresentar características de ciclones extratropicais, já em latitudes ao norte e ao sul da posição longitudinal do jato subtropical notam-se anomalias positivas. Este padrão mostra que nestas regiões os ciclones subtropicais tendem a mostrar características mais próximas dos ciclones tropicais.

Os resultados das simulações indicam que ciclones subtropicais formados próximo à costa sudeste do Brasil e nas latitudes de atuação do jato subtropical no futuro, tendem a ter características mais próximas dos ciclones extratropicais, no entanto, à medida que se afastam destas regiões estes ciclones tendem a adquirir características mais próximas às dos ciclones tropicais. 


\section{Conclusões}

Este estudo avalia tendências climáticas futuras de todos os ciclones e dos subtropicais, e ventos associados (em baixos e altos níveis), no sudoeste do Atlântico Sul considerando dois conjuntos de simulações no cenário Representative Concentration Pathways (RCP8.5). O primeiro conjunto é composto de três modelos climáticos globais (GCMs; HadGEM2-ES, MPI-ES e GFDL-ES) do CMIP5 que forneceram as condições iniciais e de fronteira para quatro regionalizações com o RegCM4 (RegCM4s) no contexto do projeto CREMA (Coppola et al., 2014). Para validação das simulações no período histórico (1979-2005), os valores médios das reanálises ERA-Interim e CFSR são utilizados como conjunto de referência. A análise das projeções climáticas utilizando os conjuntos de modelos considera todos os ciclones formados nas três principais regiões ciclogenéticas (RG1, RG2 e RG3 situadas, respectivamente, no sul-sudeste do Brasil, Uruguai e sul da Argentina) na costa leste da América do Sul. Para avaliação dos ciclones subtropicais são usados os mesmos dados, exceto a simulação RegCM4-bats e a reanálise do CFSR, formando assim o conjunto RegCM4s com três membros.

Focando nas regiões ciclogenéticas, as análises consideram: 1) a habilidade dessas simulações em reproduzir as frequências das ciclogêneses em geral (ou todos os ciclones) e das subtropicais, intensidade e trajetórias preferenciais, e ventos associados no clima presente (1979-2005), usando as reanálises como referência; 2) as projeções climáticas dos ciclones em geral, dos ciclones subtropicais e ventos associados no futuro próximo (2020-50) e distante (2070-2099) no RCP8.5.

Para o clima presente, os conjuntos RegCM4s e GCMs simulam as principais características observadas das densidades de gênese e propagação dos ciclones. Esse resultado fornece confiança para analisar as projeções de mudanças climáticas de ciclones, incluindo os subtropicais, a partir destes conjuntos de simulações.

Comparando os conjuntos GCMs e RegCM4s no período histórico em cada uma das regiões ciclogenéticas, destaca-se que a frequência anual de ciclogêneses (a) simulada pelos RegCM4s (bias de $+4,0 \%$ ) na RG1 é mais próxima da observada do que dos GCMs (bias de 
-13\%); (b) na RG2 os RegCM4s e GCMs apresentam, respectivamente, pequena superestimativa (+6\%) e subestimativa (-8\%); e (c) ambos os conjuntos subestimam em -10\% na RG3. Esses resultados indicam que nas regiões distantes das bordas (RG2 e RG1) os RegCM4s apresentam menores erros do que os GCMs, representando então um importante valor agregado da regionalização climática. Os menores biases em áreas localizadas se refletem em todo o sudoeste do Atlântico Sul onde os RegCM4s também apresentam bias menor (+6\%) do que os GCMs (-18\%) para a frequência anual de ciclogêneses.

Para cada região ciclogenética, através das densidades de ciclogêneses, densidade de trajetórias, nota-se que os RegCM4s e GCMs simulam a localização e o ciclo anual das ciclogêneses mais semelhantes aos da reanálise. Portanto, algumas diferenças são notadas com os RegCM4s mostrando menores erros em estatísticas importantes da climatologia de ciclones no período histórico. Um importante valor agregado é a maior habilidade dos RegCM4s em capturar as características observadas (número anual de eventos, fase e amplitude do ciclo anual, distribuição de frequência de intensidade) das ciclogêneses iniciadas nas regiões que estão longe da borda do domínio, ou seja, as RG1 (sul-sudeste do Brasil) e RG2 (leste do Uruguai). Nessas áreas, para o ciclo anual de ciclogêneses, os RegCM4s apresentam menor raiz quadrada do erro médio e maior correlação comparado com as reanálises. Essa melhoria impacta positivamente nas principais características para todas as ciclogêneses sobre o domínio do sudoeste do Atlântico Sul, onde os RegCM4s também apresentam menores erros e simulam ciclones mais intensos presentes na reanálise e ausentes dos GCMs. Estes são novos resultados, que mostram vantagens no uso regionalização climática considerando um conjunto composto de várias simulações, ao invés de apenas uma, para analisar ciclones sobre a costa leste da América do Sul.

Quando se considera o impacto das ciclogêneses intensas (percentil de 25\%), tem-se que nas três regiões ciclogenéticas as reanálises e os conjuntos de simulações identificam ventos em baixos níveis mais fortes ocorrendo preferencialmente no setor nordeste, ou seja, no setor quente dos ciclones em formação. Comparativamente, para a ciclogênese da RG1 e RG2 também existe uma maior concordância entre os RegCM4s e as reanálises para os ventos, tanto em termos de magnitude como de localização. Esse resultado mais uma vez representa uma importante adição de valor dos RegCM4s comparados aos GCMs referente aos impactos dos ciclones mais intensos. Em 
termos de ventos em altos níveis, ambos os conjuntos de simulações representam realisticamente a intensidade e localização da corrente de jato. Entretanto, existem pequenas diferenças para cada região: ambos os conjuntos de simulações subestimam ligeiramente a magnitude do jato para a RG1, e para a RG3 os GCMs apresentam maior proximidade com as reanálises. Mesmo assim, os erros nas simulações em relação à localização e intensidade dos jatos em altos níveis são pequenos e estima-se que não comprometem a avaliação de projeções climáticas futuras.

Para as projeções futuras, os conjuntos de simulações indicam no futuro distante (2070-2099) uma intensa diminuição de eventos nas três regiões ciclogenéticas. Para o futuro próximo (2020-2050) embora predomine tendência negativa, esse sinal é mais fraco e não homogêneo em todo o sudoeste do Atlântico Sul. No futuro próximo tem-se: 1) tendência de diminuição na atividade ciclogenética na RG3; 2) diminuição na atividade ciclônica próximo ao sudeste do Brasil e oceano adjacente e um deslocamento para norte dos caminhos preferenciais dos ciclones iniciados na RG1; 3) para a RG2 aumenta a atividade de ciclones em uma vasta área sobre o Atlântico Sul, adjacente ao leste do Uruguai e Argentina. Essa tendência para a RG2 no futuro próximo também foi encontrada em outros estudos mostrando decréscimo na frequência de ciclones sobre todo o Atlântico Sul e ligeiro aumento nas cercanias do Uruguai (Krüger et al., 2012, Reboita et al., 2018; 2019).

Em termos do ambiente sinótico médio associado com as ciclogêneses intensas, em altos níveis as projeções para o futuro distante indicam: 1) uma mudança para sul do jato polar, o que representa um padrão consistente com o deslocamento para sul da zona baroclínica climatológica; 2) um reforço do jato subtropical, desde o leste do Pacífico Sul até o Atlântico Sul, resultando em fortalecimento do cavado semi-estacionário sobre os Andes e, como consequência, a formação de uma crista/anticiclone corrente abaixo sobre o Atlântico Sul. Esta crista situa-se acima de anomalias anticiclônicas em baixos níveis, caracterizando portanto em uma resposta barotrópica ao aquecimento global na região do Atlântico Sul.

Uma mudança importante nas três regiões ciclogenéticas projetada para o futuro distante é a intensificação dos ventos em baixos níveis, associados com ciclogêneses intensas (percentil de 25\%), nas proximidades da costa sudeste do Brasil. Segundo as projeções, esses ventos irão se intensificar no setor leste/nordeste (setor quente no Hemisfério Sul) das ciclogêneses. Isto ocorre 
principalmente como consequência da intensificação de anomalias anticiclônicas em baixos níveis sobre o Atlântico Sul, centradas em média em $\sim 35^{\circ} \mathrm{W}$, mas que oscilam de latitude em função da região ciclogenética (mais para o norte $\left(\sim 40^{\circ} S\right)$ para RG1; mais ao sul $\left(\sim 46^{\circ} S\right)$ para as RG2 e RG3).

Finalmente, para cada região ciclogenética considerando valores médios e tendências, tanto no período histórico como todo o futuro (1979-2099), destacam-se alguns fatores relevantes das ciclogêneses e ventos em baixos níveis. Para o período histórico, nota-se tendência negativa da frequência de ciclogêneses para cada região ciclogenética, especialmente a RG1, onde as reanálises apresentam uma forte tendência negativa, que no entanto é menos acentuada nos conjuntos de simulações. As tendências simuladas no clima presente persistem até o futuro distante e ao mesmo tempo projeta-se aumento da velocidade do vento em baixos níveis associadas aos ciclones intensos. Esses resultados indicam para uma tendência de longo período da intensificação dos ventos em baixos níveis associados aos ciclones intensos, principalmente no leste do sul-sudeste do Brasil.

Com foco nos ciclones subtropicais, o desenvolvimento e aplicação do esquema automático (denominado SCS), a partir do rastreamento de todos os ciclones e parâmetros do espaço de fase de ciclones (CPS), se mostrou eficaz para representar a climatologia desses eventos obtida em Gozzo (2014). O SCS reproduz as regiões preferenciais de ciclogênese subtropical, trajetórias, variações mensais, sazonais, anuais e distribuição espacial dos parâmetros do CPS. Esses resultados viabilizaram a utilização do SCS na classificação de ciclones subtropicais em longas séries de dados, ou seja, nos conjuntos de simulações.

Para o clima presente, os conjuntos de simulações reproduzem as principais regiões de maior frequência de ciclogênese subtropical mostradas na ERA-Interim. Em particular, os RegCM4s aproximam-se mais da reanálise do que os GCMs, onde o principal núcleo de formação ocorre próximo à costa sudeste do Brasil. Os dois conjuntos de simulações subestimam o número médio anual de ciclogêneses subtropicais ( 1 ciclogênese por ano). Nas trajetórias, os ciclones subtropicais tendem a atuar por mais tempo próximo à costa sudeste do Brasil e os conjuntos de simulações capturam essa característica, com os RegCM4s mais próximos da ERA-Interim. Essa 
melhora em comparação com os GCMs mostra que a regionalização climática atua resolvendo os forçantes de mesoescala associados aos ciclones subtropicais próximo da costa sudeste do Brasil.

Na distribuição espacial dos parâmetros do CPS, os conjuntos simulam padrões espaciais realísticos em comparação com a ERA-Interim, ou seja, captam o aumento do parâmetro B e diminuição dos parâmetros $\mathrm{V}_{\mathrm{T}}^{\mathrm{L}}$ e $\mathrm{V}_{\mathrm{T}}^{\mathrm{U}}$ à medida que os ciclones subtropicais se afastam da costa sudeste do Brasil.

Os ventos em $1000 \mathrm{hPa}$, associados com os ciclones subtropicais, mostram uma banda com maiores velocidades adjacente à costa, desde latitudes tropicais até o Rio Grande do Sul, com velocidades médias de até $6 \mathrm{~m} \mathrm{~s}^{-1}$ na reanálise. Essa característica é simulada pelos RegCM4s, com velocidades também atingindo $6 \mathrm{~m} \mathrm{~s}^{-1}$, até a costa do Paraná, enquanto nos GCMs as velocidade são menores. Em altos níveis, sobre a região preferencial de formação dos ciclones subtropicais, na reanálise nota-se a presença de um cavado e o jato situa-se mais ao sul. Os conjuntos de simulações capturam este padrão, no entanto, o cavado é menos evidente e a região do jato tem ventos mais intensos nos RegCM4s.

Para as tendências futuras, os conjuntos de simulações projetam uma diminuição progressiva nas trajetórias nas cercanias da costa sudeste do Brasil nos futuros próximo e distante. No futuro distante projeta-se uma expansão e aprofundamento da diminuição nas trajetórias em ambos os conjuntos de simulações nesta região. Os GCMs projetam tendência positiva de trajetórias, nos futuros próximos e distante, próximo à costa do Espírito Santo e Bahia, enquanto nos RegCM4s tendências positivas são notadas na costa do Uruguai.

$\mathrm{Na}$ tendência dos ventos em $1000 \mathrm{hPa}$ no futuro próximo, os GCMs não apresentam mudança significativa sobre o Atlântico Sul, enquanto os RegCM4s projetam anomalias positivas de velocidade do vento nas imediações desde a costa sudeste do Brasil até o Uruguai. No futuro distante, as projeções não indicam mudanças de velocidade na costa sudeste do Brasil. Nos ventos em $300 \mathrm{hPa}$, os conjuntos projetam pequeno aumento de velocidade sobre a RG1, indicando um aumento do cisalhamento vertical do vento no futuro distante, e enfraquecimento no cinturão em $\sim 38^{\circ}-48^{\circ} \mathrm{S}$.

Considerando a tendência de longo período, os conjuntos de simulações projetam tendência negativa na frequência de ciclones subtropicais até o final do século. Ao mesmo tempo, nos GCMs 
a tendência de velocidade do vento em $1000 \mathrm{hPa}$ associado às ciclogêneses subtropicais é ligeiramente positiva, enquanto é próxima de zero nos RegCM4s. Portanto, assim como para todos os ciclones, as projeções indicam ventos mais intensos no futuro também nos ciclones subtropicais.

Como a maioria das ciclogêneses subtropicais ocorrem na RG1 comparou-se as tendências desses com a de todos os ciclones na RG1. Tanto as projeções dos RegCM4s como GCMs projetam tendência de diminuição da ciclogênese subtropical mais acentuada do que a de todos os ciclones. A análise dos parâmetros $\mathrm{B}$ e $\mathrm{V}_{\mathrm{T}}^{\mathrm{L}}$ do CPS não indicam grandes alterações no futuro nas proximidades da costa sudeste do Brasil. Por outro lado, para o parâmetro $\mathrm{V}_{\mathrm{T}}^{\mathrm{U}}$ os GCMs e RegCM4s projetam um significativo aumento em módulo (torna-se mais negativo), ou seja, a maior diminuição dos ciclones subtropicais em comparação com todos os ciclones na RG1 seria explicada pelo aumento do cisalhamento vertical do vento na camada superior.

Este estudo destaca a importância de monitoramento das ciclogêneses próximo à costa sul/sudeste do Brasil usando modelos climáticos e como os conjuntos, especialmente o composto pela regionalização dinâmica, são hábeis em representar importantes características observadas relacionadas com todas ciclogêneses (intensas e subtropicais) sobre a costa leste da América do Sul. Entender como as ciclogêneses e ventos próximo à superfície associados podem mudar no clima futuro é essencial para um planejamento futuro e mitigação de estratégias, a fim de evitar danos para a economia e população em cenários de mudanças climáticas.

\subsection{Sugestões para estudos futuros}

Para pesquisas relacionadas aos ciclones e ciclones subtropicais algumas questões necessitam ser aprofundadas, entre essas:

- Em termos de impactos o presente estudo concentrou-se em analisar os ventos, mas é importante entender também mudança em outras variáveis, tais como, chuva e temperatura;

- As regionalizações climáticas com o RegCM4 utilizando grade horizontal de 50 km já indicam várias melhorias em relação aos GCMs. Seria interessante conduzir análises semelhantes às apresentadas em simulações com maior resolução horizontal; 
- Avaliar como a forma da costa e a serra do mar contribuem para a formação dos ciclones e ciclones subtropicais nas proximidades da costa sudeste do Brasil;

- Em termos de ciclones intensos, aprofundar o estudo em casos de ciclones bomba ocorrendo sobre o Atlântico Sul e como os GCMs e RegCM4s simulam estes sistemas;

- Na RG1 e RG2, avaliar como ciclones com características frontais (ciclones extratropicais) provocam chuva sobre o continente e como os GCMs e RegCM4s simulam estes padrões;

- Sobre o Atlântico Sul avaliar possíveis transições tropicais nos GCMs e RegCM4s no futuro;

- Na RG3, avaliar se a expansão do domínio do RegCM4 mais para Sul melhoraria significativamente a simulação dos ciclones nesta região;

- Sobre o Atlântico Sul, avaliar quais características modulam a velocidade de deslocamento dos ciclones sobre esta bacia e como os GCMs e RegCM4s capturam estes padrões. 


\section{Referências}

Abreu, R. C., da Rocha, R. P., (2015). Experimentos numéricos para o ciclone subtropical “Anita” com o modelo WRF. Ciência e Natura, p. 69-74.

Akperov, M., Rinke, A., Mokhov, I. I., et al., (2019). Future projections of cyclone activity in the Arctic for the 21st century from regional climate models (Arctic-CORDEX). Glob Planet Change 182. https://doi.org/10.1016/j.gloplacha.2019.103005

Akhtar, N., Brauch, J., Dobler, A., et al. (2014). Medicanes in an ocean-atmosphere coupled regional climate model. Nat. Hazards Earth Syst. Sci. 14: 2189-2201

Allen, J. T., Pezza, A. B., Black, M. T., (2010). Explosive cyclogenesis: A global climatology comparing multiple reanalyses. Journal of climate, 23(24): 6468-6484.

Ambrizzi, T., Reboita, M. S., da Rocha, R. P., Llopart, M., (2019). The state of the art and fundamental aspects of regional climate modeling in South America. Ann. N.Y. Acad. Sci. (2019). https://doi.org/10.1111/nyas.13932

Bergtsson, L., Hodges K. I., Roeckner, E., (2005). Storm tracks and climate change. Journal of climate, 19, 3518-3543, https://doi.org/10.1175/JCLI3815.1.

Bengtsson LO, Hodges KI, Keenlyside N (2008) Will extratropical storms intensity in a warmer climate?. J Clim 22:2276-2301. https://doi.org/10.1175/2008JCLI2678.1

Betts, A. K., 1986: A new convective adjustment scheme. Part I: Observational and theoretical basis. Quarterly Journal of the Royal Meteorological Society, 112(473), 677-691.

Beven, J. L., II, (1997). A study of three "hybrid" storms. Preprints, 22d Conf. on Hurricanes and Tropical Meteorology, Fort Collins, CO, Amer. Meteor. Soc., 645-646.

Bjerknes, J., \& H. Solberg. (1922). Life Cycle of Cyclones and the Polar Front Theory of Atmospheric Circulation. Geof. Publ., 3 (1),3-18. 
Bonan, G. B., (1996). A land surface model (LSM version 1.0) for ecological, hydrological, and atmospheric studies. NCAR Tech. Note NCAR/TN-417+STR, 150 pp.

Brasiliense, C. S., Dereczynski, C. P., Satyamurty, P., Chou, S. C., Santos, R. S., \& Calado, R. N., (2017). Synoptic analysis of an intense rainfall event in Paraíba do Sul river basin in southeast Brazil. Royal Meteorological Society. https://doi.org/10.1002/met.1670

Browning, K. A., (2004). The sting at the end of the tail: Damaging winds associated with extratropical cyclones. Q J R Meteorol Soc 130:375-399. https://doi.org/10.1256/qj.02.143

Bugoni, L., Sander, M., \& Costa, E. S., (2007). Effects of the first Southern Atlantic hurricane on Atlantic petrels (Pterodroma incerta). Wilson Jour. Ornith., 119:725-729.

Cardoso, A. A., (2019). Ciclones subtropicais e ventos em superfície no sudoeste do Oceano Atlântico Sul: climatologia e extremos. Master thesis, Universidade de São Paulo

Charney, J. G., \& A. Eliassen, (1964). On the growth of the hurricane depression. J. Atmos. Sci. 21:68-75.

Catto, J. L., Ackerley, D., Booth, J. F. et al (2019). The Future of Midlatitude Cyclones. Curr Clim Change Rep 5:407-420

Cavicchia, L., \& von Storch, H., (2012). The simulation of medicanes in a high-resolution regional climate model. Clim. Dyn. 39: 2273-2290.

Cavicchia, L., A. Dowdy \& K. Walsh., (2018). Energetics and dynamics of subtropical Australian east coast cyclones: two contrasting cases. Mon. Weather Rev. 146. https://doi. org/10.1175/MWR-D-17-0316.1.

Cavicchia, L., Pepler, A., Dowdy, A., Evans, J., Di Luca, A., \& Walsh, K. (2020). Future changes in the occurrence of hybrid cyclones: The added value of cyclone classification for the east Australian low-pressure systems. Geophysical Research Letters, 47, e2019GL085751. https:// doi.org/10.1029/2019GL085751

Cecilio, R. O., \& Dillenburg, S. R., (2019). An ocean wind-wave climatology for the Southern Brazilian Shelf. Part II: Variability in space and time. Dyn Atmos Oceans 88:101103. 
Chou, S. C., et al., (2014). Assessment of Climate Change over South America under RCP 4.5 and 8.5 Downscaling Scenarios. American Journal of Climate Change, 3, 512-527. http://dx.doi.org/10.4236/ajcc.2014.35043

Coppola, E., Giorgi, F., Raffaele, F., Fuentes-Franco, R., Giuliani, G., Llopart, M., Mamgain, A., Mariotti, L., Diro, G. T., Torma, C., (2014). The bias and climate change signal in the Phase I CREMA experiment. Submetido no Climatic Change.

Cressman, G. P., (1959). An Operational Objective Analysis System. Mon. Wea. Rev., 7 (10), 367-374.

Crespo, N. M., da Rocha, R. P., Sprenger, M., \& Wernli, H., (2020). A Potential Vorticity Perspective on Cyclogenesis over Center-Eastern South America. Int $\mathrm{J}$ Climatol. https://doi.org/10.1002/joc.6644

Dai, Y., \& Zeng, Q. C., (1996). A land surface model (IAP94) for climate studies. Part I: Formulation and validation in off-line experiments. Adv. Atmos. Sci., 14, 433-460.

Dai YJ, Zeng XB, Dickinson RE, Baker I, Bonan GB, Bosilovich MG (2003) The common land model, Bulletin of the American Meteorological Society 84, pp. 1013-1023.

da Rocha, R. P., Reboita, M. S., Dutra, L. M. M., Llopart, M., Coppola, E., (2014). Interannual variability associated with ENSO: present and future climate projections of RegCM4 for South America-CORDEX domain. Submetido no Climatic Change.

da Rocha, R. P., Reboita, M. S., \& Ambrizzi, T., (2017). Key features of named subtropical cyclones over the southwestern South Atlantic Ocean (abstract \#1343). In Proceedings of the IAPSO-IAMAS-IAGA, Cape Town.

da Rocha, R. R., Reboita, M. S., Gozzo, L. F., Dutra, L. M. M., \& de Jesus, E. M., (2019). Subtropical cyclones over the oceanic basins: a review. Ann. N.Y. Acad. Sci. (2018) 1-19. doi: 10.1111/nyas. 13927

Dee, D. P., et al, (2011). The ERA-Interim reanalysis: configuration and performance of the data assimilation system. Q. J. R. Meteorol. Soc., 137:553-597. 
Dias Pinto, J. R., Reboita M. S., \& da Rocha R. P., (2013). Synoptic and dynamical analysis of subtropical cyclone Anita (2010) and its potential for tropical transition over the South Atlantic Ocean. J. Geophys. Res. Atmos. 118: 10870-10883.

Dickinson, R. E., Errico, R. M., Giorgi, F., Bates, G. T., (1989). A regional climate model for the 522 western United States. Climatic Change 15: 383-422

Dickinson, R. E., Henderson-Sellers, A., Kennedy, P. J., (1993). Biosphere-Atmsophere Transfer Scheme (BATS) Version 1e as coupled to the NCAR Community Model. NCAR Tech. Note NCAR/TN-3871STR, 72 pp.

Di Luca, A., Evans, J., Pepler, A., et al. (2016). Evaluating the representation of Australian East Coast Lows in a regional climate model ensemble. J. South. Hemisph. Earth Syst. Sci. 66: $108-124$.

Domingues, R., Kuwano-Yoshida, A., Chardon-Maldonado, P. et al (2019). Ocean Observations in Support of Studies and Forecasts of Tropical and Extratropical Cyclones. Front Mar Sci. https://doi.org/10.3389/fmars.2019.00446

Dowdy, A. J., Mills, G. A., \& Timbal, B., (2011). Large-scale indicators of Australian East Coast Lows and associated extreme weather events. The Centre for Australian Weather and Climate Research, Melbourne, VIC. CAWCR Technical Report No. 037.

Dunne, J. P., et al. (2012). GFDL's ESM2 Global Coupled Climate-Carbon Earth System Models. Part I: Physical Formulation and Baseline Simulation Characteristics. J. Climate, 25, 6646-6665.

Dutra, L. M. M., da Rocha R. P., Lee R. W., et al. (2017). Structure and evolution of subtropical cyclone Anita as evaluated by heat and vorticity budgets. Q. J. R. Meteorol. Soc. 143: 1539-1553.

Emanuel, K. A., (1991). A scheme for representing cumulus convection in large-scale models. J. Atmos. Sci., 48, 2313-2335.

Emanuel, K. A., \& Zivkovic-Rothman, M., (1999). Development and evaluation of a convection scheme for use in climate models. J Atmos Sci 56: 1766-1782. 
Evans, J.L. \& A. Braun. (2012). A climatology of subtropical cyclones in the South Atlantic. J. Clim. 25: 7328-7340.

Fyfe, J. C., (2003). Extratropical Southern Hemisphere Cyclones: Harbingers of climate change? Letters, 16, 2802-2805.

Gaertner, M. A., González-Alemán, J. J., Romera, R., et al. (2016). Simulation of medicanes over the Mediterranean Sea in a regional climate model ensemble: impact of ocean- atmosphere coupling and increased resolution. Clim. Dyn. https://doi.org/10.1007/s00382-016-3456-1.

Galarneau, T.J., Davis, C. A., \& Shapiro, M.A., (2013). Intensification of Hurricane Sandy (2012) through extratropical warm core seclusion. Mon. Weather Rev. 141: 4296-4321.

Gan, M. A., \& Rao, B. V., (1991). Surface ciclogenesis over South America. Mon. Wea. Rev., 119, 293- 302.

Gan, M. A., \& B. V., Rao, (1994). The influence of the Andes Cordillera on Transient Disturbances.Mon. Wea. Rev., 122, 1141-1157.

Geng, Q. Z., \& Sugi, M., (2003). Possible change of extratropical cyclone activity due to enhaced greenhouse gases and sulfate aerosols - Study with a high-resolution AGCM. J. Clim., 16, 2262-2274.

Chang, E. K. M., Guo, Y., Xia, X., (2012). CMIP5 multimodel ensemble projection of storm track change under global warming. J Geo Res 117. https://doi.org/10.1029/2012JD018578

Chang, E. K. M., (2017). Projected significant increase in the number of extreme extratropical cyclones in the Southern Hemisphere. J Clim 30:4915-4935

Giorgetta, M. A., et al., (2013). Climate and carbon cycle changes from 1850 to 2100 in MPI-ESM simulations for the coupled model intercomparison project phase 5. Journal of Advances in Modeling Earth Systems.

Giorgi, F., Marinucci, M. R., Bates, G., (1993a). Development of a second generation regional climate model (RegCM2). Part I: Boundary layer and radiative transfer processes. Mon 561 Wea Rev 121: 2794-2813. 
Giorgi, F., Marinucci, M. R., Bates, G., DeCanio, G., (1993b). Development of a second generation regional climate model (RegCM2). Part II. Convective processes and assimilation of lateral boundary conditions. Mon Wea Rev 121:2814-2832

Giorgi, F., Coppola, E., Solmon, F. et al., (2012). RegCM4: model description and preliminary tests over multiple CORDEX domains. Clim Res 52:7-29. https://doi.org/10.3354/cr01018

Giorgi, F., Coppola, E., Raffaele, F., Diro, G. T., Fuentes-Franco, R., Giuliani, G., Mamgain, A., Llopart, M., Mariotti, L., Torma, C., (2014). Changes in extremes and hydroclimatic regimes in the CREMA ensemble projections. Submetido no Climatic Change.

Gozzo, L. F., da Rocha, R. P., Reboita, M. S., \& Sugahara, S. (2014). Subtropical cyclones over the southwestern South Atlantic: Climatological aspects and case study. J of Clim, 27:8543-8562

Gozzo, L. F., da Rocha, R. P., Gimeno, L. et al., (2017). Climatology and numerical casestudy of moisturesources associated with subtropical cyclogenesis over the southwestern Atlantic Ocean. J. Geophys. Res. Atmos. 122: 5636-5653.

Gramcianinov, C. B., Hodges, K. I., \& Camargo, R., (2019). The properties and genesis environments of South Atlantic cyclones. Climate Dynamics, vol. 53, pag. 4115-4140.

Grell, G. A., (1993). Prognostic evaluation of assumptions used by cumulus parameterizations. Mon Weather Rev 121:764-787.

Grieger, J., Leckebusch, G. C., Donat, M. G., Schuster, M., Ulbrich, U., (2014). Southern Hemisphere winter cyclone activity under recent and future climate conditions in multi-model AOGCM simulations. Int J Climatol 34:3400-3416

Gutowski, Jr., W. J., L. E. Branscome \& D. A. Stewart, (1992). Life Cycles of Moist Baroclinic Eddies. J. Atmos. Sci., 49, 306-319.

Guishard, M. P., (2006). Atlantic subtropical storms: Climatology and characteristics. Tese (Doutorado em Meteorologia), Dept. of Meteorology, The Pennsylvania State University, University Park, PA 158 pp. 
Guishard, M. P., Evans, J. L., \& Hart, R. E., (2009). Atlantic Subtropical Storms. Part II: Climatology. Journal of Climate, 22, 3574-3594.

Hart, R. E., (2003). A cyclone phase space derived from thermal wind and thermal asymmetry.Monthly Weather Review, 131, 585-616.

Hawcroft, M., Walsh, E., Hodges, K., Zappa, G., (2018). Significantly increased extreme precipitation expected in Europe and North America from extratropical cyclones. Environ Res Lett 13. http://dx.doi.org/10.1088/1748-9326/aaed59

Hodges, K., Cobb, A., \& Vidale, P. L., (2017). How Well Are Tropical Cyclones Represented in Reanalysis Datasets? American Meteorological Society. https://doi.org/10.1175/JCLI-D-16-0557.1

Holtslag, A., de Bruijn, E., Pan, H. L., (1990). A high resolution air mass transformation model for short-range weather forecasting. Mon Wea Rev 118:1561-1575.

Holton, J., Hakim, G., (2012). An Introduction to Dynamic Meteorology (V. 88, 5th Ed.). Academic Press.

Homar, V., Romero, R., Stensrud, D. J., et al., (2003). Numerical diagnosis of a small, quasi-tropical cyclone over the western Mediterranean: dynamical vs. boundary factors. Q. J. R. Meteorol. Soc. 129: 1469-1490.

Hoskins B. J., \& Hodges K. I., (2005). A new perspective on southern hemisphere storm tracks. Journal of climate, 18 , 4108-4129.

IPCC, 2007: Climate Change 2007: The Physical Science Basis. Contribution of Working Group I to the Fourth Assessment Report of the Intergovernmental Panel on Climate Change, Solomon, S., D. Qin, M. Manning, Z. Chen, M. Marquis, K.B.Averyt, M. Tignor and H.L. Miller, Eds., Cambridge University Press, Cambridge, 996 pp.

IPCC, 2013: Climate Change 2013: The Physical Science Basis. Contribution of Working Group I to the Fifth Assessment Report of the Intergovernmental Panel on Climate Change. Cambridge University Press, Cambridge, United Kingdom and New York, NY, USA, 1535 pp. 
Ji, F., Evans, J. P., Argueso, D., et al. (2015). Using large-scale diagnostic quantities to investigate change in East Coast Lows. Clim. Dyn. 45: 2443-2453

Kalnay, E., M. Kanamitsu, R. Kistler, et al., (1996). The NCEP/NCAR 40-year reanalysis project. Bull. Am. Meteorol. Soc. 77: 437-471.

Kanamitsu, M.; Ebisuzaki, W.; Woollen, J.; Yang, S-K; Hnilo, J.J.; Fiorino, M.; \& Potter, G. L., (2002). NCEPDEO AMIP-II Reanalysis (R-2). Bul. Amer. Meteorol. Soc., v. 83, p. 1631-1643.

Kendall, M. G., (1975). Rank correlation methods, 4th edn. Charles Griffin, London

Kiehl, J., Hack, J., Bonan, G., Boville, B., Breigleb, B., Williamson, D., Rasch, P. (1996). Description of the NCAR Community Climate Model (CCM3). National Center for Atmospheric Research Tech Note NCAR/TN-420+STR, NCAR, Boulder, CO.

Knutti, R., Furrer, R., Tebaldi, C., Cermak, J., Meehl, G. A., (2010) Challenges in combining projections from multiple climate models. J Clim 23:2739-2758

Kodama, C., Stevens, B., Mauritsen, T., Seiki, T., Satoh, M., (2019). A New Perspective for Future Precipitation Change from Intense Extratropical Cyclones. Geophys Res Lett. https://doi.org/10.1029/2019GL084001

Koster, R. D., \& Suarez, M. J., (1992). Modeling the land surface boundary in climate models as a composite of independent vegetation stands. J. Geophys. Res., 97, 2697-2715.

Kruger, L. F., Reboita, M. S., Rocha, R. P., Ambrizzi, T., (2009). Ciclones no Atlântico Sul simulados pelo RegCM3 aninhado ao HadAM3: Clima Futuro (2071-2085). In: II Simpósio Internacional de Climatologia (SIC), 2009, Gramado - RS. II Simpósio Internacional de Climatologia (SIC).

Kruger, L. F., Da Rocha R. P., Reboita, M. S., Ambrizzi, T., (2012). RegCM3 nested in HadAM3scenarios A2 and B2: projected changes in extratropical cyclogenesis, temperature and precipitation over the South Atlantic Ocean. Climatic Change. DOI 10.1007/s10584- 011-0374-4.

Kushner, P. J., Held, I. M., Delworth, T. L., (2001). Southern Hemisphere atmospheric circulation response to global warming. Journal of Climate 14: 2238-2249. 
Lambert, S. J., (1995). The effect of enhanced greenhouse warming on winter cyclone frequencies and strengths. J. Climate, 8,1447-1452.

Lambert, S. F., \& Fyfe, J. C., (2005). Changes in winter cyclone frequencies and strengths simulated in enhaced greenhouse warning experiments: results from the models participating in the IPCC diagnostic exercise. Climate Dynamics. DOI:10.1007/s00382-006-0110-3

Lehmann, J., Coumou, D., Frieler, K., Eliseev, A. V., Levermann, A., (2014). Future changes in extratropical storm tracks and baroclinicity under climate change. Environ Res Lett 9. http://dx.doi.org/10.1088/1748-9326/9/8/084002

Leckebusch, G. C., Ulbrich, U., (2004). On the relationship between cyclones and extreme windstorm events over Europe under climate change. Glob Planet Change 44:181-193

Leonard, S. R. et al., (1999). An assessment of three automatic depression tracking schemes. Meteorol. Appl. 6, 173-183 .

Llopart, M., Coppola, E., Giorgi, F., da Rocha, R. P., Cuadra, S. V., (2014). Climate change impact on precipitation for the Amazon and La Plata basins. Clim Change 125:111-125

Llopart, M., Reboita, M. S., da Rocha, R. P., (2020). Assessment of multi-model climate projections of water resources over South America CORDEX domain. Climate Dynamics. 54, 99-116.

Machado, A. A., \& Calliari, L. J., (2016). Synoptic Systems Generators of Extreme Wind in Southern Brazil: Atmospheric Conditions and Consequences in the Coastal Zone. J Coast Res 75:1182-1186

Mann, M. E., (2008). Smoothing of climate time series revisited. Geophys Res Lett 35. https://doi.org/10.1029/2008GL034716

Marengo, J. A., (2006). Mudanças Climáticas Globais e seus Efeitos sobre a Biodiversidade; Caracterização do Clima Atual e Definição das Alterações Climáticas para o Território Brasileiro ao Longo do Século XXI.

Marengo, J. A.; Ambrizzi, T., da Rocha, R. P., Alves, L. M., Cuadra, S. V., Valverde, M., Ferraz, S. E. T., Torres, R. R., Santos, D. C., (2010b). Future change of climate in South America in the 
late XXI century: intercomparison of scenarios from three regional climate models. Climate Dynamics, v. 35, p. 1073-1097.

Mark, M., (1982). On Moist Quasi-Geostrophic Baroclinic Instability. J. Atmos. Sci., 39,2028-2037.

Martin, G. M. et al. (2011). The HadGEM2 family of Met Office Unified Model Climate configurations, Geosci. Model Dev. Discuss., 4, 765-841.

Martínez-Alvarado, O., Gray, S. L., Hart, N. C., Clark, P. A., Hodges, K. I., Roberts, M. J., (2018). Increased wind risk from sting-jet windstorms with climate change. Environ Res Lett 13. http://dx.doi.org/10.1088/1748-9326/aaae3a

Mbengue, C., Schneider, T., (2017). Storm-track shifts under climate change: Toward a mechanistic understanding using baroclinic mean available potential energy. J Atmos Sci 74:93-110

McDonald, R. E., (2011). Understanding the impact of climate change on Northern Hemisphere extra- tropical cyclones. Clim Dyn 37:1399-1425

McTaggart-Cowan, R., Bosart, L. F., Davis, C. A., et al. (2006). Analysis of Hurricane Catarina (2004). Mon. Weather Rev. 134: 3029-3053.

Mendes, D., Souza, E. P., Trigo, I. F., Miranda, P. M. A., (2007). On precursors of South American Cyclogenesis. Tellus, 59A, 114-121.

Mendes, D., E. P. Souza, J. A. Marengo e M. C. D. Mendes, 2010: Climatology of extratropical cyclones over the South American-southern oceans sector. Theoretical and Applied Climatology, 100, 239-250.

Ming, Y., Ramaswamy. V., Chen, G., (2011). A model investigation of aerosol-induced changes in boreal winter extratropical circulation. J Climate 24:6077-6091. https://doi.org/10.1175/2011JCLI4111.1

Mizuta, R., (2012). Intensification of extratropical cyclones associated with the polar jet change in the CMIP5 global warming projections. Geophys Res Lett 39. https://doi.org/10.1029/2012GL053032 
Muis, S., Verlaan, M., Winsemius, H. C., Aerts, J. C. J. H., \& Ward, P. J., (2016). A global reanalysis of storm surges and extreme sea levels. Nature Communications. DOI: 10.1038/ncomms11969

Nakicenovic, N., (2000). Greenhouse gas emissions scenarios. Technological Forecasting \& Social Change, 65(3). (In press.)

Neu, U. et al., (2013). IMILAST: A Community Effort to Intercompare Extratropical Cyclone Detection and Tracking Algorithms. AMERICAN METEOROLOGICAL SOCIETY. https://doi.org/10.1175/BAMS-D-11-00154.1

Pal, J. S., Small, E., Eltahir, E., (2000). Simulation of regional-scale water and energy budgets: representation of subgrid cloud and precipitation processes within RegCM. J Geophys Res 636 105: 29579-29594.

Pal, J. S. et al., (2007). Regional climate modeling for the developing world: the ICTP RegCM3 and RegCNET. Bull Am Meteorol Soc 88: 1395-1409.

Pepler, A.S., Di Luca, A., Ji, F., et al. (2015). Impact of identification method on the inferred characteristics and variability of Australian East Coast Lows. Mon. Weather Rev. 143: 864-877.

Pezza, A. B., \& Simmonds, I. (2005). The first South Atlantic hurricane: unprecedented blocking, low shear and climate change. Geophys. Res. Lett. 32: L15712.

Pezza, A. B., \& Ambrizzi, T. (2003). Variability of southern hemisphere cyclone and anticyclone behavior: Further analysis. Journal of Climate.

Pfahl. S., O’Gorman, P. A., Singh, M. S., (2015). Extratropical cyclones in idealized simulations of changed climates. J Clim 28:9373-9392

Ramsay, H. A., Chand, S. S., \& Camargo, S. J., (2018). A Statistical Assessment of Southern Hemisphere Tropical Cyclone Tracks in Climate Models. American Meteorological Society. https://doi.org/10.1175/JCLI-D-18-0377.1

Rauscher, S. A., Kucharski, F., Enfield, D. B., (2011). The Role of Regional SST Warming Variations in the Drying of Meso-America in Future Climate Projections. J Clim 24:2003-2016 
Reboita, M. S., (2008). Ciclones extratropicais sobre o Atlântico Sul: Simulação climática e experimentos de sensibilidade. Dissertation, Universidade de São Paulo

Reboita, M. S.; da Rocha, R. P.; Ambrizzi, T.; \& Sugahara, S., (2010). South Atlantic Ocean Cyclogenesis Climatology Simulated by Regional Climate Model (RegCM3). Climate Dynamics. 10.1007/s00382-009-0668-7.

Reboita, M. S., da Rocha, R. P., Ambrizzi, T., (2012). Dynamic and climatological features of cyclonic developments over southwestern South Atlantic Ocean. In: B. Veress and J. Szigethy (Eds.) Horizons in Earth Science Research, 6th edn. Nova Science Publishers, Inc., pp135-160.

Reboita, M. S., da Rocha, R. P., Dias, C. G., \& Ynoue, R. Y., (2014). Climate Projections for South America: RegCM3 Driven by HadCM3 and ECHAM5. Hindawi Publishing Corporation. http://dx.doi.org/10.1155/2014/376738

Reboita, M. S., da Rocha, R. P., Ambrizzi, T., Gouveia, C. D., (2015).Trend and teleconnection patterns in the climatology of extratropical cyclones over the Southern Hemisphere. Climate Dynamics, 45,1929-1944(2015).

Reboita, M. S., da Rocha, R. P., de Souza, M. R., \& Llopart, M. (2018). Extratropical cyclones over the southwestern South Atlantic Ocean: HadGEM2-ES and RegCM4 projections. Int J Climatol 38:2866-2879

Reboita, M. S., Reale, M., \& da Rocha, R. P., et al (2019). Future Changes in the Wintertime Cyclonic Activity over the CORDEX-CORE Southern Hemisphere domains in a Multi-Model Approach. Under review in Clim Dyn

Reed, R. J., Kuo, Y. H., Albright, M. D., et al., (2001). Analysis and modeling of a ropical-like cyclone in the Mediterranean Sea. Meteorol. Atmos. Phys. 76: 183-202.

Riahi, K., Rao, S., Krey, V. et al. (2011). RCP 8.5-A scenario of comparatively high greenhouse gas 914 emissions. Clim Change 109. https://doi.org/10.1007/s10584-011-0149-y

Ribeiro, R. B., Sampaio, A. F. P., Ruiz, M. S., Leitão, J. C., \& Leitão, P. C., (2019). First approach of a storm surge early warning system for Santos region. In: Climate Change in Santos Brazil: Projections, Impacts and Adaptation Options. https://doi.org/10.1007/978-3-319-96535-2_7 
Shaw, T. A., Baldwin, M., Barnes, E. A., et al (2016). Storm track processes and the opposing influences of climate change. Nat Geosci 9:656-664

Roberts, M. J., et al. (2014). Tropical Cyclones in the UPSCALE Ensemble of High-Resolution Global Climate Models. American Meteorological Society. https://doi.org/10.1175/JCLI-D-14-00131.1

Romero, R., \& Emanuel, K., (2013). Medicane risk in a changing climate. J. Geophys. Res. Atmos. 118: 5992-6001.

Romero, R., \& Emanuel, K., (2017). Climate change and hurricane-like extratropical cyclones: projections for North Atlantic polar lows and medicanes based on CMIP5 models. J. Clim. 30: 279-299

Saha, S., Moorthi, S., Pan, H. L., et al (2010). The NCEP Climate Forecast System Reanalysis. Bull Am Meteorol Soc 91:1015-1058. https://doi.org/10.1175/2010BAMS3001.1

Simmonds, I. \& Keay, K., (2000). Mean Southern Hemisphere Extratropical Cyclone Behavior in the 40-Year NCEP-NCAR Reanalysis. J. Climate, 13, 873-885.

Simpson, R. H., (1952). Evolution of the Kona storm: A subtropical cyclone. J. Meteorol., 9, 24-35.

Sinclair, M. R., (1994). An Objective Cyclone Climatology for the Southern Hemisphere. Mon. Wea. Rev., 122, 2239-2256.

Sinclair, M. R., (1995). A climatology of cyclogenesis for the Southern Hemisphere. Monthly Weather Review, 123, 1601-1619.

Sinclair, M. R., Renwick, J. A., Kidson, J. W., (1997). Low-Frequency Variability of Southern Hemisphere Sea Level Pressure and Weather System Activity. Mon. Wea. Rev., 125, 2531-2543.

Sugahara, S., da Silveira, R. B., \& da Rocha, R. P., (2010). Estimativa da probabilidade do evento extremo de precipitação de janeiro de 2000 no Vale do Paraíba, baseada na distribuição generalizada de pareto. Rev. Bras. Geofísica 28: 193-208. 
Tamarin-Brodsky. T., Kaspi, Y., (2017). Enhanced poleward propagation of storms under climate change. Nat Geosci 10:908-913

Tawfik, A. B., \& Steiner, A. L., (2011). The role of soil ice in land-atmosphere coupling over the United States: a soil moisture precipitation winter feedback mechanism. J Geophys Res 116: D02113.

Taylor, K. E., Stouffer, R. J., Meehl, G. A., (2012). An overview of CMIP5 and the experiment design. Bull Amer Meteor Soc 93:485-498

Tierney, G., Posselt, D. J., Booth, J. F., (2018). An examination of extratropical cyclone response to changes in baroclinicity and temperature in an idealized environment. Clim Dyn 51:3829-3846

Torres, R. R., Marengo, J. A., (2013). Uncertainty assessments of climate change projections over South America. Theoretical and Applied Climatology, v. 112, p. 253-272.

Tous, M. \& Romero, R., (2013). Meteorological environments associated with medicane development. Int. J. Climatol. 33: 1-14.

Utsumi, N., Kim, H., Kanae, S., Oki, T., (2017). Relative contributions of weather systems to mean and extreme global precipitation. J Geophys Res 122:152-167. https://doi.org/10.1002/2016JD025222

Vera, C. S., Vigliarolo P. K., Berbery, E. H., (2002). Cold Season Synoptic-Scale Waves over Subtropical South America. Mon. Wea. Rev., 130, 684-699.

Vianna, M. L., Menezes, V. V., Pezza, A. B., et al. (2010). Interactions between Hurricane Catarina (2004) and warm core rings in the South Atlantic Ocean. J. Geophys. Res. 115: C07002.

Wang, X. L.; Feng, Y.; Compo, G. P.; Swail, V. R.; Zwiers, F. W.; Allan, R. J.; Sardeshmukh, P. D., (2013). Trends and low frequency variability of extra-tropical cyclone activity in the ensemble of twentieth century reanalysis. Climate Dynamics, 40(11-12): 2775-2800.

Wang, X. L.; Feng, Y.; Chan, R.; Isaac, V., (2016). Inter-comparison of extra-tropical cyclone activity in nine reanalysis datasets. Atmospheric Research, 181: 133-153. 
Watterson, I. G., (2006). The intensity of precipitation during extratropical cyclones in global warming simulations: a link of cyclone intensity? Tellus, 58A, 82-97.

Walsh, K., Giorgi, F., \& Coppola, E. (2014). Mediterranean warm-core cyclones in a warmer world. Clim. Dyn.42: 1053-1066.

Wu, Y., Ting, M., Seager, R., Huang, H. P., Cane, M. A., (2011). Changes in storm tracks and energy transports in a warmer climate simulated by the GFDL CM2.1 model. Clim Dyn 37:53-72

Yanase, W., H. Niino, K. Hodges, et al. (2014). Parameter spaces of environmental fields responsible for cyclone development from tropics to extratropics. J. Clim. 27: 652-671

Yin, J. H., (2005). A consistent poleward shift of the storm tracks in simulations of 21st century climate. Geophys Res Lett 32. https://doi.org/10.1029/2005GL023684

Zhang, Y., \& Wang, W. C., (1997). Model-simulated northern winter cyclone and anticyclone activity under greenhouse warming scenario. J. Climate, 10, 1616-1634.

Zappa, G., (2019). Regional Climate Impacts of Future Changes in the Mid-Latitude Atmospheric Circulation: a Storyline View. Curr Clim Change Rep 5:358-371

Zappa, G., Shaffrey, L. C., Hodges, K. I., Sansom, P. G., Stephenson, D. B., (2013). A multimodel assessment of future projections of North Atlantic and European extratropical cyclones in the CMIP5 climate models. J Clim 26:5846-5862 


\section{Apêndice A}

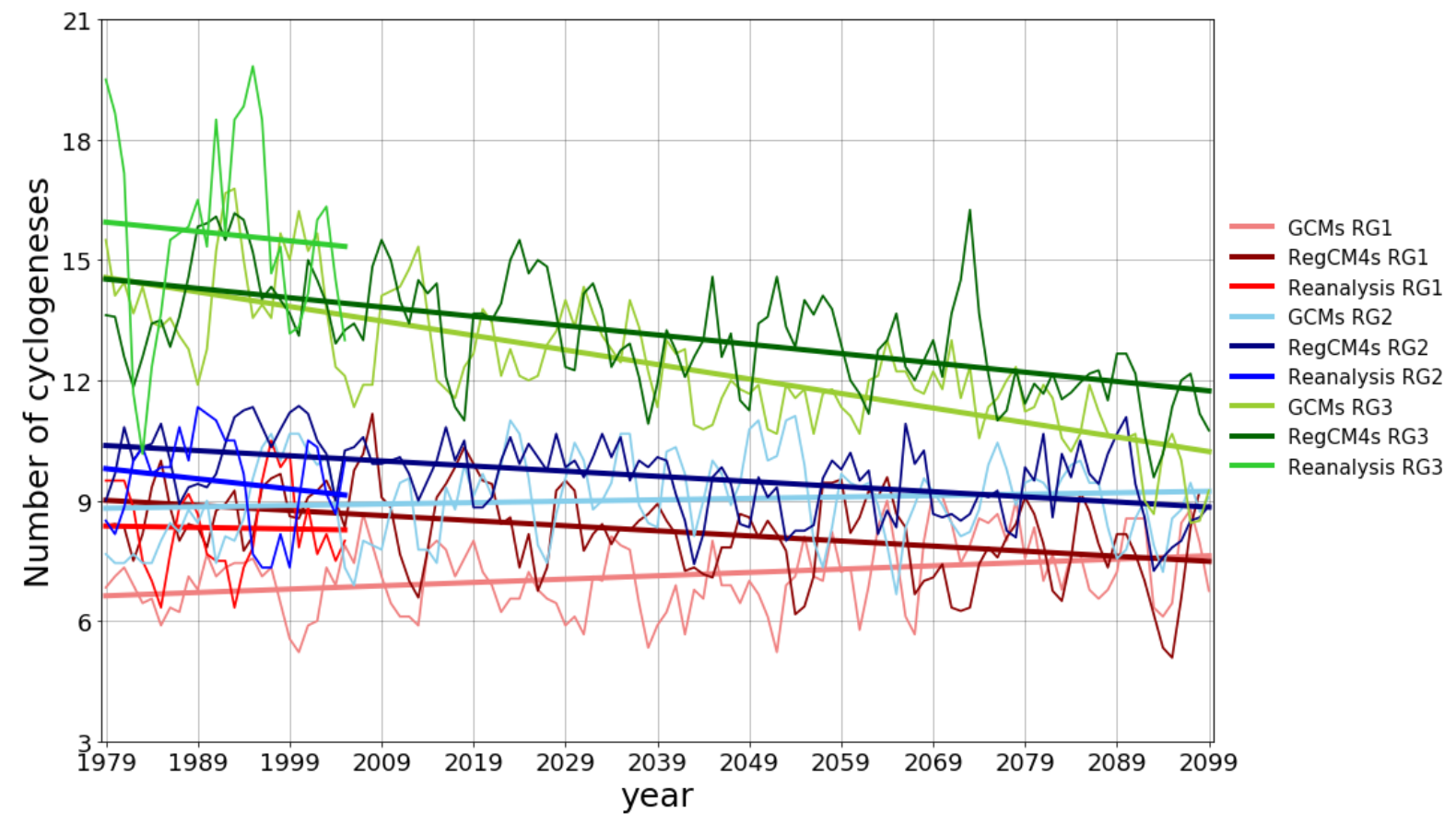

Figura A.1: Frequência absoluta anual e tendência (retas) de ciclogêneses intensas da reanálise (1979-2005) e simuladas (1979-2099) na RG1 (cores avermelhadas), RG2 (cores azuladas) e RG3 (cores esverdeadas). As linhas retas indicam a tendência. 

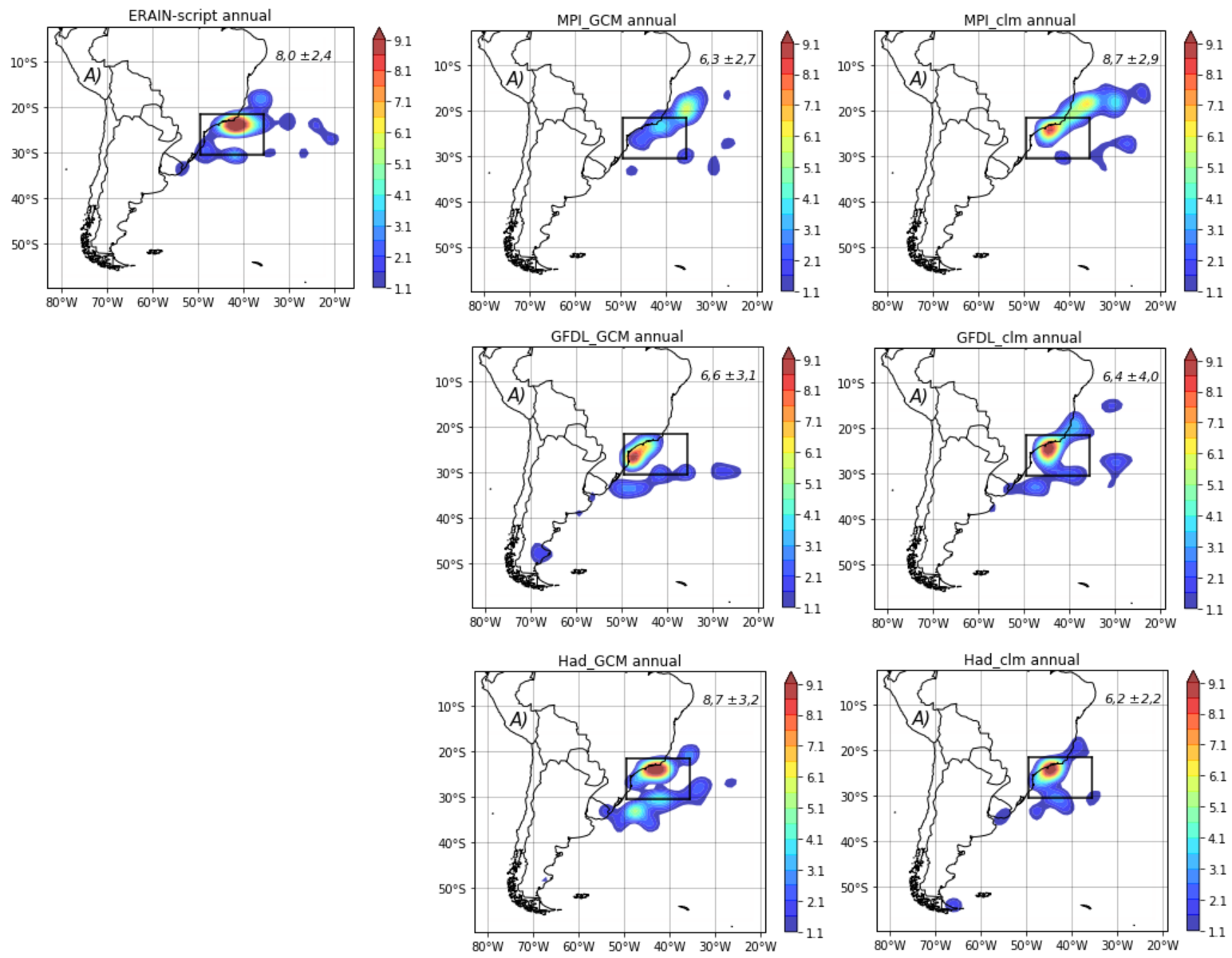

Figura A.2: Densidade média anual, no período 1979-2005, de ciclogêneses subtropicais fornecidas pela: (a) ERA-Interim, (b) MPI_GCM, (c) MPI_clm, (d) GFDL_GCM, (e) GFDL_clm, (f) Had_GCM e (g) Had_clm. Os valores no canto superior indicam a média anual e respectivo desvio padrão de ciclogêneses subtropicais. Unidade: ciclone por área $\left(\mathrm{Km}^{2}\right)$ x $10^{6}$ por ano 

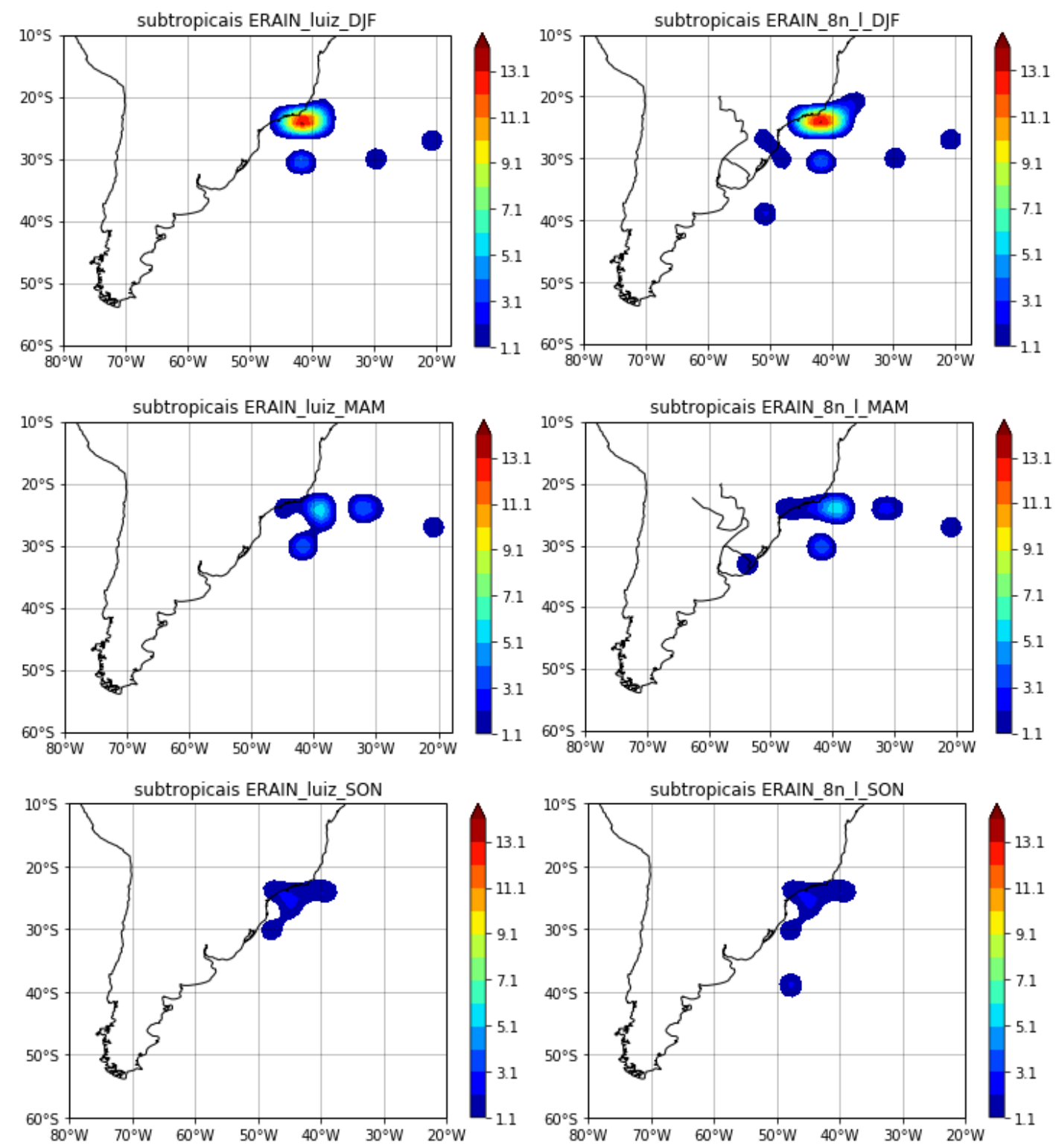

Figura A.3: Climatologia sazonal para o período de 1979-1984 da densidade de ciclones subtropicais no: verão a) Gozzo (2014), b) SCS; outono c) Gozzo (2014), d) SCS; primavera e) Gozzo (2014) e f) SCS. Unidade: ciclone por área $\left(\mathrm{Km}^{2}\right)$ x $10^{6}$ por ano. 

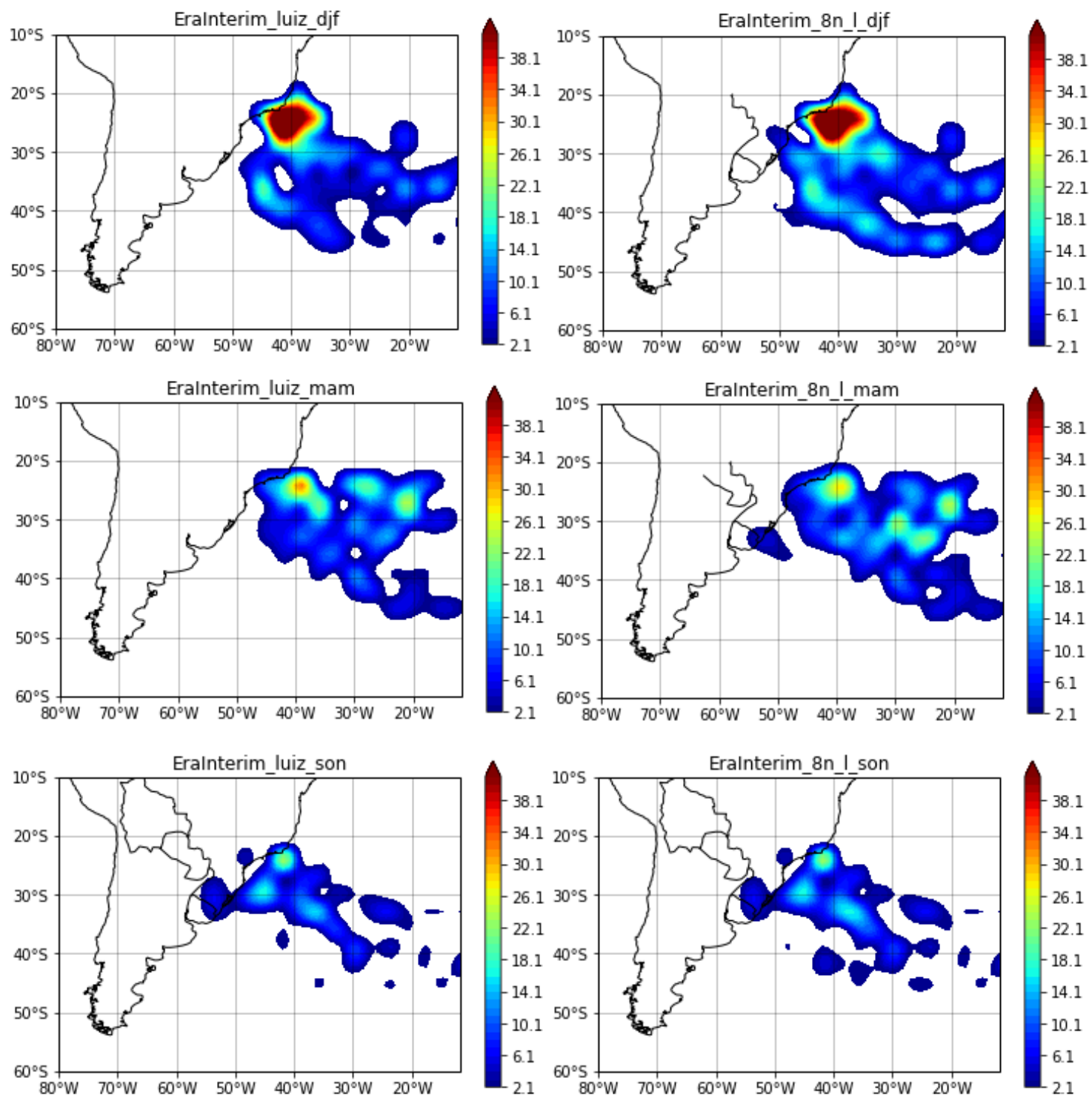

Figura A.4: Densidade de trajetória dos ciclones subtropicais para o período de 1979-1984. a) verão Gozzo (2014), b) verão SCS, c) outono Gozzo (2014), d) outono SCS, e) primavera Gozzo (2014) e primavera SCS. A unidade é ciclone por área $\left(\mathrm{km}^{2}\right) \times 10^{6}$ por ano. 

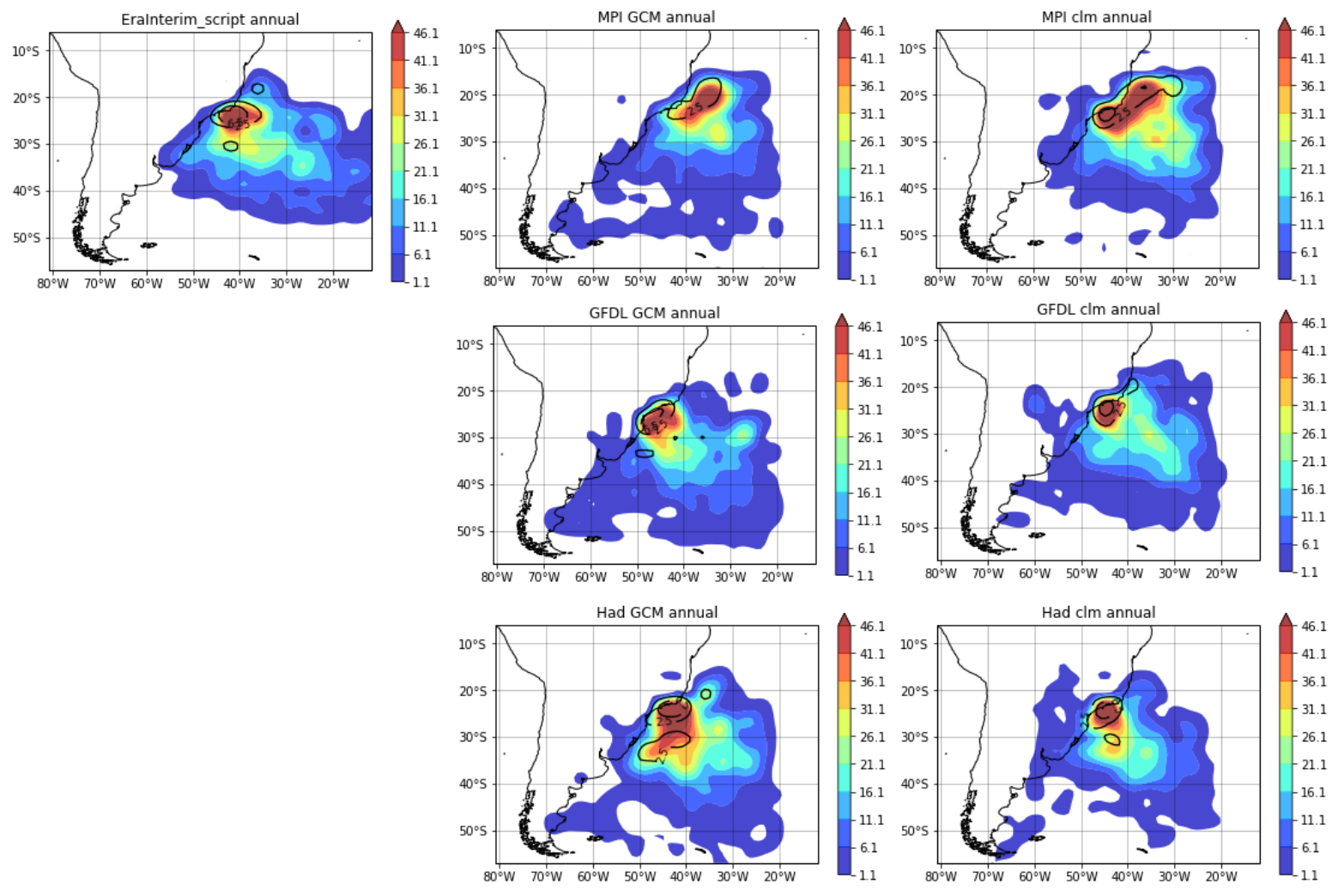

Figura A.5: Densidade média anual de trajetória (sombreado) e gênese (linhas pretas, valores de 2,5 e 6,5) dos ciclones subtropicais para o período de 1979-2005: (a) ERA-Interim, (b) MPI_GCM, (c) MPI_clm, (d) GFDL_GCM, (e) GFDL_clm, (f) Had_GCM e (g) Had_clm. Os valores no canto superior indicam a média anual e respectivo desvio padrão de ciclogêneses subtropicais. Unidade: ciclone por área $\left(\mathrm{Km}^{2}\right) \times 10^{6}$ por ano. 

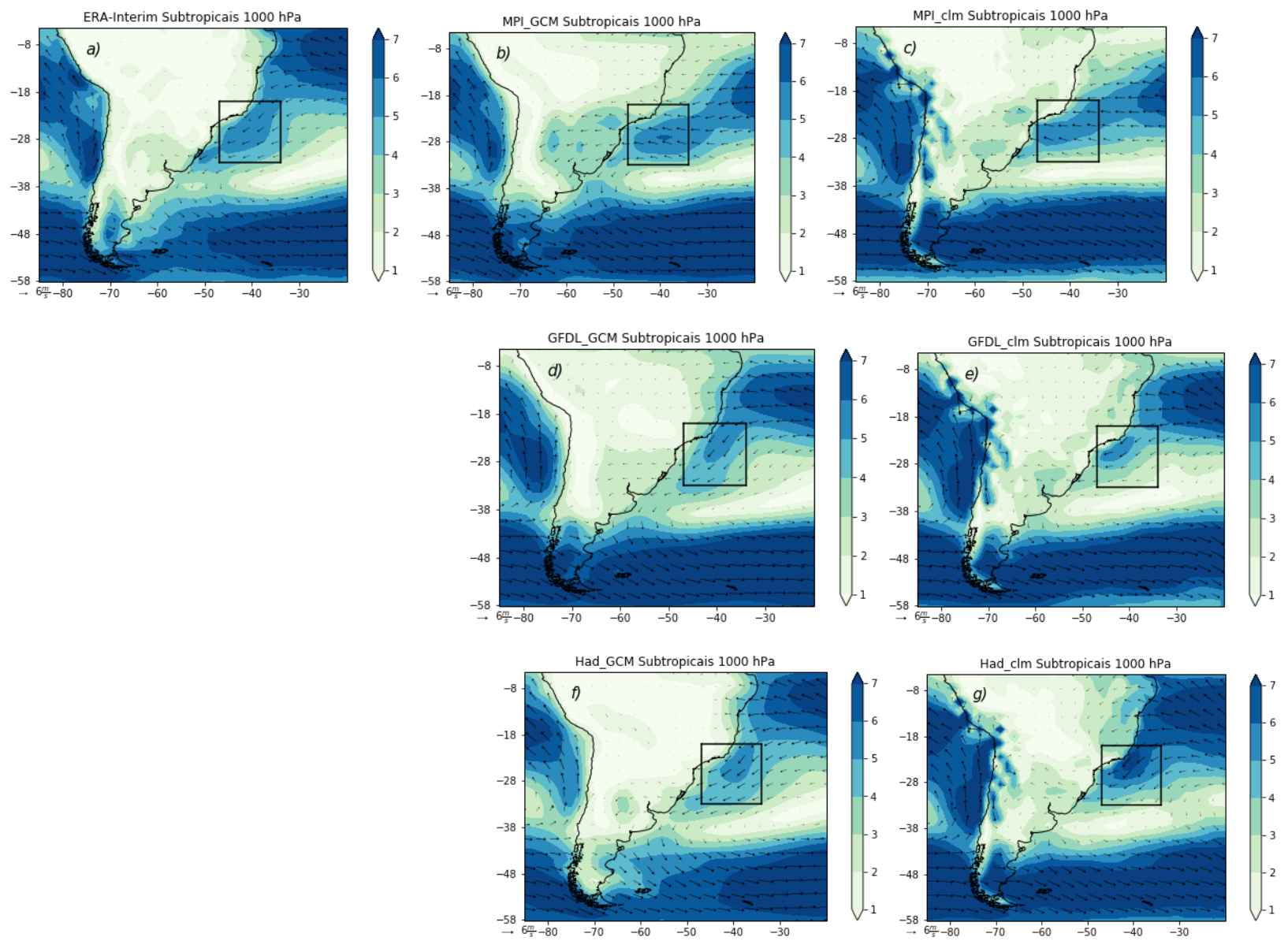

Figura A.6: Vento médio (vetores e magnitude em sombreado; m/s) em $1000 \mathrm{hPa}$ associado às ciclogêneses subtropicais para o período 1979-2005: a) reanálise ERA-Interim, b) MPI_GCM e c) MPI_clm, d) GFDL_GCM, e) GFDL_clm, f) Had_GCM e g) Had_clm. O retângulo preto indica a região de gênese dos ciclones subtropicais. 